FACULTY VIEWS OF ONLINE COMPETENCY-BASED EDUCATION, SELF-

\title{
EFFICACY, AND INSTITUTIONAL SUPPORT:
}

AN EXPLORATORY MIXED METHODS STUDY

by

Christopher Russell Prokes

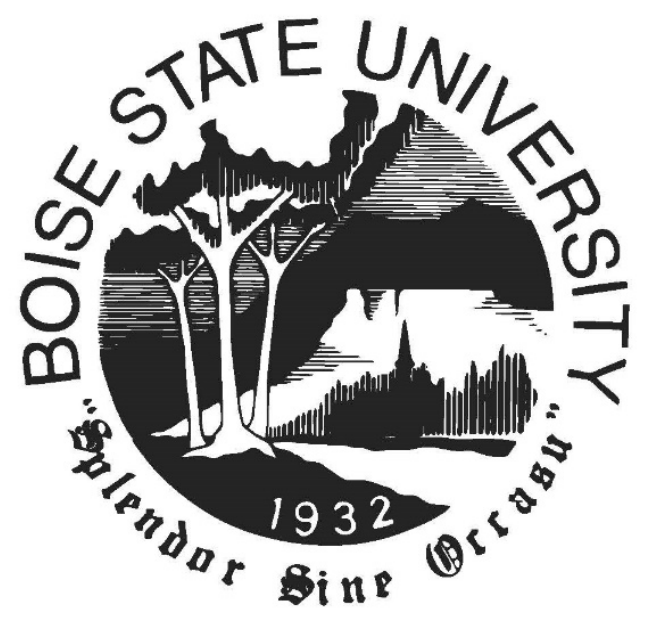

\author{
A dissertation \\ submitted in partial fulfillment \\ of the requirements for the degree of \\ Doctor of Education in Educational Technology \\ Boise State University
}

May 2021 
(C) 2021

Christopher Russell Prokes

ALL RIGHTS RESERVED 


\section{DEFENSE COMMITTEE AND FINAL READING APPROVALS}

of the dissertation submitted by

Christopher Russell Prokes

Dissertation Title: Faculty Views of Online Competency-based Education, Selfefficacy, and Institutional Support: An Exploratory Mixed Methods Study

Date of Final Oral Examination:

24 February 2021

The following individuals read and discussed the dissertation submitted by student Christopher Russell Prokes, and they evaluated the student's presentation and response to questions during the final oral examination. They found that the student passed the final oral examination.

Patrick Lowenthal, Ph.D.

Chair, Supervisory Committee

Kerry Rice, Ed.D.

Member, Supervisory Committee

Chareen Snelson, Ed.D.

Member, Supervisory Committee

The final reading approval of the dissertation was granted by Patrick Lowenthal, Ph.D., Chair of the Supervisory Committee. The dissertation was approved by the Graduate College. 


\section{DEDICATION}

I dedicate this work to my son, Zachary, and wife Erin, whose constant companionship, support, and understanding during this journey were nothing short of amazing. May they both continue their passion for life-long learning and never stop asking questions. 


\section{ACKNOWLEDGEMENTS}

I would especially like to acknowledge my dissertation committee: Dr. Patrick Lowenthal, who pushed me to dig deep and always aim for my best work - know that I am grateful for your guidance and ingenuity; Dr. Chareen Snelson, who inspired in me a interest in qualitative research and whose course design skills are at a level to which I can only aspire - know that your passion for students to succeed is warmly appreciated; and Dr. Kerry Rice, whose critical evaluation of my work throughout the program was what I needed so desperately to grow - know that your keen ability to push me to do better fueled the fire inside in all things.

My fellow students at Boise State provided a sounding board, a critical set of eyes, and an extended family making us all succeed together. My colleagues at Sinclair Community College gave me insight into research problems, participation in all of my different projects, and made sure I found the need and endeavored to meet it.

Two very special individuals also deserve gratitude: Dr. Nancy Patterson - my mentor, colleague, and friend - roles that matter to me more than I can ever put into words; and Dr. Gretta Kumpf - whose belief in a young educator and push for this degree made it not a matter of if, but when - I'm honored you saw something in me long ago.

My family and friends, who didn't think I was crazy for taking up this challenge, and understanding what it took to get here - thank you, always. Most importantly, to my late father, Russ, who departed this life far too young. For 34 years cheered me on in all things as my biggest supporter - I know you'd have done the same for this 'game', too. 


\begin{abstract}
Competency-based education (CBE) is essentially an online approach to teaching and learning featuring flexible pacing, robust competencies, and an emphasis on student completion. CBE's differs from traditional education that focuses on seat time, credit hours, and academic objectives. Though CBE has existed on college campuses in many forms, faculty are often inexperienced in teaching CBE. Facing growing demands for CBE (notably from non-traditional students), institutions must find ways to prepare faculty to take part in CBE. This mixed methods study explored faculty views of CBE, their selfefficacy, and beliefs about support mechanisms needed for those teaching and delivering CBE. Findings suggest faculty have mixed views of CBE, generally high self-efficacy due to the importance of mastery experiences, and believe in the importance of specific learning opportunities in an environment built on collaboration to ensure CBE faculty are supported and can thrive. Findings can inform current and future CBE practicing institutions to ensure faculty are trained and capable in an environment of collaboration.
\end{abstract}

Keywords: competency-based education, self-efficacy, faculty development, competencies 


\section{TABLE OF CONTENTS}

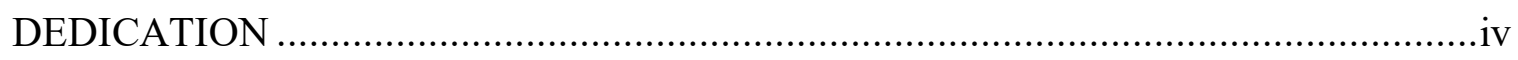

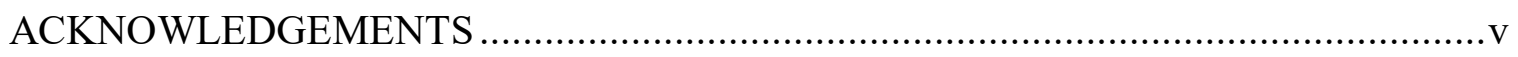

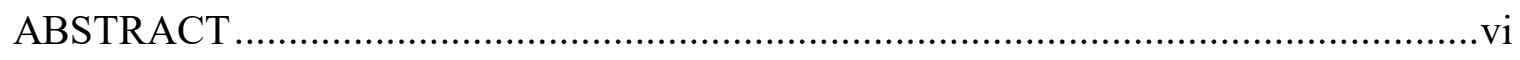

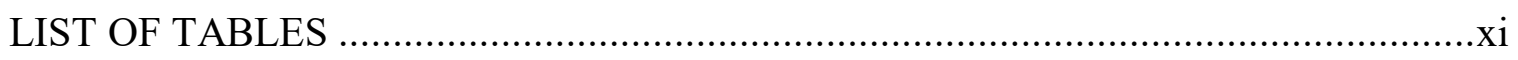

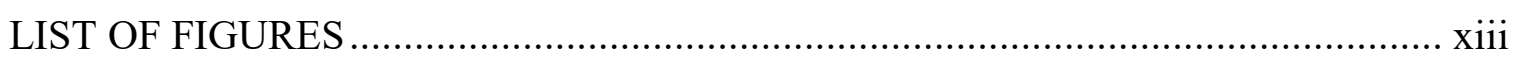

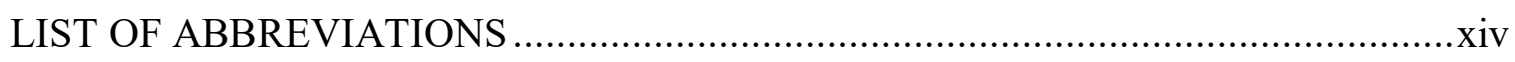

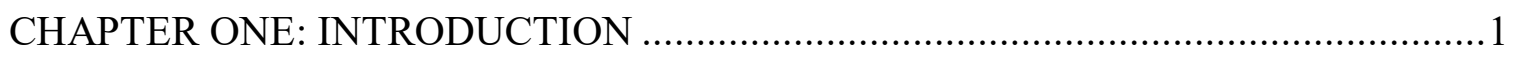

Overview of Competency-based Education ....................................................

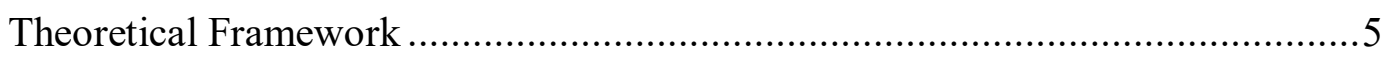

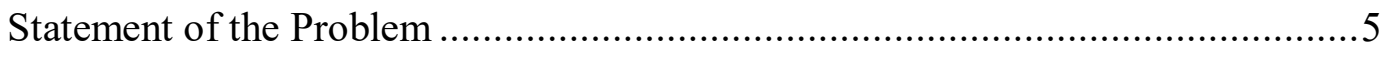

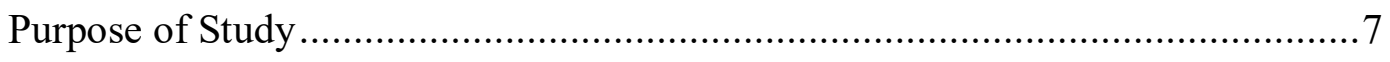

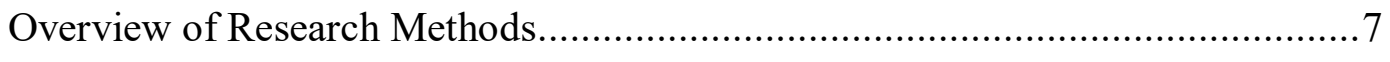

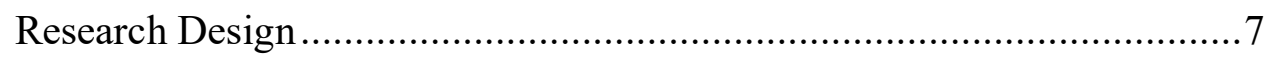

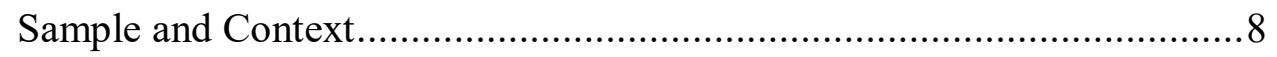

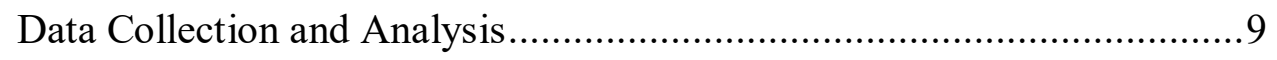

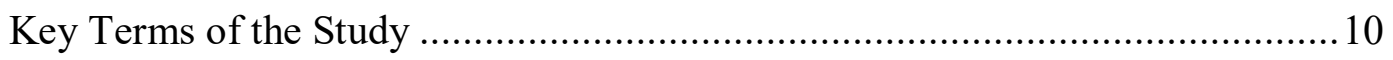

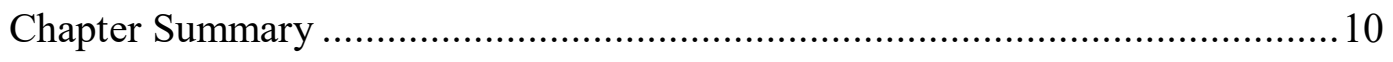

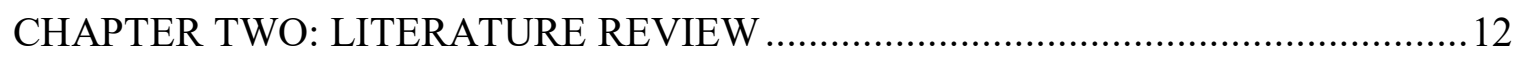

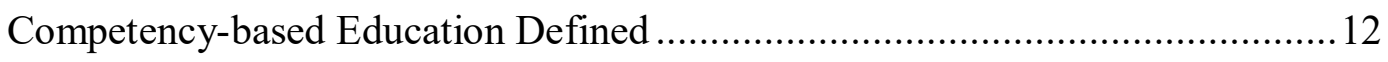




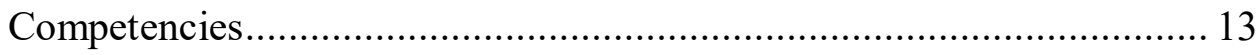

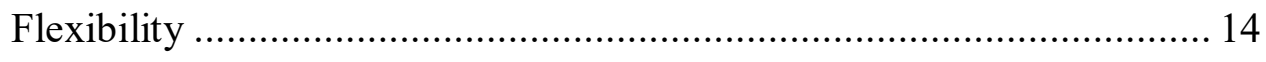

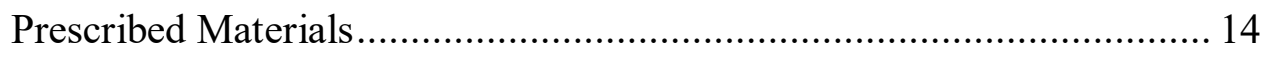

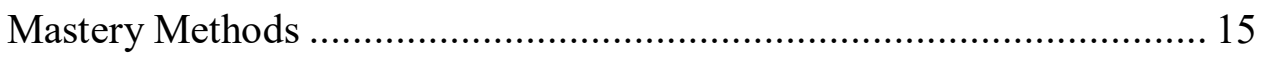

History of Competency-based Education ........................................................ 16

Competency-based Education in Practice ........................................................ 18

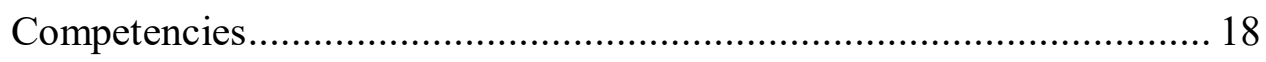

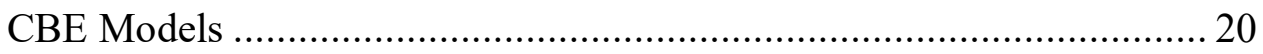

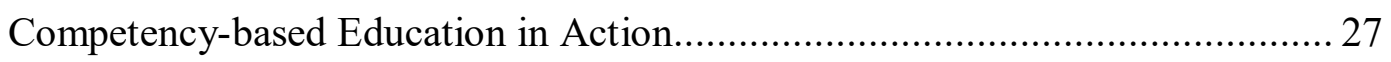

Strengths and Criticisms of Competency-based Education ................................. 33

Strengths of Competency-based Education in the Literature .................... 33

Criticisms of Competency-based Education in the Literature.................... 35

Faculty Development for New Ways of Teaching .............................................. 41

Development for Improvement of Teaching .......................................... 42

Faculty Development in the CBE Context ............................................... 43

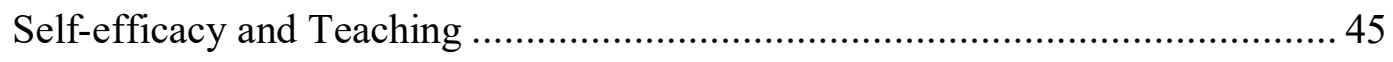

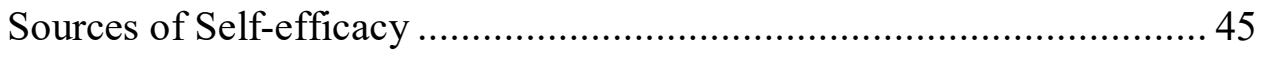

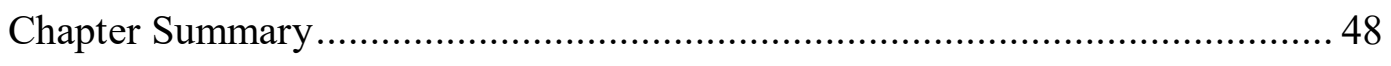

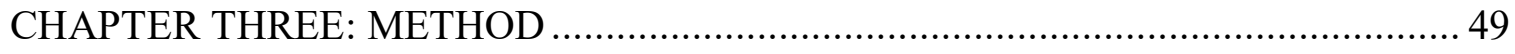

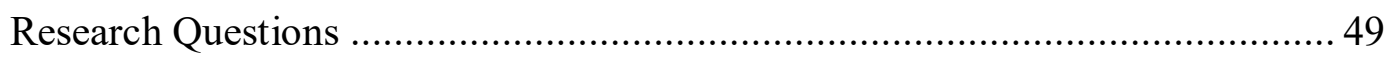

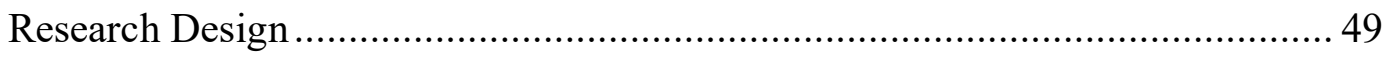

Sample and Context of the Study ………………............................................. 51

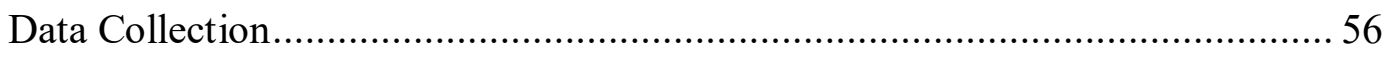


Phase 1: Qualitative Interview Collection Protocol .................................56

Phase 2: Creation of the Quantitative Instrument and Protocol.................58

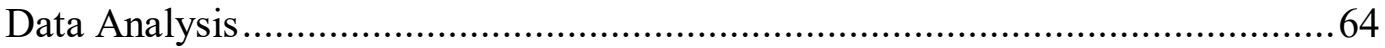

Phase 1: Qualitative Data Analysis of Interview Data ..............................64

Phase 2: Quantitative Data Analysis of Survey Data ...............................67

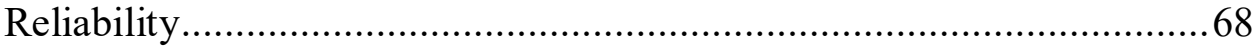

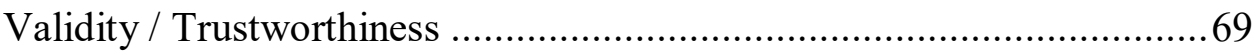

The Role of the Researcher ..................................................................70

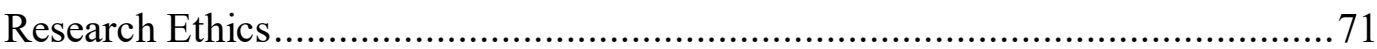

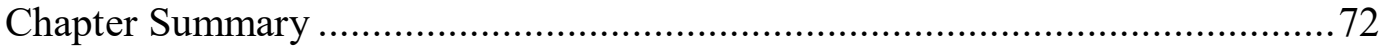

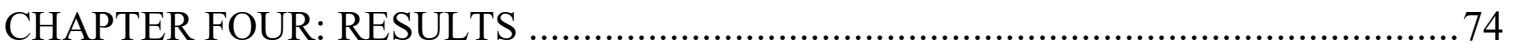

Phase One: Qualitative Results........................................................................74

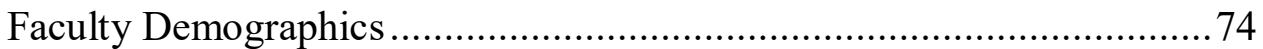

Interview Results Focused on CBE Faculty Views of CBE ......................75

Interview Results Focused on Self-efficacy ...........................................8

Interview Results Focused on Institutional Support.................................86

Summary of Qualitative Findings ……................................................91

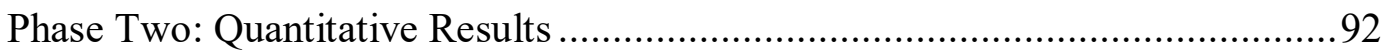

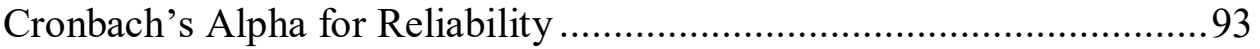

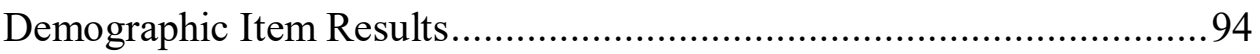

Survey Results Focused on CBE Faculty Views of CBE .........................95

Survey Results Focused on Self-efficacy ............................................101

Survey Results Focused on Institutional Support ...................................108 


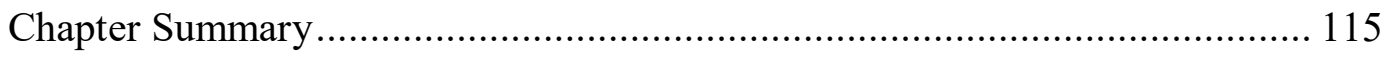

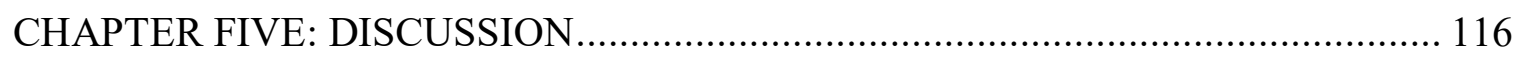

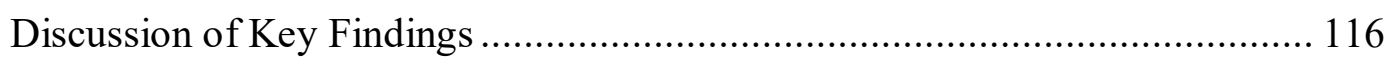

Finding \#1: Positive Views Tied to a Student Focus .............................. 117

Finding \#2: Negative Views Concern Shifts and Changes .................... 119

Finding \#3: The Importance of Repetition and Experience ................... 122

Finding \#4: Specific Learning Opportunities ...................................... 123

Finding \#5: Working Together to Improve ......................................... 125

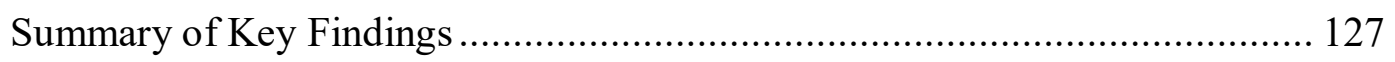

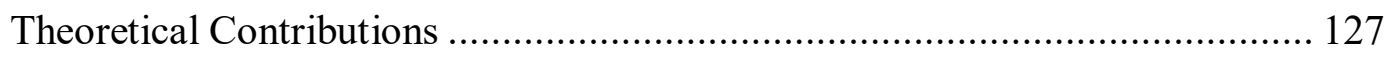

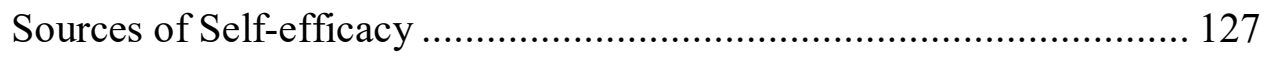

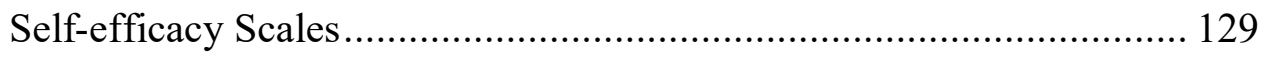

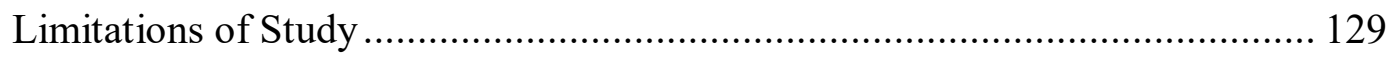

Suggestions for Future Research.............................................................. 130

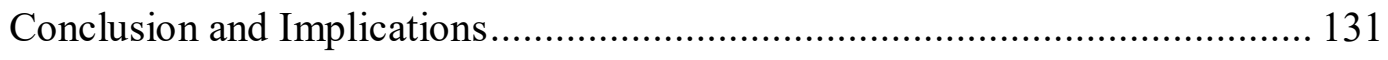

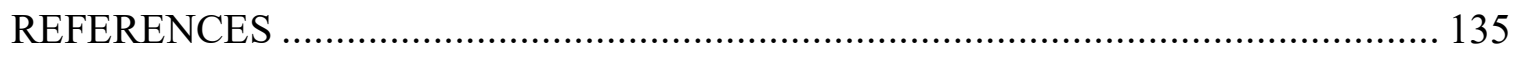

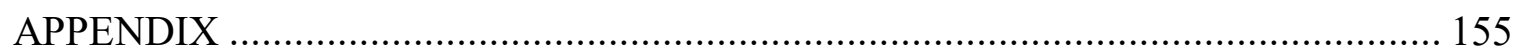




\section{LIST OF TABLES}

Table $3.1 \quad$ Five Rivers Community College CBE Data, 2018-2020..........................52

Table 3.2 Matrix of key features of Five Rivers' Training Pieces ..........................55

Table 3.3 Research Question and Interview Question Alignment ...........................57

Table 3.4 Phase Two Survey Questions and Alignment..........................................60

Table 3.5 Alignment of Research Questions to Data Analysis ...............................65

Table 4.1 Demographic Information for Interview Participants ……......................75

Table 4.2 Key Themes for Research Question 1 ...............................................76

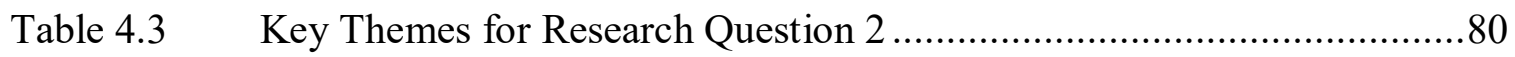

Table 4.4 Frequency Distribution for Self-efficacy Ratings by Construct ................81

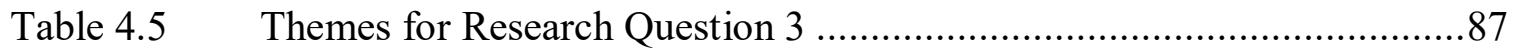

Table 4.6 Survey Participant Demographics ...........................................................95

Table 4.7. Overall Results for Views of CBE and Results by Construct...................96

Table 4.8. Perceptions of CBE Frequencies and Measures of Central Tendencies....98

Table 4.9. Perceptions of CBE by Construct and Demographic ..............................100

Table 4.10. Overall Results for Areas of Self-Efficacy and Results by Construct ....102

Table 4.11. Faculty Self-efficacy Frequencies \& Measures of Central Tendency.....103

Table 4.12. Areas of Self-Efficacy and CBE by Construct and Demographic ..........107

Table 4.13. Overall Results for Institutional Support Ideas and by Construct...........109

Table 4.14. Institutional Support Frequencies and Measures of Central Tendencies ...110 
Table 4.15. Institutional Support Ideas by Construct and Demographic ................. 114 


\section{LIST OF FIGURES}

Figure 2.1. Construct of Self-efficacy Theory From Bandura, A., (1977). Self-efficacy: Toward a unifying theory of behavioral change. Psychological Review, 84,

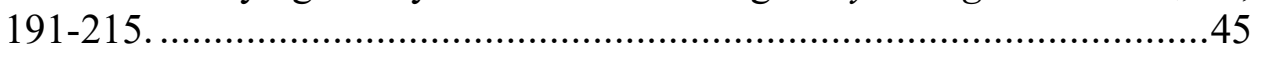

Figure 3.1. Exploratory Sequential Design. Adapted from Creswell (2015, pp. 41 \&

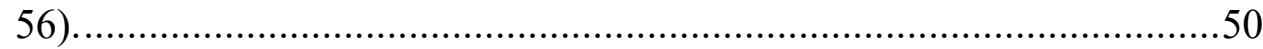




\section{LIST OF ABBREVIATIONS}

$\begin{array}{ll}\text { AIR } & \begin{array}{l}\text { American Institutes of Research } \\ \text { CBE }\end{array} \\ \text { CLEP } & \text { Competency-based Education } \\ \text { DSST } & \text { Dante's Standardized Subject Tests } \\ \text { FRCC } & \text { Five Rivers Community College } \\ \text { ODHE } & \text { Ohio Department of Higher Education } \\ \text { PLA } & \text { Prior Learning Assessment } \\ \text { WGU } & \text { Western Governors University }\end{array}$




\section{CHAPTER ONE: INTRODUCTION}

Colleges and universities find themselves serving an increasing number of nontraditional students (Hittepole, 2019). Though the number of non-traditional students peaked around 2016, researchers predict a resurgence continuing into the mid-2020s (Anderson, 2016; Smith-Barrow, 2018). These non-traditional students have different needs and characteristics than traditional 18-22 year old students. For example, a nontraditional student is at least 25 years old and likely has significant work or life experience (Fishman, Ludgate, \& Tutak, 2017; Pelletier, 2010). Many of these nontraditional students desire to apply or use their prior learning experiences, military service, or employment history in some way when earning a college degree or credential (Baker, 2015). Thus, traditional college courses focused largely on seat time, strict semester-based schedules, and a one-size fits all model often fail to meet these students' needs (Hittepole, 2019). Research suggests, however, that competency-based education (CBE) delivered online through a learning management system (LMS) might help meet many of the needs of this group of non-traditional students (ODHE, 2016).

\section{Overview of Competency-based Education}

Competency-based education (CBE) dates back to the 1860s (Duemer, 2007). While there is little consensus on defining CBE, Ainsworth (1977) defined CBE as "an instructional system where students are given credit for performing to a pre-specified level of competency under pre-specified conditions" (p. 322). Today, competency-based education can be found at an institution, program, or course level. Western Governors 
University (WGU) is one of the best examples of CBE at an institutional level. At WGU, students complete online courses designed around a set of competency statements intended to measure student performance in a given area (WGU, 2020a). Subject matter experts collaboratively develop competencies. For example, a student completing a degree in accounting might have to demonstrate a competency showing debits and credits on a balance sheet for a small business. Courses contain a set of competencies for each student to demonstrate mastery toward through multiple means of assessment including exams, assignments, and labs. One of the benefits of this approach is it enables students to complete their coursework online at a faster pace because of their prior knowledge and experience and does not force them to wait until the next semester to begin their next course.

The efficiency and flexibility of this model promotes an experience for students rooted in prior knowledge with an emphasis on growth (when there are learning gaps) rather than focusing on seat time and a 'one-size-fits all' approach (Baker, 2015; WGU, 2020a). One common CBE approach has students move through a given course at a pace determined by first assessing what they already know. The gaps in knowledge between what they know and can demonstrate and that which they cannot demonstrate in terms of mastery are then addressed through supporting materials aimed at eventual mastery of a set of competencies. This process is generally delivered online. At some institutions, existing knowledge may be demonstrated by a prior learning assessment (e.g. Dante's Standardized Subject Tests [DSST] or College Level Examination Program [CLEP]) or other mechanisms, such as a portfolio of work samples. The performance on such prior 
learning assessments help to reveal where any gaps might exist and what, if any, course credit the student can be given for their prior learning.

Computer science and business management are examples that are commonly offered as CBE programs (whether at a CBE-focused institution or others that have a CBE option) as well as traditional programs at colleges and universities. In traditional programs, students take a prescribed set of courses over a period of time (e.g., four years) toward completing a baccalaureate degree. Each year, courses are taken in a specific order during traditional academic semesters (e.g., sixteen weeks), with new courses starting each semester. Upon completion of the courses, a capstone, and possibly even an internship or field experience, a baccalaureate degree is conferred (Frost, 2016; Laitinen, 2012; Sullivan \& Downey, 2015).

In a CBE model, there is still coursework that a student must complete as a part of the baccalaureate program. Completion of coursework occurs online in a flexible pacing manner; students demonstrate their mastery of competencies (which are similar to learning objectives) for each unit of study in a given course. As students complete each unit of study and demonstrate their mastery of a given competency, the student can move on to another unit of study (or even course) rather than wait for his/her peers to complete that unit of study. While it may take some students a full academic term to complete a course, other students with prior knowledge and life experience generally complete the units of study (and therefore courses) at a faster pace which in turn can reduce time to completion of a given degree (WGU, 2020a). Take for instance a student who has worked in computer science for a decade; that student would likely be able to leverage his/her 
prior life experience and complete a course or even a degree much faster than a traditional age student with no prior experience in computer science.

Finally, though less common, CBE can even be used at a course level. This happens when a course is designed to focus on specific competencies that are aligned into specific units within a course rather than simply a week-by-week model. When this occurs, students complete each unit online at their own pace, mastering these competencies albeit in a linear fashion (i.e., unit one comes before two and so on). Thus, progress in a $\mathrm{CBE}$ course becomes student performance driven rather than time-driven (Schaffhauser, 2017). Course level CBE mirrors that of program or degree level, although instances of CBE course design can occur individually at the course level in non-CBE programs. Further, CBE promotes faster completion by students. The emphasis on reduced time to completion, known as the completion agenda (McPhail, 2011), is a key part of the mission of many of the nation's community colleges. A student who can complete coursework faster - thus reducing time to graduation - leads to quicker employment or post-graduation opportunities.

$\mathrm{CBE}$ is complex and hard to define. However, $\mathrm{CBE}$ in higher education is essentially an alternative approach to teaching and learning that emphasizes faster completion, credit for prior knowledge, and career and vocational alignment to enable a higher likelihood of completion and employment progress for students. It can benefit students, especially nontraditional students, because it assists with giving credit for life experience, past employment, or other situations to benefit a student who perhaps reenters college or wishes to accelerate their career faster. 


\section{Theoretical Framework}

Self-efficacy suggests internal expectations of confidence are a driving force behind the success of an individual in an experience (Bandura, 1977, 1986). Self-efficacy affects people's behavior as they work towards mastery of an outcome. Further, a person's belief in their ability determines whether or not they might even attempt to adjust to a given scenario and if so, how long they might actually pursue success within the task. The theory can aid in interpreting the view faculty have of their own selfefficacy and its relationship to teaching. It can also aid in understanding how faculty view their own self-efficacy and confidence with respect to teaching in new ways. The present study examined competency-based education faculty's views of CBE and the relationship between these views and self-efficacy, and finally ways that institutions might better support faculty (and thus improve their self-efficacy when it comes to CBE). The theory of self-efficacy and numerous self-efficacy scales (e.g., Sherer General Self-efficacy Scale, Generalized Self-efficacy Scale, New General Self-efficacy Scale, Self-efficacy Formative Questionnaire) helped guide this examination and are discussed more in chapter three.

\section{Statement of the Problem}

$\mathrm{CBE}$ is poised to grow in the next decade. In fact, the American Institute of Research's (2019) survey of the state of CBE found that $76 \%$ of institutions expect a growth in CBE programs by 2024. Various challenges will likely come with this growth (e.g., with registration, academic advising, and the role of faculty). One of the biggest challenges likely will be with faculty. As CBE grows, it will require more faculty to take part in $\mathrm{CBE}$ and specifically to teach $\mathrm{CBE}$ courses, often for the first time. 
This is problematic because teaching in CBE differs in many ways from teaching in a traditional course (Gruppen et al., 2016; Ordonez, 2014). For instance, students pace through a course or program at varying intervals rather than at the same pace as they do in traditional courses. Grading of student work, assisting with preparation for an exam, or other common instructional or faculty-centered tasks do not occur in tandem in a CBE course. Each student submits work at different times, so grading assignments might occur more one-off than in traditional course settings where instructors can grade all of the previous weeks' assignments together. Further, faculty tend to play a variety of different roles in CBE beyond simply teaching courses. Faculty teaching in a CBE program must also mentor students in not only the course content but CBE as a whole while also performing CBE-related administrative tasks, such as enrollment or test proctoring for individual students as opposed to an entire class at once (Klein-Collins, 2013; Newbold, Siefert, Doherty, Scheffler, \& Ray, 2017). Most faculty are not expected to complete tasks like these when teaching traditional courses and therefore lack experience doing so and will need some support when transitioning into these roles. Additionally, their confidence and self-efficacy are of primary concern as they embrace this new approach to teaching and learning.

Given that CBE is growing and the roles of faculty change when teaching in a CBE program and that most faculty have little experience with CBE, there is a need to better understand faculty views of $\mathrm{CBE}$ and how best to support them as they get more involved with CBE. Unfortunately, to date, there is very little research on faculty views of $\mathrm{CBE}$ or their self-efficacy transitioning to teaching in this new format. 


\section{Purpose of Study}

Competency-based education continues to grow at campuses across the country. Institutions must find ways to support faculty teaching in this new format. Research into faculty views of CBE could help institutions better support faculty, and in turn the students completing these programs.

Given this, the purpose of this study was to explore community college faculty views of CBE. More specifically, I investigated the following questions:

1. What are competency-based education faculty's views of CBE?

2. How do faculty involved with CBE rate their own self-efficacy?

3. How can institutions better support faculty to teach CBE courses?

\section{Overview of Research Methods}

I will briefly describe the research methods used in this study. The research methods are addressed in greater detail in chapter 3.

\section{$\underline{\text { Research Design }}$}

I used a mixed methods exploratory sequential design to answer the research questions (Creswell, 2015). This research method involves collecting qualitative data during the first phase of the study to then create an instrument (in this case a survey) for collecting quantitative data in the second phase of the study to further explore the research problem.

More specifically, I interviewed faculty teaching competency-based courses at a large community college with a robust $\mathrm{CBE}$ presence. I analyzed the data collected from the interviews and used it to inform the creation of a survey. The survey consisted of both Likert scale ranking items in three parts. First, respondents assessed their views of CBE 
as a whole. Second, they evaluated their self-efficacy as CBE faculty. Third, they rated institutional supports they believed may help faculty transitioning or continuing to teach CBE courses.

$\underline{\text { Sample and Context }}$

Five Rivers Community College (FRCC) [note: pseudonyms are used to protect institutional and individual identities] is a leader in CBE programs in Ohio (Bell, 2018; Ohio Department of Higher Education, 2018). Initial design and implementation of FRCC's CBE program was supported by a $\$ 1,000,000$ grant from the United States Department of Labor focused on supporting community colleges to address the evolving and ever-changing needs of the nation's workforce. Five Rivers' CBE program is eleven years old. FRCC currently offers eleven CBE programs that enable students to earn both short-term certificates and associate degrees; concentrations include business management, aerial sensing data analytics (unmanned aerial systems), criminal justice, and numerous areas under the computer science and information technology umbrellas (Five Rivers Community College, 2020).

The CBE courses at FRCC are predominantly online with some in-person requirements depending on the program. Most $\mathrm{CBE}$ courses provide an individual path for completion. There are a few exceptions (i.e., where collaboration occurs), though these opportunities primarily exist in peripheral situations. For example, a student may need to take a math or English course as part of a CBE program. During 2018 and 2019, an average of 474 students $(N=1,400)$ enrolled in a CBE course in one of the programs per term. Five Rivers overall enrollment during this time was approximately 19,000 students in each academic year (2018 and 2019) (NCES, 2020a). During the same 
timeframe, an average of $206 \mathrm{CBE}$ course sections were offered per term $(N=1,236)$ taught by approximately 32 faculty members $(N=179)$ including full-time, parttime/adjunct (A. Williams, personal communication, March 23, 2020).

FRCC has a strong CBE program given its age, number of students enrolled, and number of sections offered. The institution provides specific training for faculty teaching CBE courses (which will be described in more detail in chapter 3). All faculty (both full and part-time/adjunct) must complete two required trainings. One, a facilitated course delivered online, instructs participants on how to successfully teach online classes while the second is a set of self-paced tutorials on the use of the institution's learning management system. A third training is optional though encouraged and consists of active participation in an online community for faculty teaching CBE courses; faculty taking part in the community have access to a an optional a self-paced tutorial covering the institution's use of CBE.

$\underline{\text { Data Collection and Analysis }}$

There are approximately 1,050 faculty at Five Rivers Community College with a ratio of 1:3 full-to-part-time/adjunct (NCES, 2020a). Of that number, approximately 65 either previously taught or currently teach CBE courses. From that population, a sample of ten faculty members was solicited purposefully for interviews as part of the qualitative portion of the proposed study. The interviews took place via synchronous web conferencing technology. Responses were recorded, transcribed, and stored on a password-protected cloud server. NVivo, a qualitative analysis software, supported the analysis of the interview data. Through the use of multiple cycles of coding, response analysis identified themes within answers to interview questions (Miles, Huberman, \& 
Saldana, 2014). Member checking by interview participants helped increase the trustworthiness of the data (Miles et al., 2014).

The themes that emerged from the interviews guided the development of an online survey. The survey was administered to $62 \mathrm{CBE}$ faculty at FRCC with 48 responding by completing the survey for a response rate of approximately $77 \%$. SPSS was used to analyze the results and calculate the descriptive statistics.

\section{Key Terms of the Study}

Competency-based education (CBE): an outcome-based approach to education that incorporates modes of instructional delivery and assessment efforts designed to evaluate master of learning by students through their demonstration of the knowledge, attitudes, values, skills, and behaviors required for the degree sought (Gervais, 2016, p. 99).

Competencies: Klein-Collins (2012) defines competencies as statements able to be measured and include the showcasing of specific abilities in a different contexts.

Self-Efficacy: Albert Bandura defined self-efficacy as (1986), "how well one can execute courses of action required to deal with prospective situations" (p. 122).

Faculty Development: A process to help instructors improve abilities, skills, and understanding of teaching practice in appropriate settings (Steinert, 2014).

\section{Chapter Summary}

Competency-based education continues to grow. However, despite this growth, most faculty have little experience with CBE. This study explored faculty views of CBE at the community college level and which supports are necessary to support such faculty.

Chapter 1 summarized briefly the nature of CBE and the problem this study addressed as it connects to existing research. It also provided a key list of commonly used 
terms in the field. In the next chapter, chapter 2, I summarize key works as they relate to $\mathrm{CBE}$ and its related facets, self-efficacy, and faculty development. 


\section{CHAPTER TWO: LITERATURE REVIEW}

The present study explored faculty views of competency-based education (CBE), self-efficacy, and faculty development at a large community college. Competency-based education differs from traditional education in a number of ways. In the following chapter, I summarize literature defining competency-based education, its notions and historical evolution, $\mathrm{CBE}$ use in practice, its promises and challenges, faculty development and support, and self-efficacy and teaching. It is important to note that much of the literature surrounding CBE, especially its foundations, implementation processes, and history, are often non-empirical position pieces that consequently reference other similar works (Boyd et al., 2018; Daughtery, Davis, \& Miller, 2015). While many of these pieces are crucial to defining and detailing the key features of CBE, this chapter also addresses the limited empirical works on CBE that exist in the literature.

\section{Competency-based Education Defined}

Researchers struggle defining competency-based education in the higher education context. In fact, Gervais (2016) opines that, "Competency-based education has been defined in multiple ways and interpreted differently across academic programs" ( $p$. 98). The Competency-based Education Network (CBEN) created one of the more comprehensive definitions of competency-based education (CBE). According to CBEN (2019), competency-based education:

...combines an intentional and transparent approach to curricular design with an academic model in which the time it takes to demonstrate competencies varies and the expectations about learning are held constant. Students acquire and 
demonstrate their knowledge and skills by engaging in learning exercises, activities and experiences that align with clearly defined programmatic outcomes. Students receive proactive guidance and support from faculty and staff. Students earn credentials by demonstrating mastery through multiple forms of assessment, often at a personalized pace (para. 1).

There are several concepts in this definition, as it relates to $\mathrm{CBE}$ in higher education, to unpack and discuss in greater detail. Further, it is often helpful to define the different parts of CBE by focusing on how they differ from traditional forms of higher education.

\section{Competencies}

One of the defining characteristics of $\mathrm{CBE}$ is the use of competencies. CBE, whether at the course, program, or institutional level centers on the use of a set of competencies tied to a career. While some traditional higher education programs might center around a set of professional competencies (though these are more often found in professional graduate programs), traditional higher education--especially at the undergraduate level, traditionally focuses on a general set of broad outcomes rooted in academic skills that tend to align with lower levels of Bloom's Taxonomy (Sturgis \& Casey, 2018).

In $\mathrm{CBE}$, competencies are inclusive statements tied to a measurable ability and linked to a vocational or career-oriented outcome (Bornitz \& Carnaghan, 2003; Dragoo \& Barrows, 2016; Grann, 2017). For example, a competency statement in a retail management program may read, 'Write a forecasting plan for a 30 day push to increase customer check total by using register data from a previous six-month period.' The statement is specific and directly related to the tasks an individual working in retail management may later use in their career. Upon completion of a CBE program, a student emerges fully competent and able to enter the workforce because of the competencies 
they mastered. Further discussion of competencies occurs later in this chapter in a connection to $\mathrm{CBE}$ in practice.

Flexibility

Another defining characteristic of $\mathrm{CBE}$ is its flexibility. $\mathrm{CBE}$ is a flexible model where students must master a competency before moving on to another competency (or a set of competencies, in a course/credit model as discussed later in this chapter). Unlike traditional courses that center around seat time or a set schedule over an academic term (AIR, 2019; Cavanagh, 2012; Torres, Brett, Cox, \& Greler, 2018), CBE gives students a chance to learn in a setting where, as Gruppen et al. (2016) put it, time is variable while the desired outcomes are set. Thus, CBE courses are designed so that all students must demonstrate mastery of the same set of competencies for a given course, but, each student has the ability and flexibility to complete the assignments at their own pace, which in turn provides students with more prior learning or life experience the ability to proceed faster than others.

\section{$\underline{\text { Prescribed Materials }}$}

The flexibility of CBE is only successful when a prescribed set of materials exist within the course's structure to support mastery. Whereas traditional education usually requires students to complete every assignment in a given course, $\mathrm{CBE}$ course materials focus on a competency-mastery model. Therefore, materials are therefore often structured to permit students to either move quicker or take multiple attempts at assignments with intervention measures in place for those who struggle (Competency Works, 2012). This means that students can both skip certain parts of a course because they were able to demonstrate what they already know or revisit content through remediation that they do 
not know well enough to progress. Thus, a CBE student with prior life experience in a given content area may complete fewer assignments than another due to the pace at which they master a competency or set of competencies.

Mastery Methods

Demonstrating mastery in multiple ways is another key characteristic of CBE (Burnette, 2016). CBE is founded on the principle that not every student will complete or should complete every assignment, especially when it comes to assessments. CBE often uses a pre- and post-assessment model where students complete a pre-assessment to see what they may already know or be able to do with respect to a certain competency or set of competencies. If a student passes the pre-assessment, the student can skip that given unit and can instead move on to the next set of competencies. If a student fails the preassessment, the student will be given a customized set of assignments and assessments depending on how they performed on the pre-assessment (Burnette, 2016; Hagan-Short \& Addison, 2019; Nodine \& Johnstone, 2015); in many cases, these materials are specifically aligned to the gaps identified from the pre-assessment. Once complete and ready, the student would take a post-assessment to see if he/she mastered the competencies; once the student passes the post-assessment he/she can then move on to the next set of competencies (Staley \& Trinkle, 2011). In CBE, a student is often provided multiple attempts to pass a post-assessment (Hagan-Short \& Addison, 2019). A greater discussion of assessment exists later in this chapter because of its primary role in a $\mathrm{CBE}$ program but it is important to describe three ways assessment is used to demonstrate mastery of competencies in CBE. 
CBE generally uses one of three common assessment approaches, sometimes in a complementary format, to demonstrate mastery learning. First, direct assessment permits a student the chance to demonstrate their mastery of a set of competencies (Book, 2014; Nodine \& Johnstone, 2015). Second, the course/credit model places competencies into bundled packages in the format of courses with equivalent credit hours (Book, 2014). Finally, prior learning assessment (PLA), a peripheral approach, provides a student an opportunity to demonstrate or earn credit for previous learning, skills, or abilities gained from experiences that include employment, military service, or independent learning (Akos, Wasik, McDonald, Soler, \& Lys, 2019; Albanese, Mejicano, Mullan, Kokotailo, \& Gruppen, 2008). Although PLA is a peripheral approach to assessment, it has a place in $\mathrm{CBE}$ due to its ability to provide an individualized CBE experience (Brower, Humphreys, Karoff, \& Kallio, 2017). Granting credit or competency for such past experiences could reduce a student's time to completion. Assessment is further discussed later in this chapter.

\section{History of Competency-based Education}

The roots of CBE date back to the Morrill Land-Grants Acts of 1862 and 1890. Part of these acts established agricultural training colleges for students coming from the nation's farming communities who would not likely attend an academic university (Duemer, 2007). Such students focused on a set of vocational skills and abilities needed to work on the farms of rural America (Gervais, 2016).

Urbanization in the Progressive Era further influenced the development of CBE. During this time, John Dewey argued that schools should move from a focus on rote memorization to an emphasis on being able to perform and demonstrate knowledge (Le, 
Wolfe, \& Steinberg, 2014). Then during the 1950s, the theoretical underpinnings of Benjamin Bloom and Ralph Tyler pushed for a focus on outcome-based learning, with an emphasis on the measurement of competencies and outcomes (Henson \& Hitchcock, 2017; Nodine, 2015).

Over the next thirty years, many factors further enhanced CBE. The proliferation and rapid growth of community colleges took place in the 1960s with the population surge attributed to Baby Boomers and a need to focus on the workforce (Nodine, 2015). The Higher Education Act of 1965 and the 1973 Fund for the Improvement of Postsecondary Education (FISPE) provided more access for adults, as non-traditional students, to attend college. A goal of these acts was to better prepare the workforce or improve their existing skills (Brock, 2010; Gallagher, 2014). During this time, John Carroll and Fred Keller pushed learning based on ability and mastery of modules of content (Gervais, 2016). Their emphasis on modularization would later influence the design of CBE courses as students may work through courses built on modules of content related through some commonality.

More recently, the United States Department of Education began offering financial incentives to develop CBE programs as a way for faster completion of a college credential or degree (Gallagher, 2014; U.S. Department of Education, 2013). As a result, at the time of writing this chapter, there were 64 institutions offering CBE programs nationwide (AIR, 2019). Faster completion is notable at a time when many states have cut funding to higher education (Burnette, 2016). As of late 2019, the U.S. Department of Education's rulemaking process proposed legislative changes that could support facets of $\mathrm{CBE}$ including financial aid, an emphasis on workforce development, and faster 
completion (Downs, 2019; Peller, 2019). Federal support of CBE can influence institutions at any stage of $\mathrm{CBE}$ from consideration through mature program delivery.

The CBE approach differs from traditional higher education in many ways including pacing, flexibility, and methods of mastery. Historically, CBE grew into its current status as a result of educational developments going back to the 1860 s. The contemporary landscape of $\mathrm{CBE}$ does face hurdles at times such as scrutiny over financial aid. However, recent proposed policy shifts (e.g., applicability of federal financial aid to CBE programs) may provide federal support to overcome such challenges. CBE appears to be growing based on the number of institutions supporting CBE at various stages of development (AIR, 2019). However, an historical and theoretical discussion must be complemented by views of CBE in practice.

\section{Competency-based Education in Practice}

Now that I have described what CBE is and how it has evolved over time, I am going to focus on describing what $\mathrm{CBE}$ actually looks like in practice. In the following section, I will elaborate further on competencies and then describe three key CBE program design approaches. Notably, these approaches are rooted in assessment as the guiding factor.

Competencies

Competency, just like competency-based education as mentioned earlier, is a contested term (O'Donoghue \& Chapman, 2010). An analysis of the literature on CBE in higher education suggests that competencies in practice ideally include six key principles.

First, competencies in CBE must be measurable in terms of performance of what students can actually do (Bornitz \& Carnaghan, 2003). Though similar to objectives, 
competencies often directly connect to vocational application (Grann, 2017; ten Cate, 2005). Some institutions even use objectives as a basis for developing competencies. This is done by taking basic skills from objectives, grouping them together in some form of organization, and then using these as the basis for developing higher order competency statements within the scope of a particular field (Hagan-Short \& Addison, 2019).

Second, well-developed competencies focus on higher levels of learning (e.g., Bloom's taxonomy) (Palardy \& Eisele, 1972, Fitzgerald et al., 2016). Rather than simple identification, these statements move toward more demonstrable requirements, and may use verbs such as construct, compose, or vocationally-related terms like cut, handle, or perform.

Third, the scope of competencies permit the direct application of knowledge into the workplace (Dragoo \& Barrows, 2016). The ability for a student to take their knowledge and ability directly to an employer or work-based situation means that both the employer and employee benefit from the learning experience.

Fourth, well-written competencies identify how to measure mastery of the given competencies. For instance, the plan for assessment and the criteria used for evaluation are often included within a given competency wording and even includes time allotment or a performance threshold (Palardy \& Eisele, 1972). For example, a competency statement may read: "Calculate the proper mathematical result for a manufacturing assembly problem within the first two minutes of acquiring the raw products from the distributor with at least 95\% accuracy."

Fifth, competencies align a desired student's performance to actual, real needs of employers in an industry or field. In fact, competencies are ideally developed in close 
partnerships with an industry and/or field to ensure rigor and the ability to adapt to the changing needs of the workforce and how institutions meet those needs (Clerkin \& Simon, 2014; Hagan-Short \& Anderson, 2019; Johnstone \& Soares, 2014). These partnerships are with professional organizations or industry trade groups (Adelman, Ewell, Gaston, \& Schneider, 2014) who assist with competency development to ensure alignment to the industry. For example, partners may include groups like the Association of Professional Drone Pilots (APDP) or even the U.S. Air Force.

Sixth, well-written competencies are transparent. Competencies should be created with numerous parties involved in an open process. This can ensure that all involved in CBE (i.e. students, faculty, employers, industry partners and even alumni) are aware of expectations and procedures. Doing so also promotes continuous improvement to ensure the accuracy of such statements (Albanese et al., 2008; Dragoo \& Barrows, 2016; Gervais, 2016).

At FRCC, competency development took place in concert with local employers and students (even those who were not CBE program graduates) who provided first hand insight into what graduates should demonstrate in the workforce. Competencies then guided the creation of courses where students can effectively demonstrate these skills and abilities. As part of internal program review, competencies, the courses in which they exist, and the assessments used to gauge mastery, are evaluated on a regular basis by committee to ensure alignment and rigor are maintained.

\section{$\underline{\text { CBE Models }}$}

As mentioned earlier, assessment plays a central role in CBE. Assessment in CBE is a foundational concept largely influencing common designs of $\mathrm{CBE}$ courses and 
programs. There are three key types of assessment approaches guiding CBE in higher education: direct assessment, course/credit hour, and as a peripheral model, prior learning assessment. Though often used exclusively in CBE courses and programs, they can also exist in conjunction with each other. For example, a program may use the direct assessment model within a course itself, but use the course/credit model in developing those courses providing the direct assessment opportunity. Outside of coursework, prior learning may be an option to allow students to demonstrate mastery of a set of competencies, without actually taking a course, and in turn accelerate completion.

\section{$\underline{\text { Direct Assessment Model }}$}

The direct assessment model allows students to demonstrate their ability to master a set of competencies at a flexible pace (though still within the parameters of a course). Learning materials allow self-pacing and an assessment is available when students are ready to demonstrate mastery of a competency (Book, 2014; Nodine \& Johnstone, 2015). The pre- and post-assessment approach fits within the direct assessment model where students demonstrate what they already know and then focus on weaker areas.

Attainment of credit is based on the work put forth towards mastery of competencies. This work guides completion more than how long they spend in a given course (i.e., seat time) (Book, 2014; ODHE, 2016).

I began this chapter noting the lack of empirical research on CBE. Though scholarship is limited, two studies found the direct assessment approach using pre- and post-assessments to show significant gains for students. In one study, Thurman and Sanders (1987) investigated the differences between students in two groups: one, a traditional curriculum and the other a competency-based curriculum for one unit of 
content. Both groups took a pre-assessment and post-assessment. Results showed that the competency-based treatment group, who were given interventions based on their preassessment scores, had higher post-assessment scores than the traditional control group who simply completed the unit in a normal fashion.

In another study, Altahawi, Sisk, Poloskey, Hicks, and Dannefer (2012) investigated student perceptions of feedback on assessments. They conducted a case study of four medical students required to complete a portfolio classified as an entrustable professional activity (EPA). An EPA takes competencies and transforms them into feasible, authentic experiences or tasks toward which a student can show competence aligned with a real-world scenario, such as a career (ten Cate, 2005). Findings from the study indicated the transition from standard grading to an EPA reviewed by a committee of assessors, coupled with feedback intended to make the student more self-regulatory, promoted further success on the required competencies when evaluated. If a student had not passed the EPA, then supporting material (via the feedback mechanism) would afford them chances to learn and attempt to re-master the competency defined as sub-par. What makes these limited studies standout, however, is the fact they were often done in the medical field where much of the empirical works on CBE emanate.

\section{Course/Credit Model}

The course/credit hour model is similar to a traditional method of course completion that students complete while pursuing a credential in a traditional program. The key difference, though, with this model in CBE comes back to time. In the course/credit model, overall program competencies are bundled into courses based on similarity or another factor, such as an order of completion. Once a student completes the 
bundled competencies (which may even include direct assessment for each), they are awarded credit just like in a traditional course (Book, 2014; ODHE, 2016). As an example, a student may enroll into a criminal justice certificate program containing 24 competencies. The program structure includes eight courses each containing a set of three bundled competencies. The student would complete each course's three competencies at their own pace and upon completion receive that course's equivalent credits. Once a course is complete, they can move into the next course, then the third, and so on. Once all eight courses (and thus, 24 competencies) are complete, the credential is awarded. The use of this model and its output of equivalent credits ensures that credits are transferable (Boyer \& Bucklew, 2019).

Grann (2017) illustrated the course/credit model in a case study of Capella University. At Capella University, every course assignment aligns with one or more competencies, with each competency meant to mirror an authentic scenario. Though Capella customizes its use of the course/credit model for its own needs, their use of the model does offer insight for other institutions seeking to create a course/credit hour program. At Capella, competencies and their assessments and supporting material for students with gaps are bundled into courses like in the course/credit model. The key difference is that competencies are focused more on supporting the overall institutional learning outcomes, such as effective communication (Grann, 2017). Capella's use of CBE in this manner exists because of the institution's primary focus on the adult student. Thus, the overall institutional learning outcomes are addressed towards such students where other institutions may only partly focus on adult students and thus have institutional outcomes not tied to competencies. 
Gruppen et al. (2016) studied the University of Michigan's CBE course/credit model in medical education. Rather than structuring competencies into courses, the program packages them into entrustable professional activities (EPAs). ten Cate (2013) describes EPAs as the key tasks or abilities needed for the real clinical setting. A student can be trusted to perform these tasks and abilities once they demonstrate required adequate competency. The application of EPAs to a clinical setting indicates they are found in healthcare CBE programs. At the University of Michigan, EPAs are designed around related competencies that guide the completion of the program's requirements (Gruppen et al., 2016). As students complete each EPA - and thus set of competencies they can move to subsequent ones as they demonstrate their abilities. Gruppen et al., (2016) found that EPAs helped students emphasize their ability, focus on outcomes, and complete program requirements faster in an environment centered around their abilities individually. A further study on students who used an EPA and translation to success in actual health professions would provide more insight into both feasibility and effectiveness.

\section{$\underline{\text { Prior Learning Assessment (PLA) Peripheral Model }}$}

In addition to the direct assessment and course/credit hour models, CBE also uses prior learning assessments (PLAs) as a peripheral part of assessment and design. Though more complementary than mainstream, PLAs often support CBE as an embedded piece of a larger approach (ODHE, 2016) and often include experiential learning which may include on-the-job experiences or hands-on opportunities (Valenzuela, MacIntyre, KleinCollins, \& Clerx, 2016). The experience of a student can provide opportunities to demonstrate this knowledge and receive credit. 
The desire to infuse prior learning into a student's path lies in the fact that many students, especially non-traditional ones, tend to enter college with extensive knowledge skills, and abilities gained from a number of potential experiences (Fishman et al., 2017). These may include work or employment history, on-the-job training at a current or prior employer in a related area, military service, or independent knowledge acquisition (Akos et al., 2019; Albanese et al., 2008). Universities who seek to entice such a student to enroll must be willing to provide some college credit for this previous experience. From a competitive enrollment standpoint, students are more likely to enroll in a program that enables them to get the most college credit for their prior knowledge and experience, which in turn will help them complete the degree faster and often save some money as well.

For example, many military students possess extensive knowledge of Unmanned Aerial Systems (i.e., drones; USAF, 2020). Upon entering the private sector, veterans may wish to obtain civilian certifications to continue working in the field. By demonstrating their previous knowledge, an institution could give a student credit and enable quicker completion. An assessment of this knowledge would replace the courses (and thus competencies) of the CBE program.

Porter and Reilly (2014) argued that PLAs are vital to push faster completion through a course or program as well as cost savings and an increased likelihood of completion. Additionally, several outlets already supply usable instruments an institution could use for PLA purposes as they can meet needs for PLA and keep costs low versus an internal development (Pelletier, 2010). For example, the Council for Experiential Learning (2020) has a tool to identify the best way to assess prior knowledge for students 
on an individual basis through self-identification. CAEL's tool is not a true assessment, but rather an aid to help a student identify what in their history of experience, earned credentials, or other means can result in a potential award of PLA credit. CAEL (2020) also provides ways an institution can support a student's possible PLA.

Another example of an existing PLA is the College-Level Examination Program (CLEP) and its set of exams. There are more than 30 exams in areas such as writing, literature, foreign languages, and social sciences (CLEP, 2020). Boatman, Hurwitz, Lee, and Smith (2017) examined all CLEP exam takers over a seven year period. Findings indicated a $17.3 \%$ increase in likelihood of completing a two-year degree for a student having earned prior learning credit through taking a CLEP test versus those without receipt of prior learning credit. Further examples of established PLA approaches include Advanced Placement Exams for high school students and credit recommendation services (Lawrence, Perry, \& Vanderford, 2018)

Conversely, creating PLAs internally could also address this need, however such an effort requires significant resources (Akos et al., 2019). An institution may create its own PLA versions for a number of reasons. For example, given the alignment of competencies to industry and employer needs, an institution may want to create its own PLA program to ensure that the skills or experiences brought by students are aligned to local needs in a specific way (Ohio Board of Regents, 2014). An additional reason is the need to develop PLA opportunities while simultaneously training internal staff on both PLA alignment of such efforts with institutional needs for prior learning (Lawrence et al., 2018). With portfolio assessments or an EPA activity, creating a customized approach that incorporates an institution's systems would be more beneficial than trying to use an 
existing mechanism that is hard to integrate. At a course or individual level, creation of internal PLA versions may also benefit faculty members and their intimate knowledge of course materials (Lakin, Seymour, Nellum, \& Crandall, 2015). Since a faculty member designs a course for delivery, permitting them to create a PLA (e.g. a proficiency exam based on their content) would benefit the institution on a more individual level to control what went into the PLA instrument.

Kelchen (2016) analyzed CBE from a number of perspectives, including institutions using PLAs $(N=13)$. He highlighted different examples of how institutions used existing instruments including CLEP, the Excelsior College Examination Program (UExcel), and the Defense Activity for Non-Traditional Education Support. He cautioned though that PLAs are only appropriate for assessing prior knowledge and not for building or learning new information. While the study was informative, Kelchen was unable to make broader connections with respect to PLAs. Further research into PLAs, such as a comparison of success rates for students who completed them versus those who did not, is needed to provide further insight into effectiveness or usability of PLAs.

\section{Competency-based Education in Action}

CBE can take many forms. One can get a better understanding of CBE by seeing some different examples of it in action. One of the best places to turn for details on $\mathrm{CBE}$ is The American Institutes for Research (AIR) work on CBE; AIR publishes an annual report on the state of the post-secondary CBE field. The most recent version (2019) indicated that $75 \%$ of institutions surveyed predicted a surge of CBE over the next five years. Of those institutions using CBE, both mature and emerging programs exist and are found at public, private, and for-profit four-year institutions. Three examples of mature 
programs include the University of Wisconsin Flexible Option, Southern New Hampshire's College for America, and Western Governors University. Three examples of more recent, emerging programs include the University of Michigan, Texas A\&M University - Commerce, and Peirce College in Philadelphia. This section discusses the characteristics of these programs.

Cautiously, there are also institutions with CBE under development, those simply interested in CBE, and those who are not interested at all. The AIR survey (2019) found three notable trends. First, many of the institutions with CBE underway $(N=302)$ consisted of two types: two-year community colleges or private, for-profit universities. Second, those institutions simply interested in CBE consisted primarily of four-year universities - both private and public. Finally, four-year private institutions also comprised the largest group of universities disinterested in $\mathrm{CBE}$ at the time of the survey.

Course delivery method is also an important factor to consider when thinking about $\mathrm{CBE}$ in practice. There is no universal course delivery approach for CBE programs; programs use a variety of online, blended, and in-person delivery options (Garrett \& Lurie, 2016; Hilliard, Bushway, Krauss, \& Anderson, 2018). However, many of the following examples use online courses to deliver their CBE programs, with one using blended learning.

\section{A Mature Program: University of Wisconsin System}

The University of Wisconsin System (UW)'s UW Flexible Option is an example of a mature CBE program. UW Flexible Option includes degrees delivered online in business administration, health sciences, and information technology along with certificates in business communications and project management (University of 
Wisconsin, 2020). Each program is offered fully online and uses direct assessment combined with prior learning assessment for students to progress through associate and bachelor's degree programs (Brower, 2014). The UW Flex System is based on a studentcentered approach. Each student is guided by a team to assist with enrollment and aid as well as coaching for success (University of Wisconsin, 2020). CBE students can start a course at the beginning of a month and all courses are compacted into three-month subscription periods. The flexibility of the UW Flex Program gives students the opportunity to engage with coursework on their own schedule. The skills in each program, supported by personalized coaching, are tied to those valued by employers so that graduates are ready to immediately enter the workforce (Brower, 2014).

\section{A Mature Program: SNHU - College for America}

Southern New Hampshire University (SNHU) is a four-year private institution. SNHU also has a two-year arm (i.e. a community college) called College for America (CfA) that houses and delivers its CBE programs. Students take online courses through a project-based means designed to show mastery of competencies. CfA's programs emphasize faster completion, flexibility, and personalization (CfA Staff, 2016a; SNHU, 2020). A key difference in this institution versus many others is that students must be employed by a partner organization to the college (i.e. one who helped to design competencies for alignment to real needs) while in the program.

Degrees include general studies, healthcare management, communications, and business (SNHU, 2020). Projects are submitted to faculty and subject matter experts for assessment in a path similar to entrustable professional activities (EPAs) in healthcare fields using a CBE course/credit model (CfA, 2016a; ten Cate, 2005). For example, an 
associate degree holder can complete 120 advanced competencies equivalent to 60 credit hours. Upon mastery, a four-year degree can be earned based on these competencies (CfA Staff, 2016b). Like many programs, CfA's decision to pursue CBE came from a need to support a growing workforce and uses a course/credit model with subscription tuition. Students enroll in a six month subscription period where they can complete as many competency clusters to turn into credit hours as they desire (CfA Staff, 2016b).

\section{A Mature Program: Western Governors University}

Western Governors University (WGU) is one of the most mature CBE programs (Fain, 2019). WGU creates competencies with subject experts from the field for each of their programs. Assessments are created in a number of formats to gauge mastery of each competency in a pass-fail manner. Using the course/credit model, coursework created by in-house developers bundles competencies into each course. Students complete courses online through subscription periods with rolling starts with a course mentor there to support their progress (WGU, 2020b). Each college at WGU (i.e. education, business, health professions, etc.) has its own tuition (WGU, 2020c; WGU, 2020d). WGU awarded nearly 35,000 bachelor and master degrees and credentials in 2019 from a pool of 121,437 students (NCES, 2020d). This rate is notable as the entire university exists online using the CBE delivery method (WGU, 2020a) An Emerging Program: University of Michigan

An example of an emerging CBE program is the University of Michigan's (UM) Master of Health Professions Education. This program uses CBE alongside entrustable professional activities (EPAs) in a course/credit model (ten Cate, 2005; University of Michigan, 2020). These portfolio-like tools track and illustrate student progress as they 
work through demonstrating medical-related competencies in their programs and possess a unique place within CBE medical education (ten Cate, 2005). UM began the program in 2014 (Fain, 2014a). Like the UW system, students complete courses online in flexible pacing under the auspices of faculty and a team of mentors to support progress. The program also promises on-the-job learning with two annual face-to-face meetings (i.e. blended learning) as opposed to online courses through five specific competency domains in the program. Also like UW, tuition is set for the six semesters the program is designed to take and students are admitted on a rolling basis - that is, potential students can apply throughout the year (University of Michigan, 2020). The program graduated 50 students in 2019 (NCES, 2020c).

\section{An Emerging Program: Texas A\&M - Commerce}

In 2015, the Texas University System began a CBE program at Texas A\&M University - Commerce (TAMU-C) (TAMU-C, 2020b; University of Texas System, 2014). TAMU-C has a course/credit-based four-year CBE degree in organizational leadership done online via seven week online terms (TAMU-C, 2020a). TAMU-C is classified as an emerging program because itheir CBE only supports one degree program at present, though with high success rates. Degree requirements include courses alongside 48 credit hours of professional development activities. With an average student age of 38 , the program boasts 306 students with 121 graduates to date. Additionally, students enter the program with nearly two-thirds of a degree complete and finish up the four year degree in just under 42 weeks (6 terms) (TAMU-C, 2020c). Rivers and Sebesta (2017) studied satisfaction among the program's graduates $(N=121)$ compared to those in a traditional program and found $86 \%$ of CBE graduates were satisfied with the quality of 
their experience compared to $62.5 \%$ in a traditional program. Additionally, $86 \%$ of CBE graduates said they would recommend the program to someone else compared to $76 \%$ of traditional graduates.

An Emerging Program: Peirce College

Peirce College is a third example of an emerging program offering a single CBE bachelor degree program in Networking, Administration, and Information Security starting in 2016. Like other examples in this chapter, the program is offered fully online in a self-paced, flexible format. Course competencies align to workforce needs to promote post-graduation employment; 75 percent of students in the program are over the age of 25 (Kratsas, 2017). Those who enter the program can receive credit for previously completed courses or industry certifications through PLA. The program contains a coach for each student and uses a direct assessment model for competencies in courses. Completion of competencies in a course translates in part to completion of overall program competencies and then credits (i.e. the course/credit model). Students complete courses/credits through subscription-based terms with unlimited credit completion permitted within the term (Peirce College, 2020a, 2020b). A unique element of this program is that students may earn an associate degree along the way to earning their bachelor's degree (CAEL, 2016). Fifteen students completed the program in 2019 (NCES, 2020b).

Each of these examples, whether emerging or mature, is unique in its own way. However, there are some similarities between programs. For example, each program focuses on earning a degree more affordable for students. Further, each program focuses on offering flexible programs, in terms of how fast a student can progress. Finally, each 
program in some way focuses on providing mentoring and support to help ensure the nontraditional students who typically enroll in their programs stay on track.

In many ways, these similarities are part of the strengths of $\mathrm{CBE}$ as a whole. The goals of $\mathrm{CBE}$ in supporting faster completion and workforce readiness are paramount to the growth of the field. The above vignettes highlight both mature and emerging programs. There are also institutions who have not yet implemented $\mathrm{CBE}$ and are either in process or disinterested. Many of the reasons cited by this latter group are presented in the next section of this chapter as strengths.

\section{Strengths and Criticisms of Competency-based Education}

Literature on CBE focuses heavily on historical development, advocacy narratives, and opinion-based suggestions for implementation (Daugherty et al., 2015). However, these pieces are still useful in discussing the strengths and criticisms of CBE. Many of the previously discussed facets of CBE focus on its strengths- such as flexible pacing or employment potential. However, there still exists some criticisms or drawbacks to $\mathrm{CBE}$ such as the disaggregation of the faculty role. I provide a brief overview of each in the following section.

Strengths of Competency-based Education in the Literature

Proponents of CBE have identified a number of strengths of this format of education. The American Institute of Research (2019) indicated three key strengths of CBE: (1) enhancing student employability and workforce opportunities, (2) expanding opportunities and credit for non-traditional students, and (3) flexible learning outcomes. I will address each in below. 


\section{Enhancing Employability and Workforce Opportunities}

Literature details the relationship between $\mathrm{CBE}$ and preparing a strong workforce, improving employment opportunities, or retraining the workforce (California Edge Coalition, 2019; Henrich, 2016; Wax \& Klein-Collins, 2015). For instance, the Lumina Foundation suggests that CBE may help reduce inequity within post-secondary education with respect to employment (Krauss, 2017). By enabling more access to higher education, those previously not able to attend, complete, and improve their employment standing now can. CBE programs focused on training the unemployed or underemployed can help students to finish and re-enter or grow within the workforce where not previously possible (Krauss, 2017). Further, literature suggests that students in CBE courses begin to see the learning process as one which connects to their working lives and see the value of degree or credential in the workplace as it helps them remain competitive (Edcor, 2020).

\section{Expanding Opportunities for Nontraditional Students}

Traditional models of higher education were designed for traditional college students; that is students aged 18-22 and students who might work at most part time, if at all. Literature suggests that one of the strengths of $\mathrm{CBE}$ is its ability to expand learning opportunities to nontraditional students (Golod, 2014; Kelchen, 2016; LeBlanc, 2020). As this large population continues to grow, institutions are faced with ways to best serve these students. These students need, among other things, a quicker approach to degree completion (Edcor, 2020), flexible pacing (Baker, 2015), and way to leverage what they already know and/or their prior college credits degree (Krauss, 2017). Research suggests that $\mathrm{CBE}$ is a more appealing choice for these learners than traditional formats of higher 
education (Kelchen, 2016). In Ohio, the location of the present study, policymakers created the TechCred Program to provide all Ohioans a chance at earning a credential while becoming part of a more talented workforce (Ohio TechCred, 2019). The consideration of the non-traditional student can certainly support that aim. Flexible Learning Outcomes

Flexibility in learning outcomes is one last commonly cited strength of CBE (Austin Community College, 2020; Lieberman, 2019). Nontraditional students, many who are working full time, need flexibility. CBE is flexible in terms of where and when learning takes place, includes online and in-person sessions, and understands the unique demands placed on students (Krauss, 2017). The literature suggests that giving students the ability to learn according to their own schedule helps them not fall behind the way they might when forced to adhere to someone else's schedule (Weise, 2014). CBE courses tend to be offered online through a learning management system (LMS) because they can add more flexibility than in-person courses. Bell (2018) argues that, in many ways, $\mathrm{CBE}$ is not necessarily creating something entirely brand-new but rather improving teaching and learning overall. Students have reported that they favor CBE over traditional models because of its flexibility. In one study, Wang (2015) found more than $85 \%$ of students preferred CBE courses due to their flexibility. Such a preference by students indicates a strength of the CBE approach.

\section{Criticisms of Competency-based Education in the Literature}

CBE also has its critics. The traditional model of higher education is centuries old. Many do not see a need to change it. Some of the criticisms of CBE center around: (1) the changing the role of faculty, (2) issues with depth and rigor of learning, (3) 
concerns over economic factors and industry partnerships, (4) institutional resource allocation, and (5) accreditation and policy constraints.

\section{A Disaggregated Faculty Role}

A common criticism of $\mathrm{CBE}$, and one of the motivations to complete this study, is the concerns many faculty have about the disaggregated role of faculty in CBE programs (Neem, 2013; Ohio Department of Higher Education, 2016). Faculty have traditionally served as content experts (Oleson \& Hora, 2013). However, in CBE faculty often take on more of a mentor or guiding role (Burnette, 2016) Literature has shown that faculty often struggle with these changing roles in CBE (Monahan, 2015). Fain (2014b) also noted faculty struggle because they are often overlooked during the institutional efforts to implement $\mathrm{CBE}$ on their campus. This problem is significant because faculty must often participate in competency development (Albanese et al., 2008) and asking for their input after the fact may cause strife between faculty and the institution. Had involvement occurred at the onset, this issue may manifest itself.

A disaggregated role can further confuse faculty because in a CBE program different faculty may hold different roles. For example, one faculty member may be tasked with answering content questions and another serving as assessment evaluator. Lieberman (2019) worries this use of multiple people may lead to faculty not getting to know their students. Additionally, with the individualization of CBE, faculty must be ready to assess student performance in an inconsistent manner since such performance and progress vary by student (Viola, 2016). While assessment of student progress is a common role for faculty, it may be the case in CBE that the faculty becomes more focused on addressing problems than providing their expertise. In fact, Robbins (2017) 
worries that this marginalization of faculty can lead to faculty--despite years of academic training and expertise--being unnecessary. This may lead institutions to question the cost of having full-time faculty teaching CBE courses and lead to job loss or even make working at the institution appear less attractive.

\section{Rigor and Depth of Learning}

Some question the rigor and depth of learning in CBE and its tenets (Dragoo \& Barrows, 2016; Robison, 2012). Ashworth and Saxton (1990) worried almost thirty years ago that assessment of competencies would not adequately measure learning. There are many other causes and impacts on learning, such as student attributes, motivation, and the like. With the emphasis CBE places on completion, many courses that are historically a part of a rounded curriculum are often overlooked. Ward (2016) notes the over-emphasis on bankable skills versus a more liberal arts approach to learning will reduce overall knowledge gains in favor of job training that is rushed to completion. Robbins (2017) echoed this concern that an over-emphasis on vocational training can lead to a view of education as only good enough to suffice in getting a job and not truly the acquisition of academic knowledge. Robbins (2017) also found that the CBE approach fails to consider some of the natural differences and overall abilities each student possesses. Further, if a student simply can 'test out' of a part of a course or program, reinforcement of certain skills or knowledge is easily overlooked.

\section{Economic and Employer Concerns}

There are also economic and employer concerns about CBE. Though CBE often best fits within vocational programs, Franklin and Lytle (2015) surveyed nearly 500 employers about CBE. They found that more than half lacked a basic understanding of 
CBE and how it can benefit an employer. Robbins (2017) and Viola (2016) attribute this lack of understanding to the non-existence of a common definition of CBE. Without a common definition, how $\mathrm{CBE}$ applies and connects from institution to employer may inherently vary from one vocational sector to another. There is no utilitarian nature overall to $\mathrm{CBE}$ in this case.

CBE also purports an emphasis on individual student needs which can have quite a cost effect. The completion of a PLA by the student or the assessment of it by an evaluator has a cost. For example, at the American Public University (APU; 2020), a student must pay $\$ 250$ for an assessor to evaluate their PLA portfolio submission. Even if the cost of the assessment is less than tuition for the course it will replace, failure to pass the assessment and the resulting cost of having to then take the course will lead to a higher overall cost for the learner and no realized savings. Gruppen et al. (2016) found the cost of individualization expensive, and the American Institutes of Research (2019) suggested a 'sticker shock' may result from the upfront cost of implementation.

Conversely, savings from faster completion do not occur organically. Kelchen (2016) and Valenzuela et al. (2016) found student circumstances that drive pace of completion were the biggest factors in whether or not savings actually occurred.

A longer time to completion, despite or due to the flexibility of CBE, may not reduce costs for either the student or institution. For example, in cases of subscription programs, a student can complete as many or as few courses in a specified subscription period as they are able to. If a student is only able to complete one course and another completes six, the former student does not realize the economic savings the latter student does. Additionally, the longer a student takes to complete a CBE program, the more costs 
are accumulated by the institution. The student must still register for courses, benefit from advising or mentoring services, and exist within the technological infrastructure.

\section{Institutional Resource Commitment}

Another critique of $\mathrm{CBE}$ is the institutional resources needed to run programs.

Most institutional departments and systems are not designed to support CBE. For example, data management software, tuition strategy, learning management systems, and the integration of such pieces are often in conflict with the CBE approach (Robbins, 2017; Viola, 2016). One of the biggest issues is that CBE courses often do not fit into the academic terms that scheduling software are designed to support. A second calendar of courses, alternative tuition structure, non-standard academic advising or enrollment hours, or special protocols within a learning management system are necessary to support $\mathrm{CBE}$, and many institutions lack the infrastructure to accomplish this end (Boyer \& Bucklew, 2019; Lieberman, 2019).

\section{Policy and Accreditation Constraints}

A final area of criticism is related to accreditation and policy. Institutions of higher education in the United States are regulated by accrediting bodies. However, each accrediting body approaches CBE a little differently (Eaton, 2016). Valenzuela et al. (2016) conducted a study on both individual state policies and those of the seven major accrediting bodies affiliated with the Council for Higher Education Accreditation. They found that each group took a different approach to regulating CBE and prior learning assessments. With such variability to regulations and accreditation, making comparisons between programs in different states and under the umbrella of accreditors is difficult. 
At the federal level, recent rule-making efforts involving the Department of Education addressed this variability. Proposed rule changes would give institutions more control over CBE as opposed to the accreditors (Krieghbaum \& Fain, 2019). Even though accreditors have varying ways to regulate $\mathrm{CBE}$, there are still only seven major regional accrediting bodies versus thousands of possible institutions. With differences in regulations and scope by institution, it is difficult to compare programs across different contexts; support for CBE could certainly wane if an institution has difficulty applying what another institution has done to its own context. Moreover, though accreditors would have less control, institutions are still bound to federal regulations in ways (e.g., financial aid) that cannot be overlooked.

Lieberman (2019) expresses concern over federal financial aid policies and CBE. The U.S. The Department of Education (2020) requires all distance education programs (which includes $\mathrm{CBE}$ ) receiving federal aid to have regular and substantive interaction. WGU was the first institution to be audited about the level of interaction in their CBE programs. Busta (2019) summarized the 2017 audit of WGU and its findings as they relate to this issue. WGU hosts its CBE program entirely online which falls under the banner of distance education in the federal definition. Despite issues that surround the practice of this type of interaction (see OLC, 2019), the requirement states that interaction between instructor and student is fairly robust -- as opposed to correspondence courses where it is minimal (United States Department of Education, 2020). The audit reported that WGU was operating as a correspondence program versus a distance education program and thus made it ineligible for Title IV funding. However, the Department of Education later abruptly reversed its decision and surmised that WGU 
made an effort toward the required interaction (Busta, 2019). Combined with the 2019 rule-making sessions this decision by the Department of Education still suggests a concern over policy with respect to $\mathrm{CBE}$.

In its 2019 survey of the state of CBE, the American Institutes for Research (AIR) found many of the criticisms presented here - faculty concerns, internal processes and support structures unable to adapt to $\mathrm{CBE}$, and complex federal regulations - were in the top five of barriers identified by institutions overall regardless of level of adoption (AIR, 2019). However, despite these barriers, the CBE movement continues. As of 2019, more than $75 \%$ of institutions predict a growth of CBE programs through 2024 (AIR, 2019). Regardless of the opposing views, there still thus exists an impetus to support those who will teach in this method.

\section{Faculty Development for New Ways of Teaching}

In an overall sense, most faculty begin teaching as content experts with little knowledge on how to teach (Oleson \& Hora, 2013). Institutions must provide mechanisms and programs to train, support, and grow the teaching knowledge of their faculty. Often, these efforts fall under the umbrella of faculty development initiatives. Steinert (2014) defines these practices as pursuits intended to help instructors improve their understanding, abilities, and actions as they relate to teaching in a number of settings. Faculty development practices lie on a continuum (Koellner \& Jacobs, 2015). Such practices often include workshops, courses, mentoring by other faculty, or similar experiences, with many dating back to the 1960s (Levinson-Rose \& Menges, 1981). 


\section{Development for Improvement of Teaching}

Colleges increasingly want to provide opportunities to help faculty become better teachers. Several key themes emerge from the literature on using faculty development to improve teaching. Stes, Min-Leliveld, Gijbels, and Van Petegem (2009) analyzed 36 articles about faculty development. They found that first, most faculty development addressed faculty learning through one or more subdomains such as instructional attitudes, concepts and perceptions of teaching, and skills. Second, faculty development often serves a larger institutional need, especially when such programs communicate policy changes for teaching practices to align with campus-wide initiatives. Third, many efforts aimed to examine the impact of development efforts on students through their perception of teaching quality.

Steinert et al. (2016) also conducted a literature review of 116 studies over a twoyear period. Their review supported Stes et al.'s (2009) results and added two further themes. Most faculty generally had a positive view of faculty development efforts. Further, participants left such efforts with a feeling of increased skills, knowledge, and abilities due to evidence-based learning of accepted approaches to education in a community of practice setting. That is, learning and working with peers and their experiences provided a better long-term outcome.

Finally, more focused themes regarding the creation of development opportunities were found by Matthias (2019) in a literature review focusing on Christian institutions. Three themes must guide the creation of development opportunities. First, planners must view their faculty as individuals whose careers are at many different stages. Second, the immersion of new teaching knowledge must occur in different contexts and situations for 
teaching. Finally, faculty must be encouraged to work together to improve their teaching practice in a united manner.

\section{Faculty Development in the CBE Context}

There is limited research focused on faculty development and competency-based education. In fact, Kelly and Columbus (2016) evaluated 380 studies on faculty development and found scant references connecting training and CBE development. The little literature that does exist tends to focus on the medical field. In one study, Dath and Iobst (2010) evaluated the state of the medical education field in terms of CBE support and training. They found that faculty new to $\mathrm{CBE}$ needed knowledge about $\mathrm{CBE}$ as a whole, learning opportunities for new teaching techniques, and an understanding of how to provide the experiential and specific assessments that are part of CBE. Most importantly, though, Dath and Iobst (2010) concluded in suggesting any faculty support efforts must not exist exclusively at the institutional or individual faculty levels. Rather, a balance must be struck based on the institution's own needs. Their assertion further aids in justifying the present study because findings can impact how institutional mechanisms support CBE programs and faculty.

In another study, McLean, Cilliers, and Van Wyk (2008) analyzed factors influencing faculty development in the medical field and found two interesting parallels to CBE. First, they argued that the efforts toward development in the medical field should include similar facets to a more general view of teaching versus teaching within the field itself. Second, they noted that faculty development outcomes should be task-oriented and encourage peer reflection and experiential learning. Both outcomes are also a key part of CBE courses. The use of a similar mindset in developing and delivering faculty 
development programs can sustain the work of CBE faculty. In the McClean, Cilliers, and Van Wyk (2008) study, the research site provided an experiential learning opportunity for faculty that actually used the CBE approach. In essence, faculty were immersed in the CBE approach as learners thus giving them an opportunity to experience CBE as their students would.

Working in CBE is not simply about teaching. Faculty often may be asked to take an active role in curriculum development for such courses. Echols, Neely, and Dusick (2018) surveyed 70 faculty members tasked with creating a CBE curriculum. Results indicated a significant positive relationship between motivation through supportive means and the level of competence in curriculum planning. Echols et al.'s (2018) recommend that institutions use a direct assessment model, commonly found in CBE programs, when developing faculty development programs. This type of approach involves pre-assessing faculty talents and skill, supporting faculty in developing CBE curriculum, and then using a post-assessment to inform future support opportunities. Like McClean et al.'s (2008) suggestion, the approach of using a CBE-type situation (i.e. exposing them to $\mathrm{CBE}$ ) may enhance confidence and performance.

New approaches to teaching and learning require faculty training and support opportunities. While newer, more diverse roles arguably exist for any faculty member in higher education (Austin \& Sorcinelli, 2013), the shifts of the faculty role promoted by CBE require support mechanisms to exist for those teaching in the field. Such an effort will in-part affect the confidence of those teaching in CBE. In order to remain a strong faculty member, institutions must also consider this confidence when asking faculty to teach CBE courses. 


\section{Self-efficacy and Teaching}

The extent of one's confidence with respect to a particular need or task is a powerful construct. With the recency and against-the-grain nature of $\mathrm{CBE}$, the confidence of those involved is of utmost importance. Alfred Bandura (1986) labeled this confidence as self-efficacy since then, research has shown how self-efficacy and teaching are related. Figure 2.1 displays visually his Self-efficacy Theory which served as the theoretical framework for this study (see chapter one).

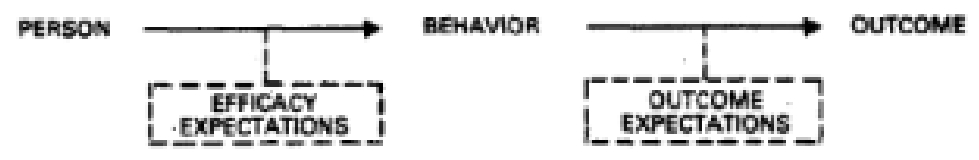

Figure 2.1. Construct of Self-efficacy Theory From Bandura, A., (1977). Selfefficacy: Toward a unifying theory of behavioral change. Psychological Review, 84, 191-215.

Bandura (1977) argued that self-efficacy is the driving force behind one's success. He believed (1986) those with high self-efficacy were internally motivated, interested, and embraced challenges as opposed to those with lower self-efficacy who were more likely to give up. Efficacy related to teaching is teacher efficacy and questions remain on how it is developed. Faculty self-efficacy is a teacher's personal views of their ability to oversee the learning process for students and to keep them engaged (Guskey \& Passaro, 1994).

\section{Sources of Self-efficacy}

Faculty self-efficacy can affect one's capability to influence the learning process (Ross, 1994; Tschannen-Moran \& Woolfolk Hoy, 2001; Wertheim \& Leyser, 2002; Woolfolk Hoy, 2004). Thus, increasing the self-efficacy of faculty should help them 
improve their ability to teach $\mathrm{CBE}$ courses. $\mathrm{CBE}$ as a challenging approach to teaching may elicit all four sources of self-efficacy theory. These include mastery experiences, vicarious experiences, verbal persuasion, and emotional or physiological states (Bandura, 1977; Muretta, 2004). First, mastery experiences are those an individual acquires when they encounter and engage with a challenge over and over. Repeated experiences lead to proficiency while failures lead to a reduced likelihood of revisiting a challenge. Lopez and Lent (1992) determined that such experiences were the most influential predictor of strong self-efficacy for specific contexts of learning. Tschannen-Moran and Woolfolk Hoy (2007) noted mastery experiences remained influential on self-efficacy throughout the entire career of an educator from novice years to veteran standing. Though CBE is somewhat new, this finding suggests that long-term teaching of CBE courses will be prudent for the overall confidence of faculty who teach them.

As the second source, vicarious experiences address the ability for a peer or another party to mentor an individual as they engage a challenge (Bandura, 1977). Ideally the mentor would have already mastered the experience. Thus, emulation of the peer can lead to an increase in self-efficacy since the individual sees that success is possible. Wang, Ertmer, and Newby (2004) found vicarious experiences influential on self-efficacy with respect to technology integration in the classroom. Their study of teachers $(\mathrm{N}=280)$ found an experienced mentor who helps set goals for mastering technology integration led to higher levels of self-efficacy as reported by the novice teacher. Since CBE courses are commonly online, this finding is important with respect to the use of technology to deliver instruction. 
The third source of self-efficacy is verbal persuasion. While this source relates to experiences via communication, persuasion is when a person is simply told a task is possible (Bandura, 1977). If an individual hears they can succeed, they will likely put forth the effort to do so; likewise, failing to hear this may lead to avoidance. Morris and Usher (2011) studied higher education faculty and found that verbal persuasion in many forms - such as praise from students and award recognition - most positively affected self-efficacy.

Finally, physiological states tie into emotional ends of a task. Assuming a person already attempted a challenge, a positive experience would lead to positive emotions (with the opposite also true). Higher emotional response leads to higher likelihood of more effort. This stance is notable given the results of Cansiz and Cansiz's (2019) study of pre-service teachers and their beliefs of education as either traditional or constructivist. Though the present study did not attempt to define CBE as a constructivist concept, it is certainly non-traditional. Cansiz and Cansiz found that pre-service teachers with elevated levels of anxiety, fear, or stress often reverted to a more traditional view of education. As such, a CBE faculty, especially a pre-service one (defined as not having previously taught $\mathrm{CBE}$ ) with high fear and anxiety may resist learning how to successfully teach CBE and revert to preferring traditional forms of education. Overcoming this fear through support and thus stronger emotions will posit stronger levels of self-efficacy.

Questions remain on the best ways to increase CBE faculty self-efficacy as there is limited research connecting the two. Repeated teaching of CBE courses may posit more success each time a course is taught. The knowledge that peer faculty are also new to teaching $\mathrm{CBE}$, and their potential use as resources or mentors (especially for brand 
new or adjunct faculty) could provide for emulation of success. This would be potentially truer with the art of conversation, supportive communication, or an institutional message supporting faculty success in teaching CBE. Finally, connecting the proposed study's findings to an emotional domain or physiological response situation may better help the applicability of findings.

\section{Chapter Summary}

Competency-based education uses robust competencies to plan instruction, offers flexibility in delivery and course completion, and uses a prescribed approach to assessment all designed to support all students, but especially non-traditional students. However, despite these benefits, there are detractors of CBE as well, and their arguments certainly have merit as legitimate concerns often echoed even by those already using CBE.

Regardless of views, CBE is a new way of teaching. As such, institutions must empower CBE faculty through development and support initiatives. This support can have an effect on the self-efficacy of CBE faculty as the connection between self-efficacy and teaching is readily apparent. However, the lack of literature on the role of selfefficacy with $\mathrm{CBE}$ faculty, along with views of $\mathrm{CBE}$ and views of faculty support, is clear and thus, more research is needed to explore these connections. The present research attempted to address the gap in literature so that institutions can better plan, implement, and provide support for CBE faculty by understanding the role self-efficacy and views play with respect to $\mathrm{CBE}$. In the next chapter, I will discuss further in detail the methodology of the study. 


\section{CHAPTER THREE: METHOD}

Competency-based education (CBE) is growing at colleges and universities. As CBE grows, more faculty will be needed to run and teach in these programs. Most faculty though have little experience with $\mathrm{CBE}$. Institutions that hope to create or further grow CBE programs must find ways to help support and develop faculty to teach and run these programs. One way to learn how to do this is to ask faculty who are currently involved with CBE what they think. The present mixed methods study attempted to address this need and gap in the literature.

\section{Research Questions}

The goal of this study was to explore what CBE faculty think of CBE in hopes of finding ways that institutions can better support CBE faculty. More specifically, I investigated the following research questions:

1. What are competency-based education faculty's views of CBE?

2. How do faculty involved with CBE rate their own self-efficacy?

3. How can institutions better support faculty to teach CBE courses?

\section{Research Design}

A mixed method research design was used for this study. Mixed methods are recommended in cases where neither quantitative nor qualitative inquiry are individually enough to answer the research questions (Scoles, McArthur, \& Huxham, 2014). Creswell (2015) justifies mixed methods as a suitable model for research where the inquiry gathers data in both closed-ended and open-ended approaches (i.e. quantitative and qualitative) to 
better understand and solve a research problem. Further, mixed methods are not solely independent processes of a study, but rather almost complementary processes that combine different sources of data to clearly analyze the context of a problem (Creswell, 2014, 2015).

More specifically, in this study I used a mixed methods exploratory sequential design (Creswell, 2015), which is illustrated in Figure 3.1. This approach is particularly useful in cases where little is known about the context of the research questions or the research population is neither studied deeply nor substantially understood. Both factors in part support its use in the study. There are five key steps, according to Creswell (2015), in an exploratory sequential design: (1) Obtain and analyze qualitative data; (2) Use qualitative results to create a quantitative instrument or design an intervention for the sample, often using an existing instrument already tested with participants; (3) Assess the quantitative instrument and examine its validity and reliability, or conduct an experimental trial; (4) Administer the quantitative instrument or intervention to a larger sample; and (5) Report on the quantitative results as to how they inform answers to the research questions, improve an intervention, or make a generalization about the initial results from the qualitative phase.

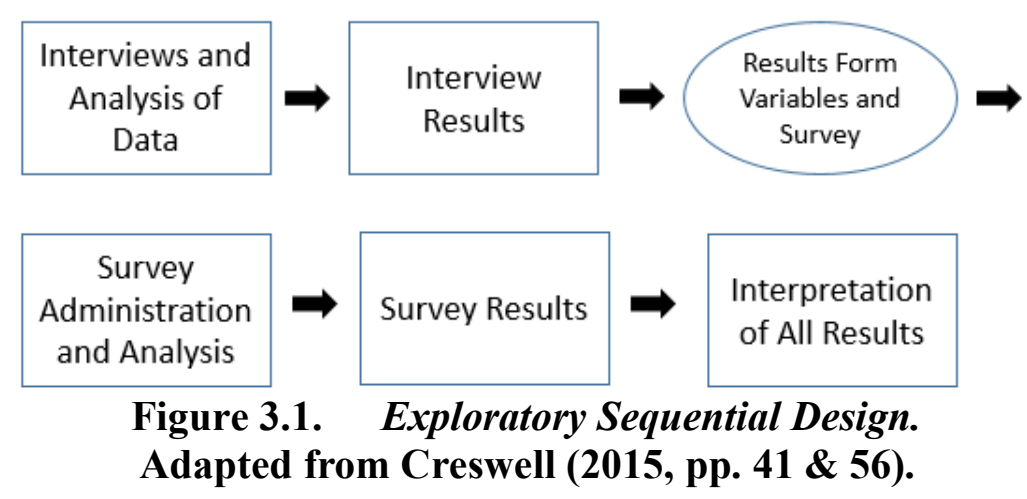




\section{Sample and Context of the Study}

The present study took place at Five Rivers Community College (FRCC). FRCC was purposefully selected because it is one of Ohio's leading institutions in terms of CBE programs (Bell, 2018; Ohio Department of Higher Education, 2018). They began their CBE programs more than ten years ago; they offer eleven CBE programs in a diverse set of areas, including retail management, unmanned aerial systems, and information technology and computer science. Students can earn academic certificates (such as industry credentials in information technology), associate of arts, and associate of science degrees (Five Rivers Community College, 2020).

At Five Rivers, CBE courses are delivered primarily online with occasional inperson requirements depending on the program and possible hands-on components (e.g., in unmanned aerial systems and advanced manufacturing). Hands-on learning may also occur experientially. For example, a student in retail management may need to complete certain tasks while working in a retail setting and then use such an experience for a course assignment.

Table 3.1 provides a recent snapshot of CBE data at Five Rivers over two recent academic terms. Over the nine academic terms covered in the table, an average of 512 students took a CBE course, representing approximately $2.8 \%$ of the total student population. It is important to note that enrollment at Five Rivers is highly variable per term as is common in community colleges. The success rate for CBE students (measured as completing all course requirements at an $80 \%$ or higher) is $76 \%$. Completion time for CBE students on average was between 60 and 80 calendar days, compared to 112 days for full-term non-CBE students. 
At Five Rivers, CBE courses are offered within a traditional academic term (16 weeks in fall and spring, 12 weeks in summer). A student may enroll in a CBE course (or multiple courses) through week 6 of the spring and fall terms and week 4 of the summer. Table 3.1 Five Rivers Community College CBE Data, 2018-2020

\begin{tabular}{lcccc}
\hline Term & 2018 & 2019 & 2020 & Totals \\
\hline Students & 1464 & 1379 & 1769 & 4612 \\
Faculty (duplicated)* & 86 & 93 & 100 & 279 \\
Course Sections & 612 & 624 & 485 & 1721 \\
\hline
\end{tabular}

*indicates that a faculty may have taught more than one term during the calendar year (i.e. both during spring and fall terms)

Regardless of the date of enrollment, all course materials must be complete and submitted by the end of the term in which they take a course (i.e., the beginning of May for the spring semester, August for the summer semester, or December for the fall semester). CBE students must take courses required for their program in the CBE format but may also take other courses (i.e. general education requirements) in other modalities such as face-to-face, blended, or online. At FRCC, a student may complete a CBE course before the end of the term, but they may not start another CBE course or courses until the start of the next term (unlike the subscription models presented in chapter 2). CBE students have a $70 \%$ retention rate from year-to-year and complete industry credentials at a rate three times their non-CBE peers (Thiebault \& Amato, 2016). The retention rate for non-CBE students is $56 \%$ (NCES, 2020a). 
While I work at FRCC and have been involved with $\mathrm{CBE}$ at FRCC in the past, I purposefully selected this sample because of its robust CBE programs. Creswell and Plano-Clark (2011) and Onwuegbuzie and Collins (2007) define purposeful sampling as a key aspect to qualitative research. Participants are selected through an intentional process because they have specific experience with the issue under study. In this study, faculty were intentionally chosen due to their familiarity and teaching experience with CBE.

On average, there are 31 out of $65 \mathrm{CBE}$ faculty at $\mathrm{FRCC}$ who teach $\mathrm{CBE}$ courses each term (A. Williams, personal communication, March 23, 2020 and October 7, 2020). This number includes new faculty hired during the three year scope of the data presented in Table 3.1. Overall, there are 1,050 faculty at Five Rivers with a 1:3 ratio of full-time to part-time/adjunct (NCES, 2020a). In order to teach CBE courses, faculty must complete two required and one optional training courses (see Table 3.2).

The first training is a facilitated (group-paced) three week online course covering the fundamentals of teaching online; CBE faculty have to complete this course because FRCC's CBE courses are administered online using the LMS. The second training faculty complete is a set of individual tutorials within the LMS that cover the technical aspects of its use such as communication tools, grading interfaces and rubrics, and basic content development. The tutorials are available for use at any time and take a few minutes to complete. These first two items are required for any faculty who teaches online, blended, or CBE courses at Five Rivers. The tutorials are available for any faculty member. The third training is an optional, though highly encouraged, training course on CBE teaching. The institution's LMS houses the training and takes approximately four 
hours to complete. The training course on CBE uses the CBE approach, including preand post- 
Table 3.2 Matrix of key features of Five Rivers' Training Pieces

\begin{tabular}{|c|c|c|c|}
\hline \multicolumn{4}{|c|}{ Training Examples } \\
\hline Aspect & Teaching Online & LMS Tutorials & $\begin{array}{l}\text { CBE Training/ } \\
\text { Community }\end{array}$ \\
\hline Required & Yes & Yes, in certain cases & $\begin{array}{l}\text { No though } \\
\text { encouraged in both } \\
\text { cases }\end{array}$ \\
\hline $\begin{array}{l}\text { Moderated or } \\
\text { Self-Paced }\end{array}$ & $\begin{array}{l}\text { Moderated by a faculty } \\
\text { member }\end{array}$ & $\begin{array}{l}\text { Not moderated } \\
\text { Maintained by college's } \\
\text { eLearning Division }\end{array}$ & $\begin{array}{l}\text { Moderated by a } \\
\text { faculty member }\end{array}$ \\
\hline Availability & $\begin{array}{l}\text { As assigned by college } \\
\text { and only in term } \\
\text { completed. }\end{array}$ & Unlimited availability & $\begin{array}{l}\text { Must be enrolled into } \\
\text { training; community } \\
\text { has unlimited } \\
\text { availability }\end{array}$ \\
\hline Audience & $\begin{array}{l}\text { Any faculty teaching in } \\
\text { online, } \mathrm{CBE} \text {, and blended } \\
\text { methods. }\end{array}$ & $\begin{array}{l}\text { All faculty using LMS } \\
\text { (modality agnostic) }\end{array}$ & $\begin{array}{l}\text { CBE faculty, coaches, } \\
\text { and other personnel. }\end{array}$ \\
\hline $\begin{array}{l}\text { Time to } \\
\text { Complete }\end{array}$ & $\begin{array}{l}\text { Three weeks, } \\
\text { approximately } 8-10 \text { hours } \\
\text { per week. }\end{array}$ & Minutes per tutorial & $\begin{array}{l}\text { Four Hours, } \\
\text { depending on } \\
\text { performance. }\end{array}$ \\
\hline Content & TOPICS: & TOPICS: & TOPICS: \\
\hline Summary & $\begin{array}{l}\text {-Views of online learning } \\
\text {-Starting out teaching } \\
\text { online } \\
\text {-Engaging online } \\
\text { students } \\
\text {-Creating an online } \\
\text { community of learners } \\
\text {-Netiquette } \\
\text {-Grading philosophies } \\
\text { online learning in the } \\
\text { LMS } \\
\text {-Providing meaningful } \\
\text { feedback and evaluation } \\
\text { of work }\end{array}$ & $\begin{array}{l}\text {-All LMS tools (basic, } \\
\text { intermediate, advanced } \\
\text { functionality) } \\
\text {-Navigating the LMS } \\
\text {-Preparing to teach in the } \\
\text { LMS } \\
\text {-Assessment tools and } \\
\text { technical grading } \\
\text { information } \\
\text {-Communication in LMS } \\
\text {-Accessibility of LMS use } \\
\text {-Third party integrations } \\
\text { into the LMS }\end{array}$ & $\begin{array}{l}\text {-The who, what, why, } \\
\text { and how of CBE } \\
\text {-CBE course design at } \\
\text { the institution } \\
\text {-Interaction and } \\
\text { student success in } \\
\text { CBE courses } \\
\text {-Grading philosophies } \\
\text { of CBE programs } \\
\text {-Conclusion and } \\
\text { reflection }\end{array}$ \\
\hline
\end{tabular}


assessments with supporting learning material for each module, to mirror the CBE experience of a student. Like a CBE course, it is also facilitated by a faculty member. This enables the faculty to understand a bit more how the student engages with a CBE course. The shell also contains numerous CBE-related items, a community discussion, and is used as a vehicle for updates to the institution's CBE programs.

\section{Data Collection}

As a mixed methods exploratory sequential design, data collection followed a specific process of qualitative and then quantitative procedures (Creswell, 2015). In this study, data were conducted in two phases. I will explain each phase below including steps I took and how I engaged with potential participants and then actual research subjects.

\section{Phase 1: Qualitative Interview Collection Protocol}

In the first phase of the study, I interviewed ten faculty teaching CBE courses at Five Rivers. To recruit participants (faculty) I used a convenience sample and sent a solicitation email to all 65 faculty teaching $\mathrm{CBE}$, and scheduled interviews once the ten faculty were recruited. To select the interview participants, I assigned each faculty who said they would participate an identification number. I then used a random number generator and chose the first ten identification numbers for interviews. In the scheduling process, I provided informed consent to interview subjects. The interviews took place over Zoom, a synchronous communication software. The interviews were recorded and notes were taken during the interview. Once complete, the recordings were transcribed and all materials were uploaded to a secure Google Drive folder to protect the integrity of the data and provide security. 
The questions for the interviews were developed to align to the research questions

of the study. Table 3.3 lists the interview questions used and how they align to the research questions.

\section{Table 3.3 Research Question and Interview Question Alignment}

Interview Question

1. How long have you been teaching CBE?

2. Why did you begin teaching CBE courses?
Research Question

Demographics

RQ1 What are

CBE faculty's

views of CBE?

4. What do you like or dislike about CBE?

5. Do you think it is a good way for students to learn? Can you explain why or why not?

6. Can you describe what you like or don't like about teaching CBE courses?

Self-efficacy is defined as the way one believes in their internal ability to take on a challenge, stay with it, and ultimately persevere.

7. How satisfied are you with your interactions with students in CBE courses?

8. How confident are you in your ability to teach a CBE course?

9. How confident are you with providing content instruction?

10. How confident are you with specifically providing support or intervention?

11. What has shaped or influenced your confidence to teach CBE?
RQ2 How do faculty involved with CBE rate their own selfefficacy?
12. How did you learn to teach a CBE course?

13. How prepared were you when you first began teaching CBE courses?

14. What kinds of support do you think faculty new to CBE need to be successful and confident?
RQ3. How can institutions better support faculty to teach CBE courses?

15. How can the institutions improve faculty views of $\mathrm{CBE}$ ? 
The interviews essentially consisted of four parts. In part one, there were two questions focused on demographics to understand participant's context with respect to CBE. Part two consisted of five questions focused on faculty's views of CBE. Part three consisted of four questions focused on self-efficacy and were based on Bandura's (2006) Guide for Constructing Self-efficacy Scales. This source contains suggestions for basing the interview questions in related self-efficacy concepts including instruction, communication, support and intervention, interaction, and decision-making and is important because there is not one all-encompassing instrument to measure self-efficacy. Bandura (2006) suggests using scales based off the Guide because scales to measure selfefficacy must be customized for the context in which they are to be used and have items that specifically consider the construct under study. The suggestions in the Guide have been used in a number of different contexts to create self-efficacy scales (e.g. Axboe, Christense, Kofed, \& Ammentorp, 2016; Everett, Salamonson, \& Davidson, 2009; Kitching, Cassidy, Eachus, \& Hogg, 2011). Finally, part four consisted of four questions focused on faculty preparedness to teach CBE as well as their views on support for such faculty.

Once all interviews were complete and transcribed, I uploaded all related files to NVivo, a qualitative analysis software. This process is further discussed in the Data Analysis section later in this chapter.

\section{Phase 2: Creation of the Quantitative Instrument and Protocol}

The second part of an exploratory sequential mixed methods study involves taking the results of qualitative methods - in this case interviews - and then creating a second, quantitative instrument (Creswell, 2015). Upon completion of interview data 
analysis, I used that information to create a 46 Likert item survey with four sections; the first section asked for demographic information, and the remaining three sections aligned to the three research questions of the study. Table 3.4 contains the survey items reflecting this alignment with further organization by construct. These constructs were sub-themes of coded responses in phase one.

To construct items, Bandura's (2006) Guide for Constructing Self-efficacy Scales was used again though the majority of items were developed largely from the statements of faculty who participated in interviews during phase one. By using or translating faculty statements directly into items on the survey, a clear connection from phase one to phase two existed thus supporting reliability and validity of the instrument. For example, item two under research question 1, "CBE is a niche for a select group of students" came from responses of three faculty interview participants. Both reliability and validity were important to consider as this instrument was not previous field tested, though it did return a high Cronbach's alpha reliability measure (42 items, $a=.86)$. 


\section{Table 3.4 Phase Two Survey Questions and Alignment}

\begin{tabular}{l} 
Question \\
\hline 1. Approximately how many years have you been involved with CBE? \\
(options from less than one to ten) \\
2. How long have you been in higher education? (options from less than one \\
to more than twenty) \\
3. Do you have industry experience outside of the academic setting? (option \\
of yes or no) \\
4. What is your gender? (option of male, female, gender fluid or nonbinary, \\
prefer not to answer)
\end{tabular}

1. The premise of $\mathrm{CBE}$ is appropriate for certain vocational fields.

2. $\mathrm{CBE}$ is a niche for a select group of students.

RQ Construct

3. My involvement with $\mathrm{CBE}$ began through my own curiosity or interest.

4. I began working with CBE because it was a logical 'next step' for my career.

N/A Demographics

5. CBE's flexible pacing supports the personal situations of students.

6. The ability for students to apply prior knowledge or experience means they can earn credentials faster than their peers.

7. The instructor is more of a guide or mentor in CBE courses than anything else.

General Tenets

8. I am satisfied with the way our institution uses CBE.

9. I like teaching CBE courses.

Teaching/

10. I view the $\mathrm{CBE}$ workload is unmanageable compared to other course

Delivery of delivery formats.

CBE

1. I am confident in my ability to interact with CBE students in general.

2. I struggle to provide meaningful interaction with students since CBE students don't require much interaction.

Student Focus

Origins of

Teaching CBE

3. I reflect on my confidence in terms of interacting with $\mathrm{CBE}$ students each time I teach a CBE course.

4. I am confident in teaching CBE courses.

5. My experience in industry leads to a higher confidence teaching CBE.

6. Experience teaching in other modalities translated into confidence to teach CBE.

Interaction

Background 
9. I feel as confident in the content of CBE courses as I do in other modalities.

10. I am confident in providing support or intervention for CBE students.

11. I am confident pointing CBE students to the resources available to support them if I am unable to.

12. Handling CBE student issues is easier than handing student issues in more traditional course settings.

13. Knowing there is institutional support for CBE faculty makes me feel confident to teach CBE.

14. Faculty training or development focused on $\mathrm{CBE}$ helped me become confident.

15. My confidence level with respect to $\mathrm{CBE}$ is often driven by student performance in courses or their feedback.

1. I learned to teach $\mathrm{CBE}$ through a specific training program, such as a course, workshop, or seminar.

2. Most of my knowledge as to teaching CBE came from self-exploration or being "thrown into the deep end."

3. Trial and error or student performance is the most effective way to learn the specifics of CBE.

4. Faculty new to CBE must have a mentor or co-teacher the first time they teach CBE.

5. Faculty should take a CBE course before teaching one.

6. Creating mentorship programs or cohorts to share resources, experiences, and concerns would lead to a feeling of support.

7. To support faculty teaching CBE, they should have ongoing access to an instructional designer even if the course is already designed.

8. Supporting faculty means letting them see a CBE course from a previous term to learn from.

9. The support of faculty in other modalities can be easily applied to supporting CBE faculty.

10. To get faculty buy-in to CBE requires a grassroots approach versus one that is top down.

11. Faculty would view CBE more positively if there was a logical-emotional appeal.

Relationships

or Roles

Existing

Resources

12. The institution needs to clarify expectations for delivery of CBE to improve perceptions.

13. To impact or affect faculty's interest in CBE requires evaluating the infrastructure, compensation, and workload of CBE faculty.

Perceptions Communicate and Promote

Perceptions Expectations

14. Clarifying student benefits would help improve perceptions of CBE. 
15. Showcasing student or faculty success stories would improve how faculty view $\mathrm{CBE}$.

16. Realignment with industry partners and leading CBE institutions would improve its views on campus.

17. I think faculty would like to create $\mathrm{CBE}$ versions of courses they currently teach based on what they may learn about CBE.

Perceptions Actionable Research

In crafting survey items, though based on interview responses, I followed recommendations provided in the literature for survey construction for Likert items and actual statements. For example, I employed a Likert scale with five options in a unipolar format. That is, the scale only measured one construct (Chiang, Jhangiani, \& Price, 2015; Harrison, 2007). Further, the options were clearly labeled as opposed to only labeling the extremes, and options were spaced evenly (Artino, LaRochelle, Dezee, \& Gehlbach, 2014; Dillman, Smyth, \& Christian, 2009). Use of even spacing and omitting only extreme options, for example, prevented a potential for the respondent's eyes to naturally draw towards one extreme or the other.

Statements for participants to rate also followed best practices. Peterson (2000) suggests using the acronym BRUSO as a framework to reduce unintended effects on context and push reliability and validity of responses from participants (Fowler \& Cosenza, 2008). BRUSO stands for brief, relevant, unambiguous, specific, and objective. Statements that practice brevity are short and get to the point of the item quickly without excess additional language. Relevancy promotes connection back to the research question. The statements used on the survey instrument were directly crafted from responses of interview participants. This was done to ensure alignment between both phases of the study, and to connect survey statements to the three research questions guiding the study. 
An unambiguous statement is one generally interpreted by the participant in one way. For example, asking about more general statements like 'good instruction' may lend to a vast array of interpretations and should be more specific. Consequently, specificity, the fourth part of BRUSO, suggests a clear notion of what the response is about to the researcher while clear to the respondent. While similar to brevity, specific statements tend to be more to the point. Finally, objective statements contain language that does not indicate anything related to the researcher's opinions or push the participants to answer items in any specific way. BRUSO implies a strongly worded statement or item that measures its purposeful concept while not measuring other, extraneous areas. It also ensures that all respondents will interpret the statement in a similar manner (Harrison, 2007). Using appropriate means to design the survey will ensure a high degree of validity and reliability in results.

Once the survey was ready, data indicated the potential pool of CBE faculty increased for the fall 2020 academic term. As such, the survey was then sent via email to 65 faculty who currently or previously taught CBE. At the welcome screen of the survey, delivered using Google Forms, faculty were greeted with informed consent, risk, benefits, and the like. The link to the survey remained open for one month to allow ample time for completion. Reminder emails went out every ten days until the window closed (an example email is provided in Appendix A). Analysis then took place using SPSS statistical analysis software. A further discussion of this process occurs in the data analysis section of this chapter.

The data collection section of this chapter provided an overview of the general process that guided the proposed study. This process included the creation of a survey 
from the data provided by interview responses and their analysis. The use of a quantitative instrument after a qualitative process is a hallmark of the exploratory sequential design (Creswell, 2015).

\section{Data Analysis}

The study included two main phases of both data collection and thus data analysis: qualitative and quantitative (see Table 3.5).

Phase 1: Qualitative Data Analysis of Interview Data

Interview notes and audio files were stored on a secure Google Drive as discussed above. Once interviews concluded, I uploaded the relevant files into NVivo, a qualitative 
Table 3.5 Alignment of Research Questions to Data Analysis

\begin{tabular}{|c|c|c|}
\hline Research Questions & Data & Data Analysis \\
\hline \multirow[t]{2}{*}{ Demographic items } & Interviews & $\begin{array}{l}\text { Description of } \\
\text { results }\end{array}$ \\
\hline & Survey & $\begin{array}{l}\text { Descriptive } \\
\text { Statistics }\end{array}$ \\
\hline \multirow[t]{2}{*}{ 1. What are CBE faculty's views of CBE? } & Interviews & $\begin{array}{l}\text { Coding of } \\
\text { Responses }\end{array}$ \\
\hline & Survey & $\begin{array}{l}\text { Descriptive } \\
\text { Statistics }\end{array}$ \\
\hline \multirow[t]{2}{*}{$\begin{array}{l}\text { 2. How do faculty involved with CBE rate their own } \\
\text { self-efficacy? }\end{array}$} & Interviews & $\begin{array}{l}\text { Coding of } \\
\text { Responses }\end{array}$ \\
\hline & Survey & $\begin{array}{l}\text { Descriptive } \\
\text { Statistics }\end{array}$ \\
\hline \multirow[t]{2}{*}{$\begin{array}{l}\text { 3. How can institutions better support faculty to } \\
\text { teach CBE courses? }\end{array}$} & Interviews & $\begin{array}{l}\text { Coding of } \\
\text { Responses }\end{array}$ \\
\hline & Survey & $\begin{array}{l}\text { Descriptive } \\
\text { Statistics }\end{array}$ \\
\hline
\end{tabular}

data analysis (QDA) software. NVivo enabled coding (in multiple cycles) of the data to discover themes. Such themes framed the overall reporting of results for the qualitative phase of the study.

Coding took place over a number of steps. In the first step known as first cycle coding, I used an in vivo approach. In vivo is appropriate when the researcher is new to the process but also because it seeks to respect the notions of the participant (Miles et al., 
2014). In vivo coding involves the researcher using short words or phrases as labels in order to analyze spoken words of participants (Manning, 2017). This method is a sort of first impression of reading through interviews to identify meaning in the data. For example, under views of CBE, the phrases 'student-centered,' 'had to get involved,' 'great for vocationally displaced workers,' and 'not enough pay for large classes' were short sets of words and patterns used in analyzing faculty responses.

Next, I used second cycle coding through the pattern code approach. This process takes the first cycle results further through nodes that take larger chunks or blocks of data and put them into more manageable pieces. In the areas covering perceptions of CBE and ideas for institutional support, I used my own labeling approach based on these themes to help explain results and later connections back to the research. For example, in first cycle coding, the phrases identified above translated into patterns such as 'ideally centered for students,' strong vocational connections,' and 'concerns over infrastructure that need fixed.'

Conversely, in self-efficacy items, I coded responses under the key tenets of selfefficacy theory (i.e., the four sources of self-efficacy: vicarious experiences, mastery experiences, physiological states, and verbal persuasion.) This a priori framework served analysis well because the questions in this section, as developed, were directly influenced by this theory. It became further apparent in second cycle coding that the short phrases and statements identified in first cycle coding aligned to the four factors affecting selfefficacy in the self-efficacy part of this study.

Second cycle coding can also include early attempts at analysis such as a mindmap of emergent themes. It can also provide a general direction for later steps in the 
research project (Miles et al., 2014). Since the results of the qualitative part of the proposed study influenced the quantitative piece, it was important to begin analysis earlier rather than later. Further, pattern coding (Onwuegbuzie, Frels, \& Hwang, 2016) enables the creation of logical relationships or sub-codes back to the larger patterns and themes found in the first cycle.

I used memos and notes to assist with the qualitative analysis process as well. This was especially useful as I largely used an in vivo approach where I in part determined codes and themes as opposed to an a priori framework. Fram (2013) suggests that the use of these strategies as a check and balance system supports the progression of the project. Further, they can help begin the organization of findings as an opportunity to visualize, critically assess, and describe the data (Miles et al., 2014). Once full data analysis occurred, findings in terms of themes informed the further phase of quantitative methods.

Phase 2: Quantitative Data Analysis of Survey Data

The second half of the study involved a quantitative instrument derived from the results of surveys in the first half. Items on the survey came directly from the responses of faculty who participated in phase one and were inspired again by Bandura's (2006) Guide for Constructing Self-efficacy Scales. Moreover, items were the result of the connection between first cycle in vivo coding and second cycle pattern coding. For example, survey item 1 under the views of $\mathrm{CBE}$ section, "The premise of $\mathrm{CBE}$ is appropriate for certain vocational fields" and item 10, "I view the CBE workload as unmanageable compared to other course delivery formats" emerged from the first cycle codes 'great for vocationally displaced workers' and 'not enough pay for large classes' 
respectively, and the second cycle code 'concerns over infrastructure that need fixed.' This connection also shows the alignment between faculty interview responses and survey item language.

The survey was administered via Google Forms. Results from the survey were stored in a Google Sheet. Both the survey and response file were also stored on a secure Google Drive owned by the researcher. Later, I stored output files from analysis on this drive.

Responses were analyzed using the Statistical Package for Social Science, or SPSS. It is important to mention that results from Likert items were assigned a number for analysis purposes (i.e. strongly disagree as a 1 to strongly agree as a 5). Once complete, I entered data into SPSS for analysis.

For analysis, descriptive statistics (both of central tendency and frequency) provided a summary of responses and included mean and standard deviation. Such statistics were of each item on the Likert scale on the survey instrument and any other pertinent items incumbent on the design of the instrument. Descriptive statistics help to summarize, describe, and potentially pattern data (Laerd, 2020). While they do not permit conclusions to be made about the research aims, they can certainly assist in a basic level of interpretation. The results are presented in chapter four by overall section score (i.e. by research question), construct (i.e. groups of questions as shown in Table 3.4), and by demographic breakdown as determined by results of the initial demographic questions. $\underline{\text { Reliability }}$

The issue of reliability in statistics is effectively the degree to which scores could be replicated in a consistent manner. In other words, it measures the extent to which a test 
measures what it is intended to measure (Bandura, 2006). For the quantitative survey, I used Cronbach's alpha (a) to measure the internal consistency of the scale. The results of this test are included in chapter four. The alpha is a number between 0 and 1 with higher scores indicating better reliability (Hatcher, 2013; Tavakol \& Dennick, 2011).

The use of reliability measures is common in the use of surveys, especially those measuring self-efficacy. For example, McAuley and Gill (1983) found a Cronbach's alpha of .76 on a scale of physical self-efficacy for gymnasts indicating strong reliability. In a more related sense to the proposed study, Dougherty, Johnson, and Thompson (2007) found the General Self-Efficacy Scale (GSES) developed by Sherer et al. (1982) and based on Bandura's Social Cognitive Theory - discussed in chapter 2 - had a Cronbach's alpha of .84. Also related to the present study, Schwarzer, Schmitz, and Daytner (1999) administered a self-efficacy scale to teachers and found a Cronbach's alpha between .76 and .82 . Given the use of this statistic to gauge reliability in previous studies, the present research also successfully used the statistic. I elaborate on this statistic in chapter four.

\section{Validity / Trustworthiness}

All research projects must demonstrate validity and espouse trustworthiness. I used Lincoln and Guba's (1985) call for trustworthiness in terms, especially in the qualitative aspect of the study. I did this in an attempt to convince readers of the weight and value of the project and any anticipated findings. Their (1985) push for trustworthiness in research via truth-value, consistency, and applicability of findings largely exists through credibility. I employed several approaches to do so. First, I used triangulation using multiple interviews of faculty to support credibility as opposed to a limited number such as in a case study. Next, I used referential adequacy through 
comparing statements identified as significant in my analysis of interviews and components of meaning of those statements to the actual recordings and my notes from interviews. This permitted a cross-reference of sorts to ensure that I interpreted what I heard and wrote adequately in the context of later reporting my findings. I also used a more focused member reflection strategy (Tracy, 2010) where I attempted to include participants in the evaluation of data and overall reporting of results. Gathering their input on the flow of the process as a sort of collaborator or partner helped ensure rigorous validity of results.

The Role of the Researcher

A further area of concern related to validity is that of researcher as practitioner. This study occurred at my host institution. During the study, I was working primarily on the instructional design of eLearning courses, of which approximately ten percent were competency-based. Previously, my course design projects included more than ten percent of my workload as competency-based, but at no time was it more than twenty-five percent. After IRB approval occurred, I switched roles away from course development to more of a strategic focus, and lost the more intimate relationships with Five Rivers' faculty in the course design realm. Accordingly, for the remainder of the study, my nonentrenchment in design (and teaching) of CBE courses permitted me to bracket my own views and experiences out of the results and findings of the present study.

Issues of bias could rear in reporting of results or the discussion of the study. Dadds (1998) suggested that researchers in this situation must use care and integrity to deeply know the context in which they conduct their study. Despite the aforementioned concerns, to do this in the context of Five Rivers is more a strength of the study because 
the practitioner can explain the context sufficiently. Doing so may reduce the likelihood of diminished objectivity by the researcher (Drake \& Heath, 2011). I used bracketing and further member checking (Creswell \& Poth, 2017) in reporting of findings to lay out my own experience and knowledge to ensure readers can form their own conclusions and opinions. Additionally, the use of thick description as an approach to deeply describe findings and their context will ensure that I show the reader what to think rather than tell them how to do this (Tracy, 2010). Since CBE is an emerging field in the empirical literature, thick description will hopefully inspire deeper interpretations of the results while also urging readers to ponder applicability to their context and even future research ideas.

\section{Research Ethics}

Several aspects involving research ethics must be discussed in this chapter as they undoubtedly affected the present study. Before the study, I followed all protocols from the Institutional Research Boards at Boise State University and Five Rivers Community College. The related documents are included in Appendix A. Informed consent went to all faculty at both stages (i.e. interviews and later, the survey), with participation in the study completely voluntary. The use of procedural ethics (Tracy, 2010) ensures that from start to finish, the study followed a rigorous path of safeguards. Additionally, participation did not affect faculty member's status in any way, and they were able to withdraw from the process at any time. Following the study, all faculty received a copy of the findings. Additionally, a pseudonym replaced all identities in the reporting of results to provide a further degree of anonymity. 
During the project, I worked diligently to conduct myself in a professional manner at all times as the principal investigator. During interviews, I worked to remain objective in asking my questions and ask nothing in a leading way to potentially get an answer that is desirable. I only asked follow up questions to questions if the opportunity naturally presented itself or I needed to have the faculty member clarify their response, and they had final say on whether or not to answer.

All data collected from the study including, but not limited to, audio recordings of interviews, transcriptions, survey responses, and actual data files from NVivo and SPSS were stored on a secure password-protected server. As the study has now concluded, I plan to hold onto such materials for a period of seven years after which they will be destroyed.

The analysis and reporting stages pose a challenge to present findings in a consistent manner. This is notable because the researcher is affiliated with the host site. Even though findings may put the institution in a less-than-stellar light, the study was necessary given the justification in chapters 1 and 2. Assisting with better support and implementation of the college's CBE program can only position it to further its leadership and the way it helps other colleges and universities.

\section{Chapter Summary}

The differences between competency-based education (CBE) and traditional forms of teaching and learning warrant inquiry into a multitude of related areas. The present study explored some of these facets related to $\mathrm{CBE}$.

Using a mixed methods exploratory sequential design, the study used interviews with community college faculty to first gather qualitative data to identify themes in 
responses to then create a quantitative instrument via a survey. The piece went to all CBE faculty at the institution to gather further insight into their views of CBE. Results were analyzed using descriptive statistics. The integration of both qualitative and quantitative data throughout the study provided answers to the study's three key research questions. Results may help institutions better plan and support their CBE faculty as they teach courses in this manner different from traditional and familiar approaches.

Chapter 1 briefly summarized the nature of CBE and the problem the proposed study will address as connected to existing research. Chapter 2 then provided a review of relevant literature on competency-based education, its accolades and criticisms, selfefficacy, and faculty development. Chapter 4 provides a discussion of results from qualitative interviews and the quantitative survey instrument. Finally, chapter 5 discusses all results, provides implications for practice along with calls for further research, and concludes the study. 


\section{CHAPTER FOUR: RESULTS}

The purpose of this study was to explore faculty views of competency-based education (CBE), faculty self-efficacy, and views of institutional support for CBE faculty. The study used an exploratory sequential mixed methods design with both interviews and a survey of CBE faculty. Chapter three described the methodology of the study. This chapter now presents the results of both phases.

\section{Phase One: Qualitative Results}

Phase one of data collection consisted of interviewing faculty with CBE teaching experience $(N=10)$. Responses were transcribed and verified following interviews and then imported into NVivo for analysis. In the first cycle of coding, short words and phrases emerged from reviewing responses through in vivo coding. Second cycle coding, consisting of pattern coding, created emergent themes from responses. The sections below describe key themes organized by demographic and then research question area.

\section{Faculty Demographics}

Though not covered by a research question, part one of the interviews (see chapter 3) focused on faculty background. Table 4.1 lists participating faculty by pseudonym and their relevant experience with $\mathrm{CBE}$ which range from the first year of experience to ten years, with an average of 5.4 years. 
Table 4.1 Demographic Information for Interview Participants

\begin{tabular}{lllll}
\hline Faculty Name & Gender & $\begin{array}{l}\text { Years in } \\
\text { CBE }\end{array}$ & $\begin{array}{l}\text { Years in Higher } \\
\text { Education }\end{array}$ & $\begin{array}{l}\text { Industry } \\
\text { Experience }\end{array}$ \\
\hline Allison & Female & 10 & $>20$ & No \\
Cheryl & Female & 10 & 14 & Yes \\
Claudia & Female & 4 & $>20$ & Yes \\
David & Male & 7 & 10 & Yes \\
Donna & Female & 8 & $>20$ & Yes \\
Erin & Female & 3 & $>20$ & Yes \\
Karen & Female & 1 & 2 & No \\
Mark & Male & 5 & 5 & Yes \\
Paul & Male & 2 & $>20$ & Yes \\
Tom & Male & 4 & 10 & Yes \\
\hline
\end{tabular}

Interview Results Focused on CBE Faculty Views of CBE

Part two interview questions aligned to the study's first research question which asked, “What are competency-based education faculty's views of CBE?" Questions asked faculty how they became affiliated with CBE, general impressions of the approach, and likes and dislikes overall and for learning and teaching through CBE. Table 4.2 displays three key themes which explain responses: compulsory participation, studentcenteredness, and necessary infrastructural improvements. Each theme is summarized below. 
Table 4.2 Key Themes for Research Question 1

\begin{tabular}{ll} 
Theme & Description \\
\hline $\begin{array}{l}\text { Compulsory } \\
\text { Participation }\end{array}$ & $\begin{array}{l}\text { Initial involvement with CBE came through compulsory means that felt } \\
\text { almost required. }\end{array}$ \\
$\begin{array}{l}\text { Student-Centeredness } \\
\text { Faculty viewed CBE positively through the value of its student-centered } \\
\text { approach. }\end{array}$ \\
$\begin{array}{l}\text { Necessary } \\
\text { Imprastructural }\end{array}$ & $\begin{array}{l}\text { Faculty's negative views of CBE largely focused on critical suggestions for } \\
\text { infrastructural improvements. }\end{array}$
\end{tabular}

\section{Compulsory Participation}

To understand faculty views of CBE, faculty were first asked, "Why did you begin teaching CBE courses?" The key theme that emerged from this question was compulsory participation. All ten faculty indicated their involvement with CBE began in a nature that felt almost required. For example, some faculty viewed it as an option to further their teaching portfolio through adding another modality of course delivery. Tom mentioned that, "I was made aware of it because I'm an adjunct and because I am an adjunct I want to take advantage of as many class opportunities as I could. So I just said 'let's give this a try."' Other faculty were simply assigned to teach a CBE course as part of their teaching load, such as Mark, who explained:

When I came into the department five years ago, we were standing up most of them (CBE) already so this became a part of my regular teaching load. I was assigned those classes for a term by (name redacted) the chair at the time.

Similarly, Erin felt compelled to become involved with CBE as she previously worked with a program with somewhat similar goals: "It was kind of familiar...we had another 
program that was like an independent study that was an individualized concept." Since

Erin was part of a prior iteration she felt an expectation for involvement again.

\section{$\underline{\text { Student-Centeredness }}$}

Faculty were then asked a series of questions regarding their thoughts about CBE in general, likes and dislikes of the approach, appropriateness of CBE for student learning, and views of teaching CBE courses. Answers to these questions were both positive and negative. The theme of student-centeredness was found for positive answers. This theme captures faculty's belief that the positives of CBE connect to the value of its student-centered approach. Faculty noted benefits came through three primary means: non-traditional students with experience in the field, flexible pacing for students with busy lives, and better post-completion prospects.

Both Mark and David noted the appropriateness of CBE for non-traditional students with industry experience to excel. David explained:

Especially in the IT world, where you can get a job...and not have a degree...so you can take a worker who's been in the field for a period of time, quickly assess where the gaps in their knowledge are, and fill those gaps in and let them progress.

Mark agreed and added:

I like the idea of CBE because a lot of people have worked (in the field) for years, and they don't have a degree, and their bosses asked them to go back and get a degree. It's allowed those people to get a jump start on their education because they don't have to sit in, you know, break down the ISO model of networking, because they've been doing it for 25 years. I've seen it a huge help for the people that have lived and breathed IT for 20 years but never had a degree or certification.

Both David and Mark also expressed the pacing of CBE as beneficial to students. David explained, "Students go at their own pace which I think really reflects a lot with 
students that are highly motivated. They have some skills, they can go a little bit faster." Mark echoed this idea when he stated “...that people can come in, our non-traditional student that has spent years in the field, and being able to come in and catch certain things and get credit for what they wouldn't have normally had credit for."

Finally, another student-centered benefit of CBE is the vocational connection it has to the post-completion context. Karen observed a vocational duality in the CBE experience and its connection to employment:

I think CBE students, those that succeed, will probably end up being better developers because the same skills you need...to succeed in $\mathrm{CBE}$ are the same ones that will aid you when you get your 'big girl'-'big boy' job as a programmer. Going out and researching stuff, taking initiative.... a certain level of selfstartedness and self-discipline to truly succeed.

Her sentiment was not solely focused on a connection between CBE and a vocation based on content, performance, or learned material. Rather, she emphasized many soft and peripheral skills needed for later success in employment.

Necessary Infrastructural Improvements

The final theme that emerged from faculty views of CBE was necessary infrastructural improvements. This theme encapsulated faculty's more critical views of CBE and specifically how they thought CBE could be improved at Five Rivers. Their concerns in this theme focused on three issues: uncontrolled openness of enrollment for CBE students, faculty compensation and workload, and academic rigor.

Earlier, faculty noted the benefits of CBE for students, notably those who were non-traditional. They felt CBE is a niche and cautioned not everyone should be simply permitted to take CBE courses. For example, Karen complained, "We allow the audience to be a bit too broad...we're not making sure they can succeed in the environment before 
we allow them to try it." Donna also had a concern over students yet offered a solution to a comparable CBE institution where she is a student:

With Western Governor's, I have to talk to my mentor every week until I graduate. We don't have that. They're saying send them an email...the coach will say send them an email...well no, the student has forgotten they are enrolled in this course."

At the time of the study, CBE faculty and academic coaches were responsible to check in with students without a mechanism to validate students' responses to these communications.

Faculty also expressed concern with working conditions and specifically workload with teaching CBE courses. Cheryl summarized the concern well:

When the numbers in the CBE program were really, really large...they've leveled down a little bit, there was a period of time where I had I think 47 students in it pressing me. And it was just killing me...I was completely overloaded with my other classes too.

At Five Rivers, non-CBE course capacities are generally capped at 25 students. If demand is present, departments can then create an additional section. At that point, a faculty member would have the added course as part of their normal contracted load, or receive additional compensation. This was not the case with $\mathrm{CBE}$, as Cheryl notes, “They're paying us less to teach." Paul expressed a similar concern when he stated that, “ ..it is more time consuming for the teacher" as did Erin who explained, "I don't like the back and forth with the emails because it's a constant five emails to answer one question." These statements suggest an indignation about the workload in a CBE section versus a non-CBE section or sections and their equivalent for payload or compensation.

Finally, faculty felt that learning in CBE courses consisted more of students showing what they already knew as opposed to learning new material or rigorously 
building new knowledge. Donna was the most critical voice, noting simply, "I don't think it's a good way to prove knowledge." In her opinion, bringing in experience was not necessarily tied to strong learning compared to traditional students. She noted:

A lot of students in traditional classes, they're forced to do the lessons, they're forced to read the book, they're forced to learn whereas in CBE if they pass that pre-unit (assessment), they move on. They're trying to get through the course as fast as possible.

Interview Results Focused on Self-efficacy

The second research question examined faculty's own self-efficacy in teaching CBE courses. Interview questions focused on interaction, content, and support and intervention, as well as factors shaping self-efficacy. Five themes emerged from the data (see Table 4.3). The following sections explain each theme.

Table 4.3 Key Themes for Research Question 2

\begin{tabular}{ll}
\hline Theme & Description \\
\hline $\begin{array}{l}\text { Varying Degrees of } \\
\text { Self-efficacy }\end{array}$ & $\begin{array}{l}\text { Faculty ratings of self-efficacy and confidence by aspect of teaching varied } \\
\text { significantly. }\end{array}$ \\
Practice Makes Perfect & $\begin{array}{l}\text { Teaching CBE courses term-to-term provides practical mastery experiences for } \\
\text { faculty that positively affects self-efficacy and confidence. }\end{array}$
\end{tabular}

Working with Others

Emotional Influences

Influence of Multiple Factors
Access to a mentor or other party helped faculty engage with and master challenges associated with CBE.

Positive and negative emotional experiences of faculty teaching CBE courses cannot be understated in terms of their influence on self-efficacy.

No single factor predominantly influenced faculty self-efficacy to teach CBE courses. 


\section{Varying Degrees of Self-efficacy}

Before answering questions focused on self-efficacy, faculty heard a definition of self-efficacy. Each following question then asked faculty to rate their own self-efficacy in the construct identified by the question (see Table 3.3). Their ratings for each item produced the first theme of varying degrees of self-efficacy, suggesting that ratings ranged from no or little confidence to full confidence by construct. Table 4.4 displays the variance. Though the number of faculty identifying their confidence tended to skew towards higher levels of confidence, the fact ratings existed across nearly all levels with leads to variance.

Table 4.4 Frequency Distribution for Self-efficacy Ratings by Construct

\begin{tabular}{lllll}
\hline Question & $\begin{array}{l}\text { Little } \\
\text { Confidence or } \\
\text { Indifferent }\end{array}$ & $\begin{array}{l}\text { Somewhat } \\
\text { Confident }\end{array}$ & $\begin{array}{l}\text { Mostly } \\
\text { Confident }\end{array}$ & $\begin{array}{l}\text { Very } \\
\text { Confident }\end{array}$ \\
\hline $\begin{array}{l}\text { How confident are you with } \\
\text { your interactions with students } \\
\text { in CBE courses? }\end{array}$ & $1(10 \%)^{*}$ & $2(20 \%)$ & $3(30 \%)$ & $4(40 \%)$ \\
\hline $\begin{array}{l}\text { How confident are you in your } \\
\text { ability to teach a CBE course? }\end{array}$ & 0 & $1(10 \%)$ & $3(30 \%)$ & $6(60 \%)$ \\
& 0 & & & \\
$\begin{array}{l}\text { How confident are you with } \\
\text { providing content instruction? }\end{array}$ & & & $3(30 \%)$ & $6(60 \%)$ \\
$\begin{array}{l}\text { How confident are you with } \\
\text { specifically providing support or } \\
\text { intervention? }\end{array}$ & $1(10 \%)$ & $2(20 \%)$ & $4(40 \%)$ & $3(30 \%)$ \\
\hline
\end{tabular}

\section{$\underline{\text { Practice Makes Perfect }}$}

The second theme was practice makes perfect. This theme aligns with mastery experiences that is one of the four sources of self-efficacy identified by Bandura (1977). Faculty teaching CBE or obtaining related supporting knowledge and experience over 
time tended to report higher levels of confidence to teach CBE courses. This theme occurred in responses to all interview questions in this part of the interview question set. Ultimately, practice came from repeated teaching of CBE courses and reflection and past experiences including industry experience and formal academic training.

Allison and Claudia both noted repeated teaching and reflecting on their performance promoted mastery and increased self-efficacy. Allison stated, I'm always looking to improve. Just this term alone...I have timely structured communications. I started trying to connect with them with like an orientation session the first week...I'm always looking for something new to connect with them." Claudia explained, "Especially after a term is over, I sit and think, 'What else could I have done?' or 'How could I have done this better?, 'How could I have reached out to that student?"' In both cases, pondering over how interaction through repetition from term-to-term improved ratings of self-efficacy.

Other faculty argued their experience from industry or formal academic training served as an opportunity to practice what was needed to teach CBE courses successfully. Tom emphasized his time in the field, noting, "My background is 20 some years (in the industry). I'm accustomed to working seven days a week, fifty two weeks a year...so I just stay on top of it. It's just the way I am." His experience working in the field helped him develop his content expertise which thus influenced his teaching. Paul called on his academic training in motivating students as opposed to teaching CBE as to his strong confidence:

I think my main aspect of my path to scholarship, of teaching and learning, was through psychology. And so I learned a lot about motivational psychology pretty early on. I found that if I could get students talking about if they could visualize themselves using this skill, if they could see or find context where they're going 
to use the skill, or people knew situations or places that wanted to be like, and I tell students (as their teacher): 'I can't give you a motivation, but I can help you discover one for yourself. And if a student can find an intrinsic motivation, I can't keep them from learning the language.

\section{Working with Others}

The third theme that emerged was the value in working with others. In this sense, faculty who work with others, such as external parties or others vested in the success of CBE students, reported stronger self-efficacy due to these relationships. This theme was most prevalent in terms of teaching and content instruction.

Cheryl noted the use of external content by others helped guide her:

I almost always start with canned content. I found a provider...then I go through and edit, change, and add more than anything things that I feel need to be there that aren't. About $85 \%$ of my classes come from somebody, and then I adjust.

Similarly, Claudia noted the role of external parties helping steer the direction of content and the way CBE courses were taught. As she explained, "I think I do a proficient or adequate job of making sure the course is current and relevant to what the students need to know. As a technical program we have an advisory committee." The advisory committee helps to ensure currency of material and applicability to the field as a whole.

Tom preferred to use others intentionally geared as support towards CBE students and explained that, "I have reached out to the student advisors that are involved in CBE a couple times to have them nudge students into getting going...It's been easy to utilize the tools that Five Rivers has for the CBE program." Like Tom, Allison's awareness of existing tools available was a vicarious experience. She noted:

I think we've got some new tools available now, but I'm trying to tap into and make use of...orientation. So I'm not afraid to figure out new tools to use. How can we connect? How can we help you be successful? 
While these relationships were more peripheral, they enabled faculty to rate their selfefficacy higher in the constructs of content instruction, teaching, and intervention and support.

\section{Emotional Influences}

The fourth theme that emerged was emotional influences and suggests that both the positive and negative emotional experiences of teaching CBE courses affected faculty self-efficacy. Both positive and negative emotions are considered physiological states (Bandura, 1977) and affected self-efficacy notably for interaction with students and support and intervention based on student needs.

Donna explained her feelings with respect to interaction were, "Horrible, because often after multiple efforts, a student, "disengaged from Five Rivers...and I call the student and say, 'where are you?' and then some students (have excuses) ... and I'm like...'you got to get involved again."” Her negative experience prompted her lower rating. Conversely, David's opined his positive emotional feelings came from interaction with students and helping their success:

I would typically try to reach out and open with, 'Hey, what do you need help with?" ..."What do you need?" Let's meet, let's get together. Sometimes there's simple questions that they won't put in an email because they think it's a stupid question....and I need them to ask me that question because I can answer that question in 30 seconds where they can read for three hours and they may not understand.

Mark provided insight into the role of emotional influences as they connect to

support and intervention. He explained:

I'm going to say not very confident...I feel that when a student needs extra help, I think my normal go to is to (suggest), 'Hey, you know I think switching to a traditional online class might be your best option'...I think when it comes to actually providing support and trying to help move a student along... a bit more time and focus - I feel like that's what I should be personally doing instead of 
offering another way out....Because that's a way out not a tired or structured support model.

The suggestion that simply taking a way out and going to a traditional course might be viewed as giving up by both student and faculty. This option would produce a negative emotional experience and possible detract from mastery.

\section{The Influence of Multiple Factors}

Finally, the fifth theme to emerge was the influence of multiple factors on faculty self-efficacy. Faculty noted how an internal drive to perform at peak level, translation of experience from other contexts, and consumption of learning experiences provided by Five Rivers impacted their self-efficacy.

Faculty reported an intrinsic drive that influenced their performance in CBE. Allison explained, "Some of it's just my nature to embrace that and not be fearful of it. And then, along with that, not being afraid to take a risk and say, 'Hey, let's try this out this term.' Cheryl, equally driven, called on her time previously spent teaching CBE as influential:

Honestly, when you've done this stuff, you've built systems (for CBE courses), they work, you know you're doing it right. I still play with the software. I still build things, I still emulate big environments. So I just try to keep my skills up to speed so that I can feel confidence in what I'm saying and doing.

Intrinsic drive to perform at peak level only impacts faculty who can say they embody such a trait. Paul did not have this internal drive but did have translated experience. Emphatically, he posited, 'I've taught many different modalities. I've also done a lot of adult education...so I think I've got sort of like theoretically but also practically a lot of the things that we put together." Tom argued his continued ability to improve how he taught CBE came through reflection and stated, "Through the first 
semester, I recognized what was necessary to provide the students with what they needed to be successful...after the first one, I said, 'okay, now I know how this works."

Faculty also noted the importance of participation in learning experiences provided by Five Rivers as influential. As described in chapter three, faculty at Five Rivers complete both required and additional optional training to learn about the learning management system and to prepare them to teach CBE courses. Karen noted how the culture of support at Five Rivers impacted her self-efficacy. She explained, "Because of just my experience working for Five Rivers for this period of time. I feel pretty confident in our procedures and policies as an institution to know how to handle any sort of situation I could think of."

Interview Results Focused on Institutional Support

The third research question focused on how institutions can support CBE faculty. Despite the general nature of the question, faculty responses all focused on their experiences with CBE at Five Rivers. The interview questions focused on faculty's initial CBE teaching experience, their preparedness, ideas for support of new CBE faculty, and ways to improve views of CBE. Table 4.5 displays the four themes that emerged from the data. The following sections will report on each theme in more detail.

\section{Trial and Error}

The first theme to emerge was the use of trial and error to learn to teach CBE courses. Trial and error was based on faculty's own effort and by calling on specific experiences. This theme emerged in part because of the compulsory opportunity that saw many faculty assigned CBE sections with limited or no experience. 


\section{Table 4.5 Themes for Research Question 3}

\begin{tabular}{ll}
\hline Theme & Description \\
\hline Trial and Error & $\begin{array}{l}\text { Faculty used trial and error both on their own and based on other experiences } \\
\text { to learn to teach CBE. }\end{array}$ \\
$\begin{array}{l}\text { Cognizance of } \\
\text { Preparation }\end{array}$ & $\begin{array}{l}\text { Faculty were aware of both the challenges that existed in preparing to teach } \\
\text { CBE and of their own feelings of readiness. }\end{array}$ \\
$\begin{array}{l}\text { Reliance on Robust } \\
\text { Peer Support }\end{array}$ & $\begin{array}{l}\text { To be successful, new faculty to CBE must benefit from a system of peer } \\
\text { support. }\end{array}$ \\
$\begin{array}{l}\text { Support through } \\
\text { Refinements }\end{array}$ & $\begin{array}{l}\text { Faculty felt that support for CBE programs from faculty would grow if } \\
\text { refinements were made in specific areas. }\end{array}$ \\
\end{tabular}

Faculty noted the importance of trial and error in learning to teach CBE courses, especially when they were first assigned a course. For instance, Cheryl, who started teaching CBE at its onset, noted, "“"The beginning was trial and error, trip and fall, get up, fix it." She continued further, humorously admonishing her early performance:

I would live to send a letter to some of those (students)...in the first two or three semesters and say, 'I am so sorry.' There were some things that just weren't great. They're much, much better now. And that doesn't mean the content was bad or that they didn't matter or what they needed to learn. It just means it could have been smoother. It could have been more polished.

Allison also reflected on her trial and error approach:

Just trial and error. I mean I was in it from the groundbreaking. So it was...the course doesn't look like what it looked like that first year or two, because there were things that just didn't work well. I didn't stick with it. We had an idea that we thought would work and then it just didn't play out like we anticipated, and you change it (if it doesn't work). 
In both cases, it was apparent that faculty were aware of the results of their efforts - what worked and what did not - in early iterations of CBE courses.

Faculty also used trial and error based on other experiences. Some faculty emphasized the importance of training to prepare faculty to teach CBE courses. For instance, Tom explained the usefulness of training for learning to teach CBE:

There was a certification program...and that was my exposure. It was similar to the online teaching certification I had, it was just a little more specific in terms of details and what to do if someone is failing and they want to convert it to a regular class.

Other faculty felt the course development process provided an opportunity to learn.

Claudia recalled learning from CBE staff and instructional designers how it worked:

They (CBE staff) came to the office and did some explanations. They met with faculty, including myself, as well working closely with the instructional designers. It makes it an easier task to accomplish. I have learned a lot...from the various instructional designers that I've been fortunate to work with at this institution.

In both cases, faculty understood that other experiences were beneficial to their success in learning to teach CBE.

\section{Cognizance in Preparation}

The second theme in this section was cognizance of preparation. Faculty

described an awareness of the challenges they would face as they prepared for or learned to teach $\mathrm{CBE}$ for the first time and also understood they came into this challenge with their own innate preparedness.

Donna provided an example of understanding the challenges faculty would face, noting, "I don't think any of us were prepared for CBE...It's a learning process." Many faculty felt prepared for their first CBE course and wanted to just get going. Allison 
noted, "I felt somewhat prepared...It's just like with anything new - you're not sure how it's going to play out on the student side until it actually does, but I wasn't fearful of it." Karen discussed understanding that new approaches, based on her past experience, come with uncertainty. She explained, "Having been the first time leading through CBE course, I could see a little uncertainty with that, just until you get your own kind of flow." This statement reflects an understanding of the nuances faced by faculty in trying to hit their teaching groove. Claudia also possessed a strong internal confidence though based on her lengthy service. She explained, 'I'm an older or experienced faculty member. I'm very comfortable with the content." Her justification is simple yet denoted an innate confidence to prepare to teach CBE. Karen had further ideas as well related to experience and the confidence that came with it. She explained, "A lot... of my experience has been just knowing what students are going to ask. And you hear teachers do that all the time."

\section{$\underline{\text { Reliance on Peer Support }}$}

The third theme to emerge was reliance on robust peer support. For new faculty, experiences must include mentorship and specific and diverse learning experiences that promote awareness of resources that exist to support faculty.

With eight years of experience, Donna stressed the importance of mentoring:

I mentored two faculty members this summer...and have had several phone calls. Faculty need to have somebody who's really patient. I call to check up on my people I'm mentoring to make sure they're okay, if they need anything, if they just want to vent. For new faculty, it's just teaching, it's just showing them how it works and walking them through the first time they teach it. Because the next time they teach it, they'll understand the process but it's so different than anything else we have.

Paul seconded the benefits of peer-to-peer mentoring, indicating, "I do think that in everything I've seen about all types of educational improvement, faculty get better by 
talking with other faculty about teaching and working with (other faculty)."

Faculty also felt specific learning experiences were vital for new CBE faculty. For instance, David advocated for a learning by doing approach when he explained, "They almost need to go through a CBE class and see what it's like." Cheryl specifically suggested, "Give them a class to start with...give them a pre-made class. Let them use that first semester and then they can make adjustments after that based on their personal preferences." Cheryl added, "I would make sure they know what resources are available."

\section{Support through Refinements}

The final theme was support through refinements so faculty can support CBE. These changes include refreshing the message on student benefits of CBE, evaluation of faculty workload and compensation, and further benchmarking Five Rivers to other colleges using CBE. In doing so, faculty believe expectations on all parties will be refined in a manner that improves perceptions of CBE.

Refreshing the message of the student benefits of CBE clearly identified by faculty in this study could help garner better support for CBE. To accomplish this, Erin suggests brevity and openness, indicating, "When they're introducing faculty to CBE, just be real about it." Likewise, Paul agreed and further suggested, "The emotional piece...its making students videos or testimony showing 'this thing worked for me'...you want to make a logical appeal, an emotional appeal."

Faculty also noted their compensation based on workload as an area to address. Mark explained that, "I think I have been through five or six different pay models. Sometimes (my faculty) get full load, sometimes they don't want to take it (a CBE course) because they didn't get the full load." Five Rivers uses a compensation model 
based on the number of students in a section, and if enrollment is low they may not get the same payload as a non-CBE course with the same low enrollment. This was also an infrastructure issue identified as a dislike of CBE under research question one.

Along with overhauling workload and compensation, faculty also reported how they thought that revisiting benchmarking Five Rivers' CBE program to other institutions would help improve perceptions. The initial push for CBE at Five Rivers included benchmarking to the limited institutions with CBE. Now that a decade has passed, this effort may once again provide insight into how other institutions deliver CBE. David argued this point, stating, "My personal opinion is it's you almost divorce that current ideology from the old ideology. I like the way students can enroll at Western Governors once a month, and then their start, that's their start date." While this model poses challenges at Five Rivers due to infrastructure, perhaps evaluating the college's systems may yield returns to justify a shift. Donna focused her thoughts on the academic coaches, arguing, "If we're going to have coaches, the coaches need to be like the mentors they have at Western Governors. Really hands-on, otherwise tell me to do it or compensate me for it."

\section{Summary of Qualitative Findings}

Qualitative interviews conducted in phase one of this study investigated faculty perceptions of CBE, self-efficacy of such faculty, and the best ways to support and develop faculty teaching CBE courses. Faculty reported compulsory participation in $\mathrm{CBE}$ through assignment or an opportunity to expand their teaching portfolio. Resulting themes for views of $\mathrm{CBE}$ indicated generally positive views of $\mathrm{CBE}$ as a student-centered 
approach to learning. Faculty were also critical of CBE and noted there were improvements that should be made to infrastructure for CBE at Five Rivers.

Self-efficacy views were mixed among faculty who reported varying degrees of self-efficacy and confidence. Faculty believed practice makes perfect through repetition of teaching CBE courses. They also indicated working with others in a mentorship approach produced higher feelings of confidence. Faculty also noted the role of the emotions felt while working in CBE courses as important. Though several themes existed for self-efficacy, no single factor influencing self-efficacy stood out as dominant.

Finally, in addressing ideas for institutional support, faculty noted the importance of using trial and error based on their own efforts or past experiences in learning to teach CBE. This was supplanted by a understanding there would be many challenges in preparing to teach $\mathrm{CBE}$ for the first time. Also significant to faculty was the importance of peer support to make sure the collective body of faculty could succeed. Finally, faculty insisted that support for CBE would grow if Five Rivers supported refinements to key areas of CBE programs.

\section{Phase Two: Quantitative Results}

After analyzing the data from the interviews, I created a survey to investigate: faculty views of CBE, ratings of self-efficacy in areas of teaching, and thoughts on institutional support for CBE faculty. More specifically, I crafted Likert survey items aligned to the three research question areas of this study using Bandura's (2006) Guide for Constructing Self-efficacy Scales and the response language of faculty who participated in interviews to promote alignment and validity between both phases of the study. The survey was administered electronically during the fall 2020 academic term to 
65 faculty who had prior experience with CBE. From the outset, three faculty declined to consider participating in the study, thus reducing the potential pool to 62 . A total of 48 completed the survey for a response rate of approximately $77 \%$.

Once survey administration concluded, faculty responses for all items were entered into SPSS. Demographic items were entered in kind by ranges for years of experience in higher education and in CBE (See Table 4.6 below). Gender entries were assigned a number (i.e. 1 - male, 2 - female) as was industry experience (i.e. 1 - yes, 2 no). Likert item responses on views of $\mathrm{CBE}$, self-efficacy, and institutional support items were assigned a number on a scale from one to five (i.e., Strongly Agree as 5, Strongly Disagree as 1). Data were then analyzed for descriptive statistics including those of central tendency and spread. Data were further analyzed by frequency distribution to provide a deeper representation of results. In the sections below, I present the results by overall measures, frequency, and demographics by each research question. In the case of overall measures and demographics, results are presented by construct versus individual item. Appendix A displays which items are in each construct.

Cronbach's Alpha for Reliability

Data was entered into SPSS to calculate Cronbach's alpha (a) to measure the internal consistency of the survey. This is done to determine whether or not an instrument measured what it intended to measure (Bandura, 2006). In the case of Cronbach's alpha, results fall between 0 and 1 with a lower score indicating lower reliability and a higher score indicating higher reliability (Hatcher, 2013; Tavakol \& Dennick, 2011). Data for parts two, three, and four of the survey were used to run this test. The survey was found to be highly reliable (42 items; $a=.86$ ). 


\section{Demographic Item Results}

Initial items on the survey, like the interviews, solicited basic demographic information which could be later used to present further findings by research questions. The items gathered data on four key demographic areas: years of involvement in CBE, years in higher education, gender, and whether or not the faculty member had industry experience outside of the academic setting. Asking participants for industry experience was done primarily because of the strong vocational connections in CBE programs versus traditional academic programs. It was also asked to examine any potential differences between faculty with and without industry experience. Table 4.6 summarizes the demographics of the faculty survey participants. Faculty experience ranged from less than one year to ten years of experience, with the average as just over four years.

More than half of faculty $(N=28)$ had more than ten years in higher education, with sixteen having more than twenty and constituting the largest group. Only one faculty member was in their first year, and approximately twenty were within the first ten years. This distribution does not match years in CBE indicating no connection between experience and initial involvement with CBE. Interestingly, most faculty involved in CBE came from early and late career stages.

When it came to industry experience, more than three-fourths $(N=37)$ of faculty had experience within fields related to the courses they teach. The remaining 11 did not have experience. Of these two groups, no clear distinction was found between experience in industry years of experience either in education as a whole or in CBE. 
Table 4.6 Survey Participant Demographics

\begin{tabular}{ccc}
\hline & $\mathrm{N}$ & Pct. \\
\hline$<1$ & Years involved in CBE & \\
$1-5$ & 6 & $12.5 \%$ \\
$6-10$ & 28 & $58.3 \%$ \\
\hline Total & 14 & $29.2 \%$ \\
\hline & 48 & $100 \%$ \\
\hline$<1$ & Years involved in higher education & \\
$1-5$ & 1 & $2 \%$ \\
$6-10$ & 6 & $13 \%$ \\
$11-15$ & 13 & $27 \%$ \\
$16-20$ & 6 & $13 \%$ \\
$>20$ & 6 & $13 \%$ \\
\hline Total & 16 & $32 \%$ \\
\hline & 48 & $100 \%$ \\
\hline Yes & Industry Experience & \\
No & 37 & $77 \%$ \\
\hline Total & 11 & $23 \%$ \\
\hline Total & 48 & $100 \%$ \\
\hline & 21 & $56 \%$ \\
\hline Female & 48 & $100 \%$ \\
\hline & &
\end{tabular}

Finally in terms of gender, there were more males $(N=27)$ than females $(N=$ 21). Like industry experience, there was no clear distinction between gender and length of $\mathrm{CBE}$ or higher education experience. Faculty were also given the opportunity to mark gender fluid or non-binary, or prefer not to answer as options under gender. No faculty selected either option, thus it was omitted from the tables in this section of the chapter. Survey Results Focused on CBE Faculty Views of CBE

The first research question in the study asked, "What are CBE faculty's views of CBE?" Initial statistics were run on perceptions of CBE from all items within the section 
of the survey and then on items by construct. Table 4.7 displays the results of these tests. Overall, faculty $(N=48)$ views of CBE were generally positive $(M=3.68)$ falling between neutral and agree. By construct (see Table 3.4), means for origins of teaching $\mathrm{CBE}(M=3.10)$ and $\mathrm{CBE}$ teaching and delivery $(M=3.10)$ were the lowest. Conversely, theory and background $(M=4.27)$ and student focus $(M=4.35)$ were the highest and approached strongly agree. Of note, the mean for student focus was the highest construct mean of any part of the survey.

Table 4.7. Overall Results for Views of CBE and Results by Construct

\begin{tabular}{lll}
\hline Construct & $\mathrm{M}$ & $\mathrm{SD}$ \\
\hline Overall Results for Views & 3.68 & 1.12 \\
Theory/Background & 4.27 & .83 \\
Origins of Teaching CBE & 3.10 & 1.13 \\
Student Focus & 4.35 & 0.62 \\
General Tenets & 3.54 & 1.08 \\
CBE Teaching/Delivery & 3.10 & 1.15 \\
\hline
\end{tabular}

Statistical tests were then performed by each item within the section agnostic of construct. Table 4.8 displays the frequencies of each score (i.e. $1=$ strongly agree, $2=$ agree, etc.) and their requisite means and standard deviations by question. Results were the lowest for questions " 10 . I view the CBE workload as unmanageable compared to other course delivery formats" $(M=2.65)$, “4. I began working with CBE because it was a logical 'next step' for my career” $(M=3.08)$, and “3. My involvement with CBE began through my own curiosity or interest" $(M=3.13)$. Conversely, results by mean were the highest for "5. CBE's flexible pacing supports the personal situations of students" ( $M=$ 4.35), “6. The ability for students to apply prior knowledge or experience means they can 
earn credentials faster than their peers" $(M=4.35)$, and " 1 . The premise of CBE is appropriate for certain vocational fields" $(M=4.50)$.

Data from responses were then analyzed by construct cross referenced with demographic areas used in section one. Table 4.9 displays the results of these analyses. By gender, the highest mean was for males in theory and background $(M=4.28)$ and the lowest mean was also for males, under teaching and delivery $(M=2.98)$. Results between gender in general tenets with means of females $(M=3.55)$ higher than males $(M$ $=3.54$ ) represented the smallest difference. The greatest difference in means was origins teaching CBE, with males $(M=2.83)$ significantly lower than females $(M=3.45)$. The next demographic area broke down years of experience with CBE into three spans and scores were analyzed for each subgroup. In this case, the highest mean overall came from responses in the student focus construct and those with less than one year of experience $(M=4.42)$. The same experience subgroup produced the lowest mean score under origins of teaching $\mathrm{CBE}(M=2.33)$. When looking at the ranges of means for all three experience spans, the closest came from teaching and delivery $(3.08-3.14)$ while the most spread came from origins teaching CBE (2.33 - 3.25). 
Table 4.8. Perceptions of CBE Frequencies and Measures of Central Tendencies

\begin{tabular}{|c|c|c|c|c|c|c|c|}
\hline Survey item & 1 & 2 & 3 & 4 & 5 & $M$ & $S D$ \\
\hline $\begin{array}{l}\text { 1. The premise of CBE is } \\
\text { appropriate for certain } \\
\text { vocational fields. }\end{array}$ & $\begin{array}{l}0 \\
(0 \%)\end{array}$ & $\begin{array}{l}0 \\
(0 \%)\end{array}$ & $\begin{array}{l}1 \\
(2 \%)\end{array}$ & $\begin{array}{l}22 \\
(45.8 \%)\end{array}$ & $\begin{array}{l}25 \\
(52.2 \%)\end{array}$ & 4.50 & 0.55 \\
\hline $\begin{array}{l}\text { 2. CBE is a niche for a } \\
\text { select group of students.* }\end{array}$ & $\begin{array}{l}1 \\
(2 \%)\end{array}$ & $\begin{array}{l}4 \\
(8.5 \%)\end{array}$ & $\begin{array}{l}4 \\
(8.5 \%)\end{array}$ & $\begin{array}{l}22 \\
(46.8 \%)\end{array}$ & $\begin{array}{l}16 \\
(34 \%)\end{array}$ & 4.04 & 1.00 \\
\hline $\begin{array}{l}\text { 3. My involvement with } \\
\text { CBE began through my } \\
\text { own curiosity or interest. }\end{array}$ & $\begin{array}{l}3 \\
(6.3 \%)\end{array}$ & $\begin{array}{l}14 \\
(29.2 \%)\end{array}$ & $\begin{array}{l}12 \\
(25 \%)\end{array}$ & $\begin{array}{l}12 \\
(25 \%)\end{array}$ & $7(14.5 \%)$ & 3.13 & 1.18 \\
\hline $\begin{array}{l}\text { 4. I began working with } \\
\text { CBE because it was a } \\
\text { logical 'next step' for my } \\
\text { career. }\end{array}$ & $\begin{array}{l}3 \\
(6.3 \%)\end{array}$ & $\begin{array}{l}12 \\
(25 \%)\end{array}$ & $\begin{array}{l}16 \\
(33.3 \%)\end{array}$ & $\begin{array}{l}12 \\
(25 \%)\end{array}$ & $5(10.4 \%)$ & 3.08 & 1.09 \\
\hline $\begin{array}{l}\text { 5. CBE's flexible pacing } \\
\text { supports the personal } \\
\text { situations of students. }\end{array}$ & $\begin{array}{l}0 \\
(0 \%)\end{array}$ & $\begin{array}{l}0 \\
(0 \%)\end{array}$ & $\begin{array}{l}3 \\
(6.3 \%)\end{array}$ & $\begin{array}{l}25 \\
(52.1 \%)\end{array}$ & $\begin{array}{l}20 \\
(41.6 \%)\end{array}$ & 4.35 & 0.60 \\
\hline $\begin{array}{l}\text { 6. The ability for students } \\
\text { to apply prior knowledge } \\
\text { or experience means they } \\
\text { can earn credentials } \\
\text { faster than their peers. }\end{array}$ & $\begin{array}{l}0 \\
(0 \%)\end{array}$ & $\begin{array}{l}0 \\
(0 \%)\end{array}$ & $\begin{array}{l}4 \\
(8.3 \%)\end{array}$ & $\begin{array}{l}23 \\
(48 \%)\end{array}$ & $\begin{array}{l}21 \\
(43.7 \%)\end{array}$ & 4.35 & 0.64 \\
\hline $\begin{array}{l}\text { 7. The instructor is more } \\
\text { of a guide or mentor in } \\
\text { CBE courses than } \\
\text { anything else. }\end{array}$ & $\begin{array}{l}1 \\
(2 \%)\end{array}$ & $\begin{array}{l}6 \\
(12.5 \%)\end{array}$ & $5(10.4 \%)$ & $\begin{array}{l}28 \\
(58.3 \%)\end{array}$ & $\begin{array}{l}8 \\
(16.8 \%)\end{array}$ & 3.75 & 0.96 \\
\hline $\begin{array}{l}\text { 8. I am satisfied with the } \\
\text { way our institution uses } \\
\text { CBE. }\end{array}$ & $\begin{array}{l}2 \\
(4.2 \%)\end{array}$ & $\begin{array}{l}12 \\
(25 \%)\end{array}$ & $\begin{array}{l}10 \\
(20.7 \%)\end{array}$ & $\begin{array}{l}16 \\
(33.3 \%)\end{array}$ & $\begin{array}{l}8 \\
(16.8 \%)\end{array}$ & 3.33 & 1.15 \\
\hline $\begin{array}{l}\text { 9. I like teaching } \mathrm{CBE} \\
\text { courses. }\end{array}$ & $\begin{array}{l}2 \\
(4.2 \%)\end{array}$ & $\begin{array}{l}4 \\
(8.3 \%)\end{array}$ & $\begin{array}{l}16 \\
(33.3 \%)\end{array}$ & $\begin{array}{l}17 \\
(35.4 \%)\end{array}$ & $\begin{array}{l}9 \\
(18.8 \%)\end{array}$ & 3.56 & 1.03 \\
\hline
\end{tabular}


10. I view the $\mathrm{CBE}$

workload as unmanageable compared to other course delivery 5 20 $(41.7 \%)$ 14 $(29.2 \%)$ 5 $(10.4 \%)$ 4 formats.

$1=$ strongly disagree, $2=$ disagree, $3=$ neutral, $4=$ agree, $5=$ strongly agree

*One faculty did not select an option for this item $(N=47)$

Six spans organized years of experience in higher education as displayed in Table 4.9. In these ranges the highest overall score from this section of the survey occurred in theory and background by those with one to five years in higher education $(M=4.67)$. 
Table 4.9. Perceptions of CBE by Construct and Demographic

\begin{tabular}{|c|c|c|c|c|c|c|c|c|c|c|}
\hline \multirow[b]{2}{*}{ Demographic } & \multicolumn{2}{|c|}{$\begin{array}{c}\text { Theory/ } \\
\text { Background }\end{array}$} & \multicolumn{2}{|c|}{$\begin{array}{l}\text { Origins } \\
\text { Teaching } \\
\text { CBE }\end{array}$} & \multicolumn{2}{|c|}{$\begin{array}{c}\text { Student } \\
\text { Focus }\end{array}$} & \multicolumn{2}{|c|}{$\begin{array}{c}\text { General } \\
\text { Tenets }\end{array}$} & \multicolumn{2}{|c|}{$\begin{array}{l}\text { Teaching/ } \\
\text { Delivery }\end{array}$} \\
\hline & M & SD & M & $\mathrm{SD}$ & M & SD & M & SD & M & SD \\
\hline Male & 4.28 & .83 & 2.83 & 1.11 & 4.31 & .64 & 3.54 & 1.02 & 2.98 & 1.05 \\
\hline Female & 4.26 & .83 & 3.45 & 1.06 & 4.40 & .59 & 3.55 & 1.15 & 3.25 & 1.25 \\
\hline$<1$ Years CBE & 4.42 & .51 & 2.33 & 1.30 & 4.42 & .67 & 3.33 & .65 & 3.08 & 1.00 \\
\hline 1-5 Years CBE & 4.23 & .81 & 3.25 & 1.01 & 4.32 & .61 & 3.61 & 1.12 & 3.09 & 1.15 \\
\hline 6-10 Years CBE & 4.29 & .98 & 3.14 & 1.18 & 4.39 & .63 & 3.50 & 1.14 & 3.14 & 1.24 \\
\hline $\begin{array}{l}<1 \text { Years Higher } \\
\text { Ed. }\end{array}$ & 4.00 & 0 & 2.00 & 0 & 4.00 & 1.41 & 3.00 & 0 & 3.00 & 0 \\
\hline $\begin{array}{l}\text { 1-5 Years Higher } \\
\text { Ed. }\end{array}$ & 4.67 & .49 & 3.58 & 1.24 & 4.58 & .51 & 4.25 & .97 & 3.58 & 1.24 \\
\hline $\begin{array}{l}\text { 6-10 Years } \\
\text { Higher Ed. }\end{array}$ & 4.35 & .69 & 2.96 & 1.04 & 4.42 & .58 & 3.23 & .99 & 2.96 & 1.01 \\
\hline $\begin{array}{l}\text { 11-15 Years } \\
\text { Higher Ed. }\end{array}$ & 4.17 & .94 & 2.5 & .90 & 4.41 & .5 & 3.67 & .89 & 2.83 & .94 \\
\hline $\begin{array}{l}\text { 16-20 Years } \\
\text { Higher Ed. }\end{array}$ & 4.42 & .51 & 3.42 & 1.16 & 4.33 & .78 & 3.50 & 1.31 & 2.83 & 1.19 \\
\hline $\begin{array}{l}>20 \text { Years } \\
\text { Higher Ed. }\end{array}$ & 4.06 & 1.05 & 3.22 & 1.16 & 4.22 & .61 & 3.53 & 1.11 & 3.25 & 1.27 \\
\hline $\begin{array}{l}\text { Industry } \\
\text { Experience }\end{array}$ & 4.32 & .78 & 3.03 & 1.13 & 4.34 & .65 & 3.53 & 1.06 & 3.01 & 1.04 \\
\hline $\begin{array}{l}\text { No Industry } \\
\text { Experience }\end{array}$ & 4.09 & .97 & 3.36 & 1.09 & 4.41 & .50 & 3.59 & 1.14 & 3.41 & 1.44 \\
\hline
\end{tabular}

The lowest overall score came from the eleven to fifteen years' experience range in the origins teaching $\mathrm{CBE}$ construct $(M=2.5)$. The widest spread in scores by construct 
occurred in student focus origins teaching CBE (2.00 - 3.58) and the smallest in student focus $(4.00-4.58)$.

A less centric distribution, however, defined total years involved in higher education. More than half of faculty $(N=28)$ had more than ten years in higher education, with sixteen having more than twenty and constituting the largest group. Only one faculty was in their first year, and approximately twenty were within the first ten years. This distribution does not match years in CBE. Interestingly, most faculty involved in $\mathrm{CBE}$ came from early and late career stages.

When it came to industry experience, more than three-fourths $(N=37)$ of faculty had experience within fields related to the courses they teach. The remaining $11 \mathrm{did}$ not have experience. Of these two groups, no clear distinction was found between experience in industry years of experience either in education as a whole or in CBE. The final demographic and response crosswalk considered whether or not the faculty member had industry experience related to the courses they teach. Vocational connections often exist in CBE courses and programs (Bornitz \& Carnaghan, 2003; Dragoo \& Barrows, 2016; Grann, 2017). Means in this demographic fell closest between subgroups under general tenets among faculty without industry experience $(M=3.59)$ higher than those without experience $(M=3.53)$. Means with the most spread occurred in teaching and delivery with industry experience $(M=3.01)$ again higher than no industry experience $(M=$ 3.41). The highest mean in this demographic subgroup occurred in student focus by those with no industry experience $(M=4.41)$ and the lowest in teaching and delivery from those with experience $(M=3.01)$. Survey Results Focused on Self-efficacy 
The next section of the survey aligned to the second research question which asked, "How do faculty involved with CBE rate their own self-efficacy?" The overall results of items (see Table 4.10) were largely positive with a mean again between neutral Table 4.10. Overall Results for Areas of Self-Efficacy and Results by Construct

\begin{tabular}{lcc}
\hline Construct & $\mathrm{M}$ & $\mathrm{SD}$ \\
\hline Overall Results for Self-efficacy & 3.76 & 1.01 \\
Interaction & 3.40 & 1.14 \\
Teaching Ability & 4.03 & .76 \\
Content Instruction & 4.15 & .83 \\
Support/Intervention & 3.59 & 1.09 \\
Influencing Factors & 3.63 & .95 \\
\hline
\end{tabular}

$\overline{\text { and agree }(M=3.76) \text {. By construct, interaction }(M=3.40) \text { and support and intervention }}$ $(M=3.59)$ had the lowest means. Teaching ability $(M=4.03)$ and content instruction $(M$ $=4.03$ ) alternatively had the highest means.

Table 4.11 shows the items in this section and their frequencies, means, and standard deviations again in order from the survey. Items "2. I struggle to provide meaningful interaction with students since CBE students don't require much interaction" $(M=2.48)$, " 12 . Handling CBE student issues is easier than handling students 
Table 4.11. Faculty Self-efficacy Frequencies \& Measures of Central Tendency

$\begin{array}{lllllllll}\text { Survey item } & 1 & 2 & 3 & 4 & 5 & M & S D\end{array}$

1. I am confident in my ability to interact with CBE students in general.

2. I struggle to provide meaningful interaction with students since $\mathrm{CBE}$ students don't require much interaction.

3. I reflect on my confidence in terms of interacting with $\mathrm{CBE}$ students each time I teach a CBE course.

4. I am confident in teaching CBE courses.

0

$(0 \%)$

$(0 \%)$

4

$(8.3 \%)$

31

$(65 \%)$

13

$(26.7 \%)$

$\begin{array}{ll}4.19 & 0.57\end{array}$

5. My experience in industry leads to a higher confidence teaching $\mathrm{CBE}$

$\begin{array}{ccccccc}1 & 3 & 15 & 19 & 9 & 3.68 & 0.93 \\ (2 \%) & (6.3 \%) & (31.3 \%) & (41.6 \%) & (18.8 \%) & & \end{array}$

6. Experience teaching in other modalities translated into confidence to teach

$\begin{array}{ccccccc}0 & 0 & 5 & 27 & 16 & 4.23 & 0.63 \\ (0 \%) & (0 \%) & (10.4 \%) & (56.3 \%) & (33.3 \%) & & \end{array}$

CBE.

7. I am confident in the content of CBE courses.

$\begin{array}{ccccccc}0 & 3 & 3 & 23 & 19 & 4.21 & 0.82 \\ (0 \%) & (6.3 \%) & (6.3 \%) & (47.5 \%) & (39.9 \%) & & \end{array}$

8. My confidence in CBE course content is due to my mastery of such content.*

$\begin{array}{ccccccc}0 & 1 & 9 & 22 & 15 & 4.09 & 0.78 \\ (0 \%) & (2 \%) & (18.8 \%) & (46.8 \%) & (32.4 \%) & & \end{array}$


9. I feel as confident in the content of CBE courses as I do in other modalities.

$\begin{array}{ccccccc}1 & 2 & 4 & 22 & 19 & 4.17 & 0.91 \\ (2 \%) & (4.2 \%) & (8.3 \%) & (46.8 \%) & (41.6 \%) & & \end{array}$

10. I am confident in providing support or intervention for $\mathrm{CBE}$ student.

$\begin{array}{ccccccc}0 & 5 & 5 & 24 & 14 & 3.98 & 0.91 \\ (0 \%) & (10.4 \%) & (10.4 \%) & (50 \%) & (29.2 \%) & & \end{array}$

11. I am confident pointing CBE students to the resources available to support them if I am unable to.

$\begin{array}{ccccccc}0 & 2 & 1 & 29 & 16 & 4.23 & 0.69 \\ (0 \%) & (4.2 \%) & (2 \%) & (60.5 \%) & (33.3 \%) & & \end{array}$

12. Handling CBE student issues is easier than handing student issues in more traditional course settings.

13. Knowing there is institutional support for CBE faculty makes me feel confident to teach $\begin{array}{ccccccc}1 & 4 & 9 & 23 & 11 & 3.81 & 0.96 \\ (2 \%) & (8.3 \%) & (18.8 \%) & (48 \%) & (22.8 \%) & & \end{array}$ CBE.

$\begin{array}{ccccccc}5 & 16 & 22 & 5 & 0 & & \\ (10.4 \%) & (33.3 \%) & (46.8 \%) & (10.4 \%) & (0 \%) & & \end{array}$

14. Faculty training or development focused on CBE helped me become confident.

$\begin{array}{ccccccc}2 & 2 & 16 & 22 & 6 & 3.58 & 0.92 \\ (4.2 \%) & (4.2 \%) & (33.3 \%) & (46.8 \%) & (12.5 \%) & & \end{array}$

15. My confidence level with respect to $\mathrm{CBE}$ is often driven by student performance in courses $\begin{array}{ccccccc}2 & 5 & 14 & 22 & 5(10.4 \%) & 3.48 & 0.97 \\ (4.2 \%) & (10.4 \%) & (29.2 \%) & (46.8 \%) & & & \end{array}$ or their feedback

$1=$ strongly disagree, $2=$ disagree, $3=$ neutral, $4=$ agree, $5=$ strongly agree

*One faculty did not select an option for this item $(N=47)$ 
issues in more traditional course settings" $(M=2.56)$, and " 15 . My confidence level with respect to $\mathrm{CBE}$ is often driven by student performance in courses or their feedback" $(M=$ 3.48 had the lowest means. The highest means came from items " 7 . I am confident in the content of CBE courses" $(M=4.21)$, “6. Experience teaching in other modalities translated into confidence to teach CBE" $(M=4.23)$, and "11. I am confident pointing CBE students to the resources available to support them if I am unable to" $(M=4.23$,).

Table 4.12 displays areas of self-efficacy and CBE by construct and demographic. By gender, the highest mean came from females under content instruction $(M=4.24)$ and the lowest from males under interaction $(M=3.36)$. Notably, the means by gender in this section of questions were predominantly higher than other sections. Support and intervention had the closest means by gender with males $(M=3.58)$ lower than females $(M=3.60)$. The construct with the largest difference between means was influencing factors. Means of males $(M=3.48)$ were .33 higher than females $(M=3.81)$.

Experience with CBE for areas of self-efficacy by faculty provided somewhat consistent means by span compared to other sections. The highest overall mean within the section came from the most experienced faculty (6-10 years of experience) under content instruction $(M=4.32)$. New faculty to CBE (less than one year) produced the lowest mean in the interaction construct $(M=3.17)$. Support and intervention means by subgroup had the smallest range between extreme means (3.44 - 3.64). The greatest (3.78 - 4.32) occurred in content instruction.

Higher education experience ranges under this section of the instrument also had consistent means. Ranges of means in influencing factors (3.44 - 4.33) and interaction (3.28 - 3.67) comprised the most and least difference, respectively. The lowest overall 
mean came from faculty with six to ten years' experience and interaction $(M=3.28)$ while the highest occurred in content instruction and faculty with one to five years $(M=$ 4.72). 
Table 4.12. Areas of Self-Efficacy and CBE by Construct and Demographic

\begin{tabular}{|c|c|c|c|c|c|c|c|c|c|c|}
\hline & \multicolumn{2}{|c|}{ Interaction } & \multicolumn{2}{|c|}{$\begin{array}{l}\text { Teaching } \\
\text { Ability }\end{array}$} & \multicolumn{2}{|c|}{$\begin{array}{l}\text { Content } \\
\text { Instruction }\end{array}$} & \multicolumn{2}{|c|}{$\begin{array}{l}\text { Support/ } \\
\text { Intervention }\end{array}$} & \multicolumn{2}{|c|}{$\begin{array}{l}\text { Influencing } \\
\text { Factors }\end{array}$} \\
\hline Demographic & M & $\mathrm{SD}$ & $\mathrm{M}$ & $\mathrm{SD}$ & $\mathrm{M}$ & $\mathrm{SD}$ & M & $\mathrm{SD}$ & M & SD \\
\hline Male & 3.36 & 1.06 & 3.98 & .79 & 4.09 & .88 & 3.58 & 1.06 & 3.48 & .94 \\
\hline Female & 3.44 & 1.23 & 4.11 & .73 & 4.24 & .76 & 3.60 & 1.14 & 3.81 & .95 \\
\hline$<1$ Years CBE & 3.17 & .99 & 3.78 & .65 & 3.78 & 1.11 & 3.44 & 1.34 & 3.61 & 1.09 \\
\hline 1-5 Years CBE & 3.44 & 1.15 & 4.11 & .71 & 4.15 & .86 & 3.60 & 1.05 & 3.77 & .86 \\
\hline 6-10 Years CBE & 3.40 & 1.17 & 4.00 & .89 & 4.32 & .57 & 3.64 & 1.08 & 3.33 & 1.03 \\
\hline $\begin{array}{l}<1 \text { Years Higher } \\
\text { Ed. }\end{array}$ & 3.67 & .58 & 4.00 & 0 & 4.00 & 0 & 4.00 & 1.73 & 4.33 & .58 \\
\hline $\begin{array}{l}\text { 1-5 Years Higher } \\
\text { Ed. }\end{array}$ & 3.61 & 1.42 & 4.56 & .62 & 4.72 & .46 & 3.94 & .94 & 4.06 & .94 \\
\hline $\begin{array}{l}\text { 6-10 Years Higher } \\
\text { Ed. }\end{array}$ & 3.28 & .94 & 3.92 & .66 & 4.03 & .90 & 3.41 & 1.04 & 3.56 & .82 \\
\hline $\begin{array}{l}\text { 11-15 Years } \\
\text { Higher Ed. }\end{array}$ & 3.33 & 1.03 & 3.72 & .75 & 3.94 & .94 & 3.33 & .97 & 3.44 & 1.15 \\
\hline $\begin{array}{l}\text { 16-20 Years } \\
\text { Higher Ed. }\end{array}$ & 3.50 & .99 & 4.11 & .76 & 4.11 & .58 & 3.56 & 1.15 & 3.61 & .98 \\
\hline $\begin{array}{l}>20 \text { Years Higher } \\
\text { Ed. }\end{array}$ & 3.38 & 1.30 & 4.02 & .85 & 4.15 & .88 & 3.69 & 1.17 & 3.54 & .97 \\
\hline $\begin{array}{l}\text { Industry } \\
\text { Experience }\end{array}$ & 3.33 & 1.12 & 4.08 & .70 & 4.13 & .89 & 3.55 & 1.08 & 3.66 & .94 \\
\hline
\end{tabular}




\begin{tabular}{lllllllllll}
\hline $\begin{array}{l}\text { No Industry } \\
\text { Experience }\end{array}$ & 3.61 & 1.17 & 3.88 & .94 & 4.25 & .62 & 3.73 & 1.15 & 3.52 & 1.00 \\
\hline
\end{tabular}

Finally, faculty with industry experience and those without time spent in the field produced two subsets of results in the manner as gender. Range of differences in this demographic were the closest across any section of questions by construct. Interaction by industry experience holders $(M=3.33)$ and those without experience $(M=3.61$, produced the greatest difference in means. Content instruction conversely produced the smallest, with industry experience $(M=4.13)$ once again lower than their peers without time spent in the field $(M=4.25)$. Experienced faculty had the lowest mean under interaction $(M=3.33)$ while non-experienced had the greatest under content instruction $(M=4.25)$.

\section{$\underline{\text { Survey Results Focused on Institutional Support }}$}

The last section of the survey contained items pertaining to the third research question, "How can institutions better support faculty to teach CBE courses?" Table 4.13 displays an overall result that was, as with means for research questions one and two, generally positive between neutral and agree $(M=3.69)$. This section contained the lowest overall mean of any section of the survey in the construct of learning to teach CBE $(M=3.04)$. The next lowest mean in the section came from the construct of communication and promotion $(M=3.51)$. The two highest construct means came through existing resources $(M=4.01)$ and expectations $(M=4.10)$.

Each item was analyzed for frequency, mean, and standard deviation (see Table 4.14). Items in this section with the lowest means consisted of " 5 . Faculty should take a 
Table 4.13. Overall Results for Institutional Support Ideas and by Construct

\begin{tabular}{lcc}
\hline Construct & $\mathrm{M}$ & $\mathrm{SD}$ \\
\hline Overall Results for Support & 3.69 & .94 \\
Learning to Teach CBE & 3.04 & 1.12 \\
Relationships or Roles & 3.55 & 1.03 \\
Existing Resources & 4.01 & .69 \\
Communication and Promotion & 3.51 & .85 \\
Expectations & 4.10 & .66 \\
Actionable Research & 3.86 & .79 \\
\hline
\end{tabular}

CBE course before teaching one $(M=3.13)$," "1. I learned to teach CBE through a specific training program, such as a course, workshop, or seminar" $(M=3.02)$, and "3. Trial and error or student performance or the most effective way to learn the specifics of CBE" $(M=2.69)$. On the other hand, "Items 8 . Supporting faculty means letting them see a CBE course from a previous term to learn from" $(M=4.06)$, " 7 . To support faculty teaching CBE, they should have ongoing access to an instructional designer even if the course is already designed" ( $M=4.08$, and " 13 . To impact or affect faculty's interest in CBE requires evaluating the infrastructure, compensation, and workload of CBE faculty" $(M=4.33)$ produced the highest means. 
Table 4.14. Institutional Support Frequencies and Measures of Central Tendencies

\begin{tabular}{|c|c|c|c|c|c|c|c|}
\hline Survey item & 1 & 2 & 3 & 4 & 5 & $M$ & $S D$ \\
\hline $\begin{array}{l}\text { 1. I learned to teach } \mathrm{CBE} \\
\text { through a specific training } \\
\text { program, such as a course, } \\
\text { workshop, or seminar. }\end{array}$ & $\begin{array}{c}7 \\
(14.6 \%)\end{array}$ & $\begin{array}{c}13 \\
(27 \%)\end{array}$ & $\begin{array}{c}7 \\
(14.6 \%)\end{array}$ & $\begin{array}{c}14 \\
(29.2 \%)\end{array}$ & $\begin{array}{c}7 \\
(14.6 \%)\end{array}$ & 3.02 & 1.33 \\
\hline $\begin{array}{l}\text { 2. Most of my knowledge } \\
\text { as to teaching CBE came } \\
\text { from self-exploration or } \\
\text { being "thrown into the } \\
\text { deep end."* }\end{array}$ & $\begin{array}{c}1 \\
(2.1 \%)\end{array}$ & $\begin{array}{c}13 \\
(27.6 \%)\end{array}$ & $\begin{array}{c}8 \\
(17 \%)\end{array}$ & $\begin{array}{c}20 \\
(42.5 \%)\end{array}$ & $\begin{array}{c}5 \\
(10.6 \%)\end{array}$ & 3.38 & 1.07 \\
\hline $\begin{array}{l}\text { 3. Trial and error or } \\
\text { student performance is the } \\
\text { most effective way to learn } \\
\text { the specifics of CBE. }\end{array}$ & $\begin{array}{c}3 \\
(6.3 \%)\end{array}$ & $\begin{array}{c}20 \\
(41.7 \%)\end{array}$ & $\begin{array}{c}15 \\
(31.2 \%)\end{array}$ & $\begin{array}{c}9 \\
(18.8 \%)\end{array}$ & $\begin{array}{c}1 \\
(2 \%)\end{array}$ & 2.69 & 0.93 \\
\hline $\begin{array}{l}\text { 4. Faculty new to CBE } \\
\text { must have a mentor or co- } \\
\text { teacher the first time they } \\
\text { teach CBE. }\end{array}$ & $\begin{array}{c}1 \\
(2 \%)\end{array}$ & $\begin{array}{c}6 \\
(12.5 \%)\end{array}$ & $\begin{array}{c}8 \\
(16.6 \%)\end{array}$ & $\begin{array}{c}26 \\
(54.3 \%)\end{array}$ & $\begin{array}{c}7 \\
(14.6 \%)\end{array}$ & 3.67 & 0.95 \\
\hline
\end{tabular}

5. Faculty should take a CBE course before teaching one.

\section{2}

$(4.2 \%)$

17

$(35 \%)$
10

$(20.8 \%)$

\begin{abstract}
11
\end{abstract}
$(23.4 \%) \quad(16.6 \%)$
$3.13 \quad 1.20$

\section{Creating mentorship} programs or cohorts to share resources, experiences, and concerns would lead to a feeling of support.*

7. To support faculty teaching CBE, they should have ongoing access to an instructional designer even if the course is already designed.

$\begin{array}{ccccccc}0 & 1 & 13 & 25 & 8 & & \\ (0 \%) & (2.1 \%) & (27.7 \%) & (63 \%) & (21.2 \%) & & \end{array}$

$\begin{array}{ccccccc}0 & 2 & 5 & 28 & 13 & & \\ (0 \%) & (4.2 \%) & (14.7 \%) & (58.3 \%) & (22.8 \%) & & 0.74\end{array}$


8. Supporting faculty means letting them see a CBE course from a previous term to learn $\begin{array}{ccccccc}0 & 1 & 4 & 34 & 9 & 4.06 & 0.60 \\ (0 \%) & (2 \%) & (8.3 \%) & (70.8 \%) & (18.9 \%) & & \end{array}$ from.

9. The support of faculty in other modalities can be easily applied to supporting CBE faculty.

$\begin{array}{ccccccc}1 & 1 & 13 & 25 & 8 & 3.79 & 0.82 \\ (2 \%) & (2 \%) & (22.8 \%) & (52 \%) & (16.6 \%) & & \end{array}$

10. To get faculty buy-in to $\mathrm{CBE}$ requires a grassroots approach versus one that is top down.

$\begin{array}{ccccccc}0 & 2 & 20 & 17 & 9 & 3.69 & 0.83 \\ (0 \%) & (4.2 \%) & (41.7 \%) & (35.3 \%) & (18.8 \%) & & \end{array}$

11. Faculty would view CBE more positively if there was a logicalemotional appeal.

$\begin{array}{ccccccc}0 & 6 & 25 & 12 & 5 & 3.33 & 0.83 \\ (0 \%) & (12.5 \%) & (52.1 \%) & (25 \%) & (10.4 \%) & & \end{array}$

12. The institution needs to clarify expectations for delivery of CBE to improve perceptions.

$\begin{array}{ccccccc}0 & 0 & 12 & 25 & 11 & 3.98 & 0.70 \\ (0 \%) & (0 \%) & (25 \%) & (52 \%) & (23 \%) & & \end{array}$

13. To impact or affect faculty's interest in CBE requires evaluating the infrastructure, compensation, and

$\begin{array}{ccccccc}0 & 0 & 3 & 26 & 19 & 4.33 & 0.60 \\ (0 \%) & (0 \%) & (6.3 \%) & (54.2 \%) & (39.5 \%) & & \end{array}$
workload of CBE faculty.

14. Clarifying student benefits would help improve perceptions of CBE.

15. Showcasing student or faculty success stories would improve how faculty view $\mathrm{CBE}$.

$\begin{array}{ccccccc}0 & 0 & 9 & 29 & 10 & 4.02 & 0.64 \\ (0 \%) & (0 \%) & (18.9 \%) & (60.4 \%) & (20.7 \%) & & \end{array}$

$\begin{array}{ccccccc}0 & 0 & 12 & 24 & 12 & 4.00 & 0.71 \\ (0 \%) & (0 \%) & (25 \%) & (50 \%) & (25 \%) & & \end{array}$


16. Realignment with industry partners and leading CBE institutions would improve its views on campus.

17. I think faculty would like to create $\mathrm{CBE}$ versions of courses they currently teach based on what they may learn about CBE.

$\begin{array}{ccccccc}0 & 0 & 16 & 22 & 10 & 3.88 & 0.73 \\ (0 \%) & (0 \%) & (33.3 \%) & (45.8 \%) & (20.8 \%) & & \end{array}$

$\begin{array}{ccccccc}2 & 2 & 15 & 21 & 8 & 3.65 & 0.96 \\ (4.2 \%) & (4.2 \%) & (31.2 \%) & (43.8 \%) & (16.6 \%) & & \end{array}$

$1=$ strongly disagree, 2 = disagree, $3=$ neutral, $4=$ agree, $5=$ strongly agree

*One faculty did not select an option for this item $(N=47)$

I then compared the results for each construct by gender (see Table 4.15). Gender differences were more pronounced than in research question one. Females had both extreme means with the lowest under learning to teach CBE $(M=2.99)$ and the highest mean under expectations $(M=4.23)$. By difference in means, the smallest difference emerged in learning to teach CBE with males $(M=3.06)$ having a higher mean than females $(M=2.99)$. Conversely, existing resources comprised the construct with the most notable gap with the mean for females $(M=4.10)$ higher than males $(M=3.90)$.

CBE faculty experience ranges and their scores comprised the next section of analysis. The lowest mean overall occurred similarly as in other research questions from the one to five years' experience subgroup $(M=2.99)$. Conversely, the highest overall mean, from the same subgroup, came from expectations $(M=4.13)$.

Range differences were the greatest in relationships or roles construct $(3.11-3.82)$ and least in communication and promotion (3.5 - 3.58). Table 4.15 also displays spans of faculty experience in higher education. By range, the relationships and roles $(3.22-4.11)$ and communication and promotion (3.33 - 4.22) jointly had the greatest difference. 
Expectations as a construct had the smallest difference (3.95 - 4.18). Learning to teach CBE produced the smallest mean $(M=2.78)$ by faculty with 11 to 15 years in higher education. Faculty with one to five years of experience in higher education had the greatest mean $(M=4.390)$. Experience in the industry again consisted of the final demographic area examined by construct for this part of the survey. The largest spread in means occurred in actionable research with no industry experience $(M=4.10)$ higher than experience $(M=3.79$,$) . The smallest difference came under learning to teach \mathrm{CBE}$, though with industry experience $(M=3.05)$ higher than none $(M=3.03)$. 
Table 4.15. Institutional Support Ideas by Construct and Demographic

\begin{tabular}{|c|c|c|c|c|c|c|c|c|c|c|c|c|}
\hline \multirow[b]{2}{*}{ Demographic } & \multicolumn{2}{|c|}{$\begin{array}{l}\text { Learning to } \\
\text { Teach CBE }\end{array}$} & \multicolumn{2}{|c|}{$\begin{array}{l}\text { Rel. \& } \\
\text { Roles }\end{array}$} & \multicolumn{2}{|c|}{$\begin{array}{c}\text { Existing } \\
\text { Resources }\end{array}$} & \multicolumn{2}{|c|}{$\begin{array}{l}\text { Comm. \& } \\
\text { Promotion }\end{array}$} & \multicolumn{2}{|c|}{$\begin{array}{c}\text { Expect- } \\
\text { ations }\end{array}$} & \multicolumn{2}{|c|}{ Action Res } \\
\hline & M & SD & M & SD & M & $\mathrm{SD}$ & M & SD & M & SD & M & SD \\
\hline Male & 3.06 & 1.19 & 3.61 & 1.02 & 3.90 & .73 & 3.37 & .84 & 3.95 & .62 & 3.72 & .79 \\
\hline Female & 2.99 & 1.06 & 3.44 & 1.07 & 4.10 & .73 & 3.62 & .93 & 4.23 & .79 & 3.98 & .85 \\
\hline$<1$ Years CBE & 3.39 & 1.20 & 3.11 & .83 & 4.00 & .97 & 3.58 & .79 & 3.95 & .64 & 4.00 & .59 \\
\hline 1-5 Years CBE & 2.99 & 1.11 & 3.52 & 1.08 & 4.10 & .57 & 3.50 & .91 & 4.13 & .67 & 3.86 & .81 \\
\hline $\begin{array}{l}\text { 6-10 Years } \\
\text { CBE }\end{array}$ & 3.00 & 1.12 & 3.82 & .93 & 3.85 & .74 & 3.50 & .76 & 4.10 & .64 & 3.79 & .83 \\
\hline $\begin{array}{l}<1 \text { Years } \\
\text { Higher Ed. }\end{array}$ & 3.33 & .58 & 3.67 & .58 & 3.33 & .58 & 4.00 & 0 & 4.00 & 1 & 4.00 & 0 \\
\hline $\begin{array}{l}\text { 1-5 Years } \\
\text { Higher Ed. }\end{array}$ & 3.00 & 1.22 & 4.11 & 1.02 & 4.22 & .43 & 3.75 & .97 & 4.17 & .51 & 4.39 & .50 \\
\hline $\begin{array}{l}\text { 6-10 Years } \\
\text { Higher Ed. }\end{array}$ & 3.13 & 1.17 & 3.44 & 1.02 & 4.00 & .69 & 3.54 & .96 & 3.95 & .69 & 3.79 & .73 \\
\hline $\begin{array}{l}\text { 11-15 Years } \\
\text { Higher Ed. }\end{array}$ & 2.78 & 1.40 & 3.22 & 1.00 & 3.78 & 1.17 & 3.25 & .45 & 4.17 & .92 & 3.67 & .84 \\
\hline $\begin{array}{l}\text { 16-20 Years } \\
\text { Higher Ed. }\end{array}$ & 3.06 & 1.06 & 3.88 & .99 & 3.89 & .58 & 3.33 & .98 & 4.11 & .58 & 3.78 & 1.00 \\
\hline $\begin{array}{l}>20 \text { Years } \\
\text { Higher Ed. }\end{array}$ & 3.07 & 1.01 & 3.42 & 1.01 & 4.13 & .50 & 3.63 & .81 & 4.18 & .58 & 3.80 & .79 \\
\hline $\begin{array}{l}\text { Industry } \\
\text { Experience }\end{array}$ & 3.05 & 1.14 & 3.50 & 1.04 & 4.00 & .75 & 3.41 & .84 & 4.07 & .67 & 3.79 & .80 \\
\hline $\begin{array}{l}\text { No Industry } \\
\text { Experience }\end{array}$ & 3.03 & 1.03 & 3.73 & .98 & 4.07 & .37 & 3.90 & .79 & 4.20 & .61 & 4.10 & .71 \\
\hline
\end{tabular}


This latter mean $(M=3.03)$ also constituted the smallest in the demographic area. Faculty without industry experience also possessed the highest mean under the expectations construct $(M=4.20)$.

\section{Chapter Summary}

The purpose of this study was to explore faculty perceptions of competency-based education, their self-efficacy in areas of teaching CBE, and ideas for institutional support of CBE faculty. First phase interviews $(N=10)$ provided insight into both positive and negative views of CBE by its faculty along with ratings of self-efficacy in areas of teaching and ideas for how Five Rivers can support CBE faculty. The responses in phase one inspired the creation of a survey in phase two administered to CBE faculty $(N=65)$. Results measured the same areas as the interviews and produced generally positive results in all areas. Because the study used a mixed methods exploratory sequential design, the results of both phased must be integrated and presented by key findings. Chapter five will encapsulate these key findings, theoretical considerations, and practical implications. 


\section{CHAPTER FIVE: DISCUSSION}

Competency-based education (CBE) has roots in the late 1800s (Duemer, 2007) but is currently growing in higher education (AIR, 2019). The purpose of this study was to explore faculty views of competency-based education and its tenets, the self-efficacy of faculty in various areas that encompass CBE teaching, and what views CBE faculty have of institutional support for current or potential CBE faculty. The study used a mixed methods exploratory sequential design composed of interviews with CBE faculty members followed by a survey to CBE faculty. Data from both phases of the study were used to answer the research questions guiding this study. This chapter provides a discussion of the key findings, their contribution to theory, implications of the study to a large audience, limitations, and recommendations for future research.

\section{Discussion of Key Findings}

Integration of results from both phases of this study produced five key findings, two of which connect to research question one, a single finding for research question two, and finally two findings related to research question three. First, faculty had positive views of CBE with respect to its student-centeredness and success potential. Second, faculty also had some critical or negative views of CBE focused on inward-facing faculty issues such as shifts in roles and institutional infrastructure. Third, faculty reported that an overwhelming need exists for faculty to engage with mastery experiences, repetition, and related experience teaching CBE courses to support stronger self-efficacy. Fourth, faculty reported a desire for specific learning opportunities to continually refine the 
ability to teach CBE. Fifth, faculty insisted that collaborative approaches for improvement and success were paramount to shifting views of $\mathrm{CBE}$ and growing as practitioners. The following sections detail each of these findings.

Finding \#1: Positive Views Tied to a Student Focus

The first research question focused on CBE faculty's views of CBE. The interview and survey results indicate that faculty generally viewed competency-based education in a positive light mainly because of its focus on student success, especially with respect to supporting student paths to completion. In fact, student focus had the highest mean of all constructs connected to views of CBE on the survey $(M=4.35)$. In particular, faculty identified $\mathrm{CBE}$ as an enabling mechanism for successful completion, employment empowerment, vocational connections, and innovation for the future.

\section{An Enabling Mechanism for Successful Completion}

Faculty's view of student-centeredness led to the belief that CBE was an enabling mechanism for successful completion, thus suggesting that $\mathrm{CBE}$ was geared towards the student with a busy life compared to a traditional post-secondary learner. For example, David indicated that pacing was a benefit, and Paul lamented the lack of time connected to the classroom in lieu of freeing learners to complete work on a pace suitable to their needs. Quantitatively, responses to survey item five $(M=4.35)$ leaned towards strong feelings of agreement for this view from the larger sample. This generalized view of student-centeredness found in this study reflected the findings of others. Gruppen et al. (2016) explained that in CBE, time is variable while outcomes are more set. Weise (2014) noted the way CBE permits learners to focus on their work based on their schedule in a flexible manner prevents them from falling behind. Students also indicate 
this view as a strong point of CBE. Wang (2015) found $85 \%$ of students favored CBE over traditional models due to the flexibility of courses and programs.

\section{$\underline{\text { Employment Empowerment }}$}

Faculty also liked CBE's ability to improve certain students' employment standing or economic mobility. For instance, when asked if CBE was a niche for a select group of students, on average faculty responses were between agreement and strong agreement $(M=4.04)$. This finding aligns with Henrich (2016) who noted employers were interested in learning more about how CBE can support their demands for a strong workforce. Others (e.g. Dragoo \& Barrows, 2016; Grann, 2017) tied the competencies used in $\mathrm{CBE}$ to a direct vocational or career-related end goal. Faculty indicated that the use of $\mathrm{CBE}$ to prepare the workforce further was a positive element. In certain responses, such as that of Tom and Allison, the right fit to the right student for CBE meant a sense of specific centeredness between learning and outcome in the workplace existed. This finding supports that of Clerkin and Simon (2014) who implored content and other partnerships between institutions and employers are vital to success of CBE programs.

\section{$\underline{\text { Strong Vocational Connections }}$}

Other survey sections related to student-centeredness noted a shift from traditional, paced approaches to learning in favor of more rapid opportunities to complete coursework with prior knowledge in mind. The survey section for this aspect, theory and background, had both a high overall result $(M=4.27)$ and similarly high results by demographic. Further results related to student focus also indicated strong agreement with this stance both overall $(M=4.65)$ and in item six inquiring about student ability to apply prior knowledge $(M=4.35)$. This finding supports those of others. Wax and Klein- 
Collins (2015) shared that CBE can benefit the employer because students in CBE programs can emphasize their skills from a real-world setting, and thus in the workplace this authentic experience is beneficial to all. Bornitz and Carnaghan (2003) noted competencies, at their root, are inclusive and meant to directly measure a specific careeroriented outcome and growth. The present study further supported this student-toemployer conduit with faculty arguing the ability for students to bring job experience, learn further skills, and then re-enter or improve mobility in the workplace as a critical element.

\section{Innovation and the Future of Learning}

Finally, faculty valued CBE as an innovative approach to learning. Responses notably that of Mark suggested that CBE was transformative for both student learning and faculty, and ultimately the path along which education should travel. Recent calls from shareholders support Mark's view and indicate traditional models of education are in critical need of review (Soulunii, 2019). Weise (2014) observed CBE connected learning to the needs of industry as an innovative workforce solution.

Finding \#2: Negative Views Concern Shifts and Changes

While CBE faculty views of CBE were largely positive, the second key finding of this study, also connected to the first research question, indicated that when faculty looked inward at Fiver Rivers' approach to CBE, views were more negative. The results from three interview questions and three questions on the survey identify some concerns faculty had with CBE, namely: initial involvement, shifts in faculty roles, and CBE infrastructure. 


\section{$\underline{\text { Initial Involvement }}$}

Faculty reported unanimously in interviews a moderate degree of pressure to participate in CBE. While some faculty, such as Tom or Mark, began teaching in CBE because of institutional needs, others, such as Erin, Paul, and Claudia felt obligated, either from industry or past experience in similar programs, to participate in CBE. The interviews did not clarify if faculty ultimately perceived the pressure to participate in CBE positively or negatively. Two survey questions though did ask participants if their involvement was through their own interest $(M=3.13)$ or due a next step for their career $(M=3.08)$. The results though on a five point scale averaged above the midpoint of the scale. This indicates the larger pool of faculty also felt pressured to get involved in CBE though it is still unclear if this pressure was viewed as positive or negative.

\section{Changes to Faculty Roles and Responsibilities}

A common cited criticism of CBE is the disaggregated role of faculty (Neem, 2013; Ohio Department of Higher Education, 2016). Results from this study were mixed but did reflect this concern. For instance, during the interviews in phase one of the study, faculty expressed frustration over their role with grading and oversight, as well as their dislike of increased roster size, student effort (e.g., procrastination) and compensation per student. However, when asked if they viewed the CBE workload as unmanageable compared to other course delivery formats during phase two of the study, faculty responded quite low $(M=2.65)$. Further, the results suggest that faculty took on a role as more of a guide or mentor in $\mathrm{CBE}$ courses than they did when teaching traditional courses $(M=3.75)$. These variable results indicate that faculty views, though mixed, 
were related to common criticisms of CBE yet still focused on student success as faculty moderately embraced newer roles.

One can find some parallels in the literature. For instance, Burnette (2016) noted faculty shift to a role of guide or mentor, and Monahan (2015) found faculty grapple with adapting to this change. A shifting role was also cause for concern among Five Rivers faculty because of the role of others in the CBE process. Lieberman (2019) indicated the use of multiple parties for CBE implementation broke connections between students and faculty. Boyer and Bucklew (2019) found faculty were often paid for assuming more than one role. Though these concerns from faculty were warranted, there were none expressed of faculty moving towards an unnecessary role as Robbins (2017) worried.

\section{Infrastructure Changes}

Another related finding focused on the need for infrastructure shifts at the institutional level. Results from both the survey and the interviews suggest that the way Five Rivers implemented CBE is not working as well as it should be. This is likely because the initial roll-out of CBE at Five Rivers occurred using existing systems and processes. The issue was that such mechanisms were used for traditional enrollment, course delivery, and teaching as opposed to those for CBE. Responses to survey item eight, "I am satisfied with the way our institution uses CBE" had the fourth-lowest overall score of questions related to perceptions $(M=3.33)$.

Comparatively other institutions, such as Western Governors University, are a CBE-first institution which built its infrastructure around CBE. Robbins (2017) and Viola (2016) cautioned this notion as traditional institutional systems were not made for the CBE approach. Further, Boyer and Bucklew (2019) surveyed 14 institutions with CBE 
and found serious flaws in the integration of different systems and processes when implementing CBE. Their key recommendation was further exploration of the interplay amongst systems that support CBE and to determine ways to create a specific set of structures. With the decade-long existence of CBE at Five Rivers, shifts have not been rapid enough to address certain issues which reflects the finding by Lieberman (2019) that many colleges and universities lack the ability to transfer operations quickly to enact needed changes.

Finding \#3: The Importance of Repetition and Experience

The third key finding in this study related to research question two (i.e. faculty self-efficacy views and influences). Results suggested prior experience and repeated practice at teaching CBE had a significant impact on CBE faculty self-efficacy. Mastery experiences cull together both factors and serves as a source of self-efficacy (Bandura, 1977; Muretta, 2004). During interviews, responses noted the importance of prior experience and repetition. For example, two faculty detailed their growth in CBE teaching confidence based on reflection and revision of ways to connect with $\mathrm{CBE}$ students. Faculty who connected their experiences term to term tended to have higher self-efficacy. Survey results also supported this finding. For example, on item three in the self-efficacy section that asked about reflection on confidence with interaction with students produced a moderately high score $(M=3.50)$. This result suggests the importance of repeated teaching and reflecting on one's performance can yield stronger self-efficacy.

The other aspect of this finding is interesting related to one of the main tenets of $\mathrm{CBE}$ as a concept. Students in CBE desire the chance to demonstrate what they know 
from prior experience. Consequently, faculty teaching CBE tended to feel more confident when they could call on their prior experience whether from teaching in other modalities or from industry. Tom, Donna, and Peter noted the importance during interviews of their time spent in the field, from formal paths of training, or longevity of teaching in CBE. There were five items on the second section of the survey addressing self-efficacy that support this particular finding. Faculty reported high ratings on items asking about existing confidence $(M=4.19)$, experience in industry translating to confidence in CBE $(M=3.68)$, experience teaching in other modalities $(M=4.23)$, content mastery from experience $(M=4.09)$, and similar feelings of confidence based on other modalities ( $M=$ 4.17). An additional survey item in this section asked about the relationship of confidence in CBE and student performance or feedback and produced similar results $(M=3.48)$. This item supports the combination of reflection and experience.

This finding is supported by the existing notion in the literature that strong selfefficacy impacts an educator's ability in the learning process (e.g. Morris \& Usher, 2011; Tschannen-Moran \& Woolfolk Hoy, 2007; Wertheim \& Leyser, 2002, Woolfolk Hoy, 2004). This finding also supports Lopez and Lent's (1992) finding that in specific contexts of learning, mastery experiences were the most influential factor on selfefficacy. The results further reflect those of Morris and Usher (2011). Though focused on verbal persuasion, they found among higher education faculty influences such as student feedback (in their case praise) positively affected self-efficacy. Finding \#4: Specific Learning Opportunities

The final research question focused on how faculty felt institutions can better support faculty in teaching CBE courses. Results from the interviews and survey suggest 
that faculty need specific learning opportunities to not only initially learn how to teach CBE but also to refine their approach as they gain more experience. During the interviews, faculty identified a number of ways institutions can better support CBE faculty, often based on their own experience learning to teach CBE courses. For instance, faculty suggested formal training programs, mentorship, allowance for trial and error or exploration of courses from prior terms, and opportunities to explore and understand available resources to help them succeed.

The survey results, though, suggested that perhaps there is not one right way to prepare and support faculty to teach CBE courses. For instance, for those new to CBE, faculty reported neutrality with learning to teach CBE through a formal program $(M=$ 3.02) and disagreed with trial and error as the most effective way to learn $(M=2.69)$. Though this result leans towards the negative side of the scale, it simply suggested that other learning opportunities may be better suited for learning. Faculty reported similarly positive results in regards to their knowledge of teaching $\mathrm{CBE}$ coming from exploration 'in the deep end' $(M=3.38)$ and the suggestion that faculty should take a CBE course themselves before teaching one $(M=3.13)$. A further item positing exploration of a $\mathrm{CBE}$ course from a prior term would support those learning to teach CBE promoted a stronger result between agree and disagree $(M=4.06)$. The suggestion of multiple ways to prepare faculty to teach CBE means that institutions can sufficiently meet the needs of faculty who come to CBE from many different backgrounds. In terms of support for existing faculty, responses to an item asking about transition of support in other modalities were positive $(M=3.79)$ as were those to items asking about mentorship cohorts $(M=3.85)$ and access to support staff such as instructional designers $(M=4.08)$. 
This finding reflects similar results from the literature such as the notion put forth by Oleson and Hora (2013) that faculty often enter fully armed with content expertise but lacking in formal teaching preparation. The need for specific learning experiences, especially over time teaching CBE, reinforces Koellner and Jacobs' (2015) stance that faculty development practices must exist on a continuum. This is further true according to Steinert (2014) who noted faculty development is about improving ability and action, not singularly defining these aspects of teaching at the onset of one's career. Dath and Iobst (2010) found CBE faculty needed to know about the approach as a whole when new to teaching CBE courses along with learning opportunities for how to teach CBE and understand its assessments. The different suggestions for faculty development espoused by responses also reflect the findings of Stes et al. (2009). Their meta-analysis of articles on faculty development determined learning experiences for instructors should focus on subdomains (i.e. instructional attitudes, concepts of teaching, skills, etc.) as part of a larger institutional push for alignment of teaching practice to institutional priorities. Given Five Rivers' college-wide adoption, spread, and growth of CBE, this finding is appropriate for Five Rivers and its CBE faculty. Finally, McClean et al. (2008) found the use of a tutorial on CBE that used the CBE approach successful for faculty. This study's faculty have at their disposal a similar training course which many faculty took and noted its usefulness.

\section{Finding \#5: Working Together to Improve}

The final key finding of this study was the perceived importance of CBE faculty to work in a collaborative environment. Such an environment must include mentorship and peer support geared towards improving overall teaching of CBE courses. This 
finding aligns with the role vicarious experiences play with self-efficacy. Research has shown that the use of a mentor or guiding party can positively affect the self-efficacy of the mentee (Bandura, 1977). In the case of faculty development, this relationship can also prove fruitful. Interview results noted mentorship was a two-way street with both new and experienced faculty able to benefit from working together. This way, support can exist over the career of a faculty member and not just at the beginning. They also noted that mentorship and peer support were not just between faculty but included other parties. For example, Donna discussed her oversight of new faculty members while Claudia detailed how she worked with a campus-wide team to improve her abilities. Finally, Cheryl worked with a third-party content provider to successfully teach her courses.

Survey results painted a similar picture for collaboration and mentorship through three items. First, those new to CBE should have a mentor or co teacher $(M=3.67)$, a mentorship program should exist for sharing of experiences, resources, and concerns ( $M$ $=3.85$ ), and faculty should have access to an instructional designer even if the course was already designed and implemented $(M=4.08)$.

This finding reflects many in the literature. Matthias (2019), who noted the importance of specific learning experiences as detailed in the section, also noted the importance of faculty working together under encouragement with peers. This finding also connects the present research to the literature reviews of Steinert et al. (2016) and Stes et al. (2009). Their themes included the importance of a community of practice for long-term success in development opportunities. Dath and Iobst (2010) noted new faculty need many experiences for success in teaching CBE. Notably, though, Dath and Iobst (2010) emphasized a lack of exclusivity and balance. Moreover, McLean et al. (2008) 
argued for balance as well, similarly to faculty in interviews, that faculty new to teaching CBE must learn about teaching as a whole and teaching within a field of specialization. When combined with the views of faculty in this study, it is clear that collaboration through mentorship and peer support are paramount to the success of faculty when beginning to teach CBE courses at Five Rivers.

\section{Summary of Key Findings}

Five key findings were identified from the results that help to answer the research questions. First, faculty generally viewed $\mathrm{CBE}$ as a positive approach to teaching and learning, namely due to its benefits for students. Conversely, the second key finding was that despite CBE faculty's positive views of CBE, they were concerned with how faculty are often pressured to initially become involved with CBE, shifts in faculty roles and responsibilities, and changes to institutional infrastructure that cause poor views of CBE. The third finding was the importance of prior experience and repetition to improve selfefficacy in the practice of teaching CBE. The fourth finding noted the importance of specific learning opportunities to prepare and support faculty as they teach CBE. The fifth and final key finding was the importance of collaboration and mentorship to develop and help CBE faculty grow in practice over their careers.

\section{Theoretical Contributions}

The present study provides two connections to self-efficacy theory described in the theoretical framework in chapter two, which I will briefly discuss below. $\underline{\text { Sources of Self-efficacy }}$

Bandura (1977) contended that self-efficacy ultimately drives a person's success in challenges. He and others (e.g. Muretta, 2004) suggest four sources of self-efficacy 
(see chapter 3). This study's findings contributed to Self-efficacy Theory through its four sources. First, mastery experiences were clearly noted by faculty in their interview responses as largely important to supporting strong self-efficacy in teaching CBE courses. Survey responses on mastery also supported their importance. This finding not only echoes Muretta (2004) and Bandura (1977) but also Tschannen-Moran and Woolfolk Hoy (2007) who found mastery experiences were the most significant predictor of self-efficacy over long-term careers.

Though mastery experiences comprised the most notable source mentioned, the other sources of vicarious experiences, verbal persuasion, and physiological states were present as well. Faculty emphasized the importance of peer relationships and mentorship (both a type of vicarious experience) for success in teaching CBE through both interview responses and corresponding survey results as a key finding of this study. Further research is needed to better understand the nature of this relationship. Verbal persuasion refers to the importance of feedback as told to the individual and was not largely present in the study. Faculty, though, did indicate using student feedback to reflect on their performance in $\mathrm{CBE}$ courses affected their self-efficacy. This finding was similar to Morris and Usher's (2011) that student praise influenced self-efficacy. Finally, physiological states (i.e. the feeling or doing well or not) lacked significant presence in this study, and the limited instances of this source yielded mixed states. As an example, faculty reported that interaction with $\mathrm{CBE}$ students yielded both positive and negative feelings and accordingly influenced self-efficacy. This mixed result partly echoed the finding of Cansiz and Cansiz (2019) that views of education were influenced by physiological states. 


\section{$\underline{\text { Self-efficacy Scales }}$}

Bandura's concept of self-efficacy is more than forty years old (1977). In that time, many scales emerged to measure self-efficacy and its different aspects such as handling student situations and needs (Sherer at al., 1982 or the role of individual traits on self-efficacy (Woodruff \& Cashman, 1993). In the present study, rather than use an existing scale, the interview questions were created based on Bandura's (2006) Guide for Creating Self-efficacy Scales. The present study supports this Guide because of its further use in a research study and the creation of context-specific instruments based on its suggestions. The instrument used for the survey was then based in part on the Guide because the items were derived from interview responses. This process is the hallmark of the exploratory sequential mixed methods design (Creswell, 2015). Though the survey was not field tested, it did return a high Cronbach's alpha reliability measure (42 items; a $=.86)$.

\section{Limitations of Study}

Mixed methods approaches present a number of inherent challenges. Creswell (2015) argues the approach is cumbersome with many possible paths. Thus, there is potential for limitations. Below, I identify three limitations to the present study.

The first limitation is the role of the researcher at the research site as an employee, a concern discussed with respect to validity in chapter three. To address this issue, I placed emphasis on remaining objective and unbiased in conducting the research by bracketing out my own experience. This led to context such as the pertinent role of an instructional designer on CBE courses at Five Rivers. 
A second limitation is the limited local scope of the research. The sample in the study came from a single institution (i.e. single research site) and was limited to a small population of CBE faculty $(N=63)$. This presents a challenge to make connections on a larger scale to other colleges or universities, for example. Further, interpretation of findings included a discussion of the local context of the research site further exacerbating transferability to another institution.

A final limitation is the overall generalization of findings. Though mixed methods can be rigorous and well-defined, the exploratory sequential design is quite broad. As such, more research on a larger scale (i.e. multiple institutions, a larger sample, etc.) is needed to make results more generalizable. This limitation concerns the CBE field more as a whole as there are many areas that warrant further inquiry. Despite these limitations, the study was still practically significant (Tracy, 2010) as it shed light on current problems of practice and can serve as a starting point for other research.

\section{Suggestions for Future Research}

While the three identified limitations may affect applicability of the results, the findings of the present study do provide insight into views of CBE, self-efficacy, and institutional support ideas. Further research can delve deeper into each of these areas.

Perhaps the most salient opportunity for further research is replication of the study to larger samples in multiple contexts versus one institution. Since CBE is a newer approach on college and university campuses, few faculty came into teaching with any $\mathrm{CBE}$ experience and this is likely the case at other institutions as well. A further study could incorporate multiple campuses completing the same instruments and then compare findings. If the context of a single institution is necessary, a longitudinal study over time 
may provide further insights into CBE. Research looking at breakdowns by demographics across different contexts may further provide understanding of faculty views of CBE, self-efficacy, and institutional support.

The results of this study noted the overwhelming importance of prior experience and repetition through mastery experiences. This finding is an indirect limitation of sorts as it only came about due to responses of faculty. In that sense, further research can focus on mastery experiences (as a source of self-efficacy) as a standalone focus of inquiry. The same could be done for other sources of self-efficacy in the context of teaching CBE. Developing an instrument focused on each of these sources would provide more focused results.

The instruments used in the present study also provide an opportunity for research. Though the interview questions and survey items drew inspiration from other sources, they were created as standalone pieces. Replication along with an analysis of the psychometric properties of each would include more rigorous tests for reliability and validity and potentially increase opportunities.

Finally, research concerning institutional support for CBE constitutes a further opportunity. Examining developed support programs designed for CBE faculty may shed light on their effectiveness. Assessment of such programs and their connections to faculty self-efficacy could provide connections between support and self-efficacy perceptions. Regardless of path, the opportunity for further research can contribute to the larger field.

\section{Conclusion and Implications}

Findings in the present study contribute to the field and its literature on faculty perceptions of competency-based education, self-efficacy of CBE faculty while 
answering the research questions. Though limitations were present, findings do provide a practical starting point for Five Rivers and other institutions and their CBE programs along with the field as a whole. There are six practical contributions from the present study to discuss.

First, the results demonstrated that CBE faculty have deep yet balanced views of CBE. Positively, it is a student-centered approach for certain students while critically, infrastructural concerns over faculty roles exist. Colleges and universities with CBE already implemented can continue examining how individual programs can use CBE to support students from the populations they serve, especially in high-demand vocational fields. As the economy shifts due to the COVID-19 pandemic, employer demands will likely change. To respond to these shifts, campuses will need to supply graduates faster and more efficiently; $\mathrm{CBE}$ can support this need. By using the views of CBE found through this study, such colleges and universities can better prepare themselves for using this approach if warranted.

Second, for institutions not already using CBE, this study adds to the potential value proposition its benefits can provide. Chapter two provided six program vignettes of CBE. Looking comprehensively at the reasons the described institutions adopted CBE and the contributions of this study, CBE can move from possibility to actuality. Student benefits can provide marketing opportunities especially in early stages of adoption. Critical views of CBE reflected in this study enable an institution to ensure it considers the challenges faced by Five Rivers in its own iteration and eliminate them at the onset versus after implementation. 
Third, the study provides an understanding of how faculty connect self-efficacy to their execution of teaching CBE classes especially through mastery and practice. Persistent teaching of $\mathrm{CBE}$ courses enabled faculty to view success as possible and improve confidence. In this sense, faculty had more confidence in their abilities related to key areas of teaching and improvements over time.

Fourth, the study provided evidence that specific opportunities for learning and growth through sustained institutional support were preferred by CBE faculty. Given the importance of repetition and practice, this contribution means that sustained, ongoing opportunities for experienced faculty must exist in complement to those for new faculty to $\mathrm{CBE}$. This contribution makes sense especially for cases where CBE has existed for a while as opposed to new iterations. However, over time, a college or university's ongoing use of CBE must include further faculty development naturally as the program grows.

Fifth, the study helps solve the grey literature problem facing the scholarship around competency-based education. Many scholars (e.g. Boyd et al, 2018; Daughtery et al., 2015) noted CBE works are often non-empirical pieces describing the history of CBE or simply suggestions for policy or implementation. This study's findings were derived from an empirical mixed methods approach thus helping solve this problem and add to the field properly.

Finally, this study contributes to extending and expanding the use of self-efficacy scales. While further research is needed to critique the reliability and validity of the instruments used, they were created under formative conditions using the BRUSO framework (Fowler \& Cosenza, 2008; Peterson, 2000). As such, future research using these tested scales would continue to contribute to Self-efficacy Theory. 
Competency-based education will continue to grow on college and university campuses well into the 2020s. For institutions already using this approach, there are many considerations for supporting faculty who teach CBE courses and their selfefficacy. This study's results will help to inform the conversation around CBE to avoid discounting the important role support plays on self-efficacy. Further, the connection between providing faculty with learning opportunities and mastery experiences needed to display confidence in teaching CBE programs means planners must consider many different approaches. This will ensure a culture of support can exist and that CBE programs will be successful because the faculty who teach in them will ultimately be empowered to perform confidently. Institutions will also see how CBE benefits students in dire need of alternatives to traditional education to meet the high demands for a competent and capable workforce into the future. 


\section{REFERENCES}

Adelman, C., Ewell, P., Gaston, P., \& Schneider, C. (2014). The degree qualifications profile. http://degreeprofile.org/wp-content/uploads/2014/09/DQP-webdownload.pdf

Ainsworth, D. (1977). Examining the basis for competency-based education. The Journal of Higher Education, 48, 321-332. https://doi.org/10.1080/00221546.1977.11780362

Akos, P., Wasik, S. Z., McDonald, A., Soler, M., \& Lys, D. (2019). The challenge and opportunity of competency-based education. Counselor Education and Supervision, 58, 98-11. http://dx.doi.org/10.1002/ceas.12134

Albanese, M. A., Mejicano, G., Mullan, P., Kokotailo, P., \& Gruppen, L. (2008). Defining characteristics of educational competencies. Medical Education, 42, 248-255. http://dx.doi.org/10.1111/j.1365-2923.2007.02996.x

Altahawi, F., Sisk, B., Poloskey, S., Hicks, C., \& Dannefer, E. F. (2012). Student perspectives on Assessment: Experience in a competency-based portfolio system. Medical Teacher, 34, 221-225. http://dx.doi.org/10.3109/0142159X.2012.652243

American Institutes for Research. (2019). 2019 State of the field: Postsecondary CBE in the US. https://www.air.org/sites/default/files/National-Survey-of-PostsecondaryCBE-2019-Infographic-rev.pdf

American Public University (APU). (2020). Prior learning assessment for academic credit. https://www.apu.apus.edu/academic/degrees-and-programs/pla.html

Anderson, L. (2016, August 3). 27 is the new 18: Adult students on the rise [Web log Message]. https://ednote.ecs.org/27-is-the-new-18-adult-students-on-the-rise/ 
Artino, A. R., LaRochelle, J. S., Dezee, K. J., \& Gehlbach, H. (2014). Developing questionnaires for educational research: AME Guide No. 87. Medical Teacher, 36, 463-474. http://dx.doi.org/10.3109/0142159X.2014.889814

Ashworth, P. D., \& Saxton, J. (1990). On 'competence.' Journal of Further and Higher Education, 14(2), 3-25. https://doi.org/10.1080/0309877900140201

Austin, A. E., \& Sorcinelli, M. D. (2013). The future of faculty development: Where are we going? New Directions for Teaching and Learning, 133, 85-97. http://dx.doi.org/10.1002/t1.20048

Austin Community College. (2020). What is CBE? https://sites.austincc.edu/cbec/what$\underline{\text { is-cbe/ }}$

Axboe, M. K., Christensen, K. J., Kofoed, P., \& Ammentorp, J. (2016). Development and validation of a self-efficacy questionnaire (SE-12) measuring the clinical communication skills of healthcare professionals. BMC Medical Education, 16 : 272. http://dx.doi.org/ 10.1186/s12909-016-0798-7

Baker, R. B. (2015). The student experience: How competency-based education providers serve students. Center on Higher Education Reform/American Enterprise Institute. http://www.aei.org/wp-content/uploads/2015/06/The-studentexperience.pdf

Bandura, A., (1977). Self-efficacy: Toward a unifying theory of behavioral change. Psychological Review, 84, 191-215. https://psycnet.apa.org/doi/10.1037/0033$\underline{295 X .84 .2 .191}$

Bandura, A. (1986). Social foundations of thought and action: A social cognitive theory. Prentice-Hall.

Bandura, A. (2006). Guide for constructing self-efficacy scales. In F. Pajares \& T. Urdan (Eds.), Self-efficacy beliefs of adolescents (307-337). Information Age Publishing.

Bell, J. (2018). Higher education: Lessons learned. Columbus CEO. https://www. columbusceo.com/business/20180223/higher-education-lessons-learned 
Boatman, A., Hurwitz, M., Lee, J., \& Smith, J. (2017). CLEP me out of here: The impact of Prior Learning Assessments on college completion. Andrew Young School of Policy Studies Research paper Series Np. 17-14.

https://dx.doi.org/10.2139/ssrn. 3080513

Book, P. A. (2014). All hands on deck: Ten lessons from early adopters of competencybased education. WICHE.

Bornitz, J. E., \& Carnaghan, C. A. (2003). Competency-based education and the assessment for the accounting profession: A critical review. Canadian Accounting Perspectives, 2, 7-42. https://doi.org/10.1506/5K7C-YT1H-0G32-90K0

Boyd, V. A., Whitehead, C. R., Thille, P., Ginsburg, S., Brydges, R., \& Kuper, A. (2018). Competency-based medical education: The discourse of infallibility. Medical Education, 52, 45-57. http://dx.doi.org/10.1111/medu.13467

Boyer, N., \& Bucklew, K. (2019). Competency-based education and higher education enterprise systems. The Journal of Competency-based Education, 4. http://dx.doi.org/10.1002/cbe2.1180

Brock, T. (2010). Young adults and higher education: Barriers and breakthroughs to success. The Future of Children, 20(1), 109-132. https://psycnet.apa.org/doi/10.1353/foc. 0.0040

Brower, A. (2014). Flexible option: A direct-assessment competency-based education model. EDUCAUSE Review. https://er.educause.edu/articles/2014/11/flexibleoption-a-directassessment-competencybased-education-model

Brower, A. M., Humphreys, D., Karoff, R., \& Kallio, S. (2017). Designing quality into direct-assessment competency-based education. The Journal of Competencybased Education, 2:e01043. https://doi.org/10.1002/cbe2.1043

Burnette, D. M. (2016). The renewal of competency-based education: A review of the literature. The Journal of Continuing Higher Education, 64, 84-93. http://dx.doi.org/10.1080/07377363.2016.1177704 
Busta, H. (2019, January 14). Western Governors U does not have to pay back $\$ 713$ M in Title IV funds. Education Dive Brief. https://www.educationdive.com/news/western-governors-u-does-not-have-to-payback-713m-in-title-iv-funds/545908/

California Edge Coalition. (2019). Competency-based education: A strategy for skills upgrading in California. https://caedge.org/wp-content/uploads/2019/07/CBEBrief-v3-WEB1.pdf

Cansiz, M., \& Cansiz, N. (2019). How do sources of self-efficacy predict preservice teachers' beliefs related to constructivist and traditional approaches to teaching and learning? SAGE Open, 1-8. https://doi.org/10.1177/2158244019885125

Cavanagh, S. (March 5, 2012). States loosening "seat time” requirements. Education Week. http://www.edweek.org/ew/articles/2012/03/07/23biz-state.h31.html

Chiang, I. A., Jhangiani, R. S., \& Price, P. C. (2015). Research methods in psychology (2nd ed.). OpenEd. https://opentextbc.ca/researchmethods/

Clerkin, K., \& Simon, Y. (2014). College for America: Student-centered, competencybased education. Change: The Magazine of Higher Education, 46(6), 6-13. http://dx.doi.org/10.1080/00091383.2014.969141

College for America Staff(CfA Staff). (2016a). What is competency-based education? https://collegeforamerica.org/what-is-competency-based-education-2017/

College for America Staff (CfA Staff). (2016b). Online competency-based education:

The case of College for America. https://collegeforamerica.org/onlinecompetency-based-education-the-case-of-college-for-america/

College-Level Examination Program (CLEP). (2020). Key exam information. https://clep.collegeboard.org/about-clep/key-exam-information

Competency-based Education Network (CBEN). (2019). What is Competency-based education? https://www.cbenetwork.org/competency-based-education/

Competency Works. (2012). What is competency education? https://www.competencyworks.org/about/competency-education/ 
Council for Adult and Experiential Learning (CAEL). (2016). Case study: Competencybased education at Peirce College: Bachelor of Science in Information Technology.

http://cdn2.hubspot.net/hubfs/617695/CBE_CaseStudy_2016\%20Peirce.pdf

Council for Adult and Experiential Learning (CAEL). (2020). Prior learning assessment services. https://www.cael.org/higher-education/prior-learning-assessmentservices\#

Creswell, J. W. (2014). Research design: Qualitative, quantitative, and mixed methods approaches. (4th ed.). SAGE.

Creswell, J. W. (2015). A concise introduction to mixed methods research. SAGE.

Creswell, J. W., \& Plano-Clark, V. (2011). Designing and conducting mixed methods research (2nd ed.). SAGE.

Creswell, J. W ., \& Poth, C. N. (2017). Qualitative inquiry and research design: Choosing among five designs (4th ed.). SAGE.

Dadds, M. (1998). Supporting practitioner research: A challenge. Educational Action Research, 6(1), 39-52. http://dx.doi.org/10.1080/09650799800200049

Dath, D., \& Iobst, W. (2010). The importance of faculty development in the transition to competency-based medical education. Medical Teacher, 32, 683-586. https://doi.org/10.3109/0142159x.2010.500710

Daugherty, L., Davis, V., \& Miller, T. (2015). Competency-based education programs in Texas: An innovative approach to higher education (Report No. RR1239-1). RAND Corporation. https://www.rand.org/pubs/research_reports/RR1239-1.htm

Dillman, D., Smyth, J., \& Christian L. (2009). Internet, mail, and mixed-mode surveys: The tailored design method. Wiley. Dougherty, C. M., Johnson, S. K., \& Thompson, E. A. (2007). Reliability and validity of the self-efficacy expectations and outcome expectations after ICD implantation scales. Applied Nursing Research, 20(3), 116-124. http://dx.doi.org/116-124. 10.1016/j.apnr.2007.04.004 
Doughtery, C. M., Johnson, S. K., \& Thompson, E. A. (2007). Reliability and validity of the self-efficacy expectations and outcome expectations after ICD implantation scales. Applied Nursing Research, 20(3), 116-124.

https://doi.org/10.1016/j.apnr.2007.04.004

Downs, L. R. (2019, January 7). ED Negotiated Rulemaking: Suggested principles for addressing issues [Web log post]. WCET Frontiers https://wcetfrontiers.org/2019/01/07/principles-2019-negotiated-rulemaking/

Dragoo, A., \& Barrows, R. (2016). Implementing competency-based business curricula in higher education. Journal of Education for Business, 91, 374-379. http://dx.doi.org/10.1080/08832323.2016.1237932

Drake, P., \& Heath, L. (2011). Practitioner research at the doctoral level: Developing coherent research methodologies. Routledge, Taylor \& Francis.

Duemer, L. S. (2007). The agricultural education origins of the Morrill Land Grant Act of 1862. In J. W. Null (Ed.), American Educational History Journal Volume 34 Numbers 1 and 2 (135-146). Information Age Publishing.

Eaton, J. S. (2016). Accreditation and competency-based education. The Journal of Competency-based Education, 1, 12-16. http://dx.doi.org/10.1002/cbe2.1006

Echols, D. G., Neely, P. W., \& Dusick, D. (2018). Understanding faculty training in competency-based curriculum development. The Journal of Competency-based Education, 3, 1-9. http://dx.doi.org/10.1002/cbe2.1162

Edcor. (2020). CBE offers advantages in higher education. https://www.edcor.com/cbeoffers-advantages-higher-education/

Everett, B., Salamonson, Y., \& Davidson, P. M. (2009). Bandura's exercise self-efficacy scale: Validation in an Australian cardiac rehabilitation setting. International Journal of Nursing Studies, 46, 824-829. https://doi.org/10.1016/j.ijnurstu.2009.01.016

Fain, P. (2014a, October 28). Big Ten and the next big thing. Inside Higher Education. https:/www.insidehighered.com/news/2014/10/28/competency-based-educationarrives-three-major-public-institutions 
Fain, P. (2014b). Moving ahead with competency: Extending the credential. Washington, DC: Inside Higher Education. https://www.insidehighered.com/booklet/extending-credential

Fain, P. (2019, January 28). Slow and steady for competency-based education.

InsideHigher Education. https://www.insidehighered.com/news/2019/01/28/slowgrowth-competency-based-education-survey-finds-interest-and-optimism-about-it

Fishman, T. D., Ludgate, A., \& Tutak, J. (2017). Success by design: Improving outcomes in American higher education. Deloitte Insights. https://www2.deloitte.com/content/dam/insights/us/articles/3523_Success-bydesign/DUP_Success-by-design.pdf

Fitzgerald, J. T., Burkhardt, J. C., Kasten, S. J., Mullan, P. B., Santen, S. A., Sheets, K., Tsai, A., Vasquez, J. A., \& Gruppen, L. D. (2016). Assessment challenges in competency-based education: A case study in health professions education. Medical Teacher, 38, 482-490. https://doi.org/10.3109/0142159x.2015.1047754

Five Rivers Community College. (2020). Fiver Rivers FlexPace. https://www.REDACTED.edu/locations/online/flexpace/

Fowler, F. J., \& Cosenza, C. (2008). Writing effective questions. In E. D. de Leeuw, J. J. Hox, D. A. Dillman (Eds.), International handbook of survey methodology (pp. 136-160). European Association of Methodology.

Fram, S. M. (2013). The constant comparative analysis method outside of grounded theory. The Qualitative Report, 18(1), 1-25. https://nsuworks.nova.edu/tqr/vol18/iss1/1/

Franklin, C., \& Lytle, R. (2015). Employer perspectives on competency-based education (ED557615). ERIC. https://files.eric.ed.gov/fulltext/ED557615.pdf

Frost, D. (2016, April 12). Moving from seat-time to competency-based credits in state policy: Ensuring all students develop mastery [Weblog Post]. https://www.inacol.org/news/moving-from-seat-time-to-competency-basedcredits-in-state-policy-ensuring-all-students-develop-mastery 
Gallagher, C. W. (2014). Disrupting the game changer: Remembering the history of competency-based education. Change: The Magazine of Higher Learning, 46(6), 16-23. http://dx.doi.org/10.1080/00091383.2014.969177

Garrett, R., \& Lurie, H. (2016). Deconstructing CBE: An assessment of institutional activity, goals, and challenges in higher education. Lumina Foundation. https://www.luminafoundation.org/files/resources/deconstructing-cbe.pdf

Gervais, J. (2016). The operational definition of competency-based education. The Journal of Competency-based Education, 1, 98-106. http://dx.doi.org/10.1002/cbe2.1011

Golod, A. (2014, September 19). Online options expanding in the higher education landscape. U.S.News and World Report. https://www.usnews.com/news/collegeof-tomorrow/articles/2014/09/22/online-options-expanding-in-higher-educationlandscape

Grann, J. (2017). Competency-based education: Capella University's excellent in assessment profile. Assessment Update, 29, 8-13. https://doi.org/10.18608/JLA.2018.53.13

Gruppen, L. D., Burkhardt, J. C., Fitzgerald, J. T., Funnel, M., Haftel, H. M., Lypson, M. L., Mullan, P. B., Santen, S. A., Sheets, K. J., Stalburg, C. M., \& Vasquez, J. A. (2016). Competency-based education: Programme design and challenges to implementation. Medical Teacher, 50, 532-539. https://doi.org/10.1111/medu.12977

Guskey, T. R., \& Passaro, P. D. (1994). Teacher efficacy: A study of construct dimensions. American Educational Research Journal, 31, 627643.https://psycnet.apa.org/doi/10.2307/1163230

Hagan-Short, M., \& Addison, P. (2019). Competency-based education: Multiple approaches a single institution. Journal of Competency-based Education, 4(3):e01194. https://doi.org/10.1002/cbe2.1194 
Harrison, C. (2007). Tip sheet on question wording. Harvard University Program on Survey Research. https://psr.iq.harvard.edu/files/psr/files/PSRQuestionnaireTipSheet_0.pdf

Hatcher, D. (2013). Advanced statistics in research: Reading, understanding, and writing up data analysis results. Shadow Finch Media.

Henrich, J. (2016). Competency-based education: The employer's perspective of higher education. The Journal of Competency-based Education, 1, 122-129. https://doi.org/10.1002/cbe2.1023

Henson, G., \& Hitchcock, N. (2017). Competency-based education has a history and its history illuminates its limitations. In Trust, 2017(1). https://www.intrust.org/Magazine/Issues/New-Year-2017/Competency-basededucation-has-a-history

Hilliard, T., Bushway, D., Krauss, S., \& Anderson, N. (2018). Next generation CBE: Solving the four big problems facing CBE for underprepared college students. JFF. https://jfforg-prod-prime.s3.amazonaws.com/media/documents/CBE5 Final.pdf

Hittepole, C. (2019). Nontraditional students: Supporting changing student populations. NASPA. https://www.naspa.org/images/uploads/main/Hittepole_NASPA_Memo.pdf

Johnstone, S. M., \& Soares, L. (2014). Principles for developing competency- based education programs. Change, 46, 2, 12-19. https://doi.org/10.1080/00091383.2014.896705

Kelchen, R. (2016). Who enrolls in competency-based education? An examination of the demographics and finances of competency-based education programs. The Journal of Competency-based Education, 1, 48-59. https://doi.org/10.1002/cbe2.1005

Kelly, A. P., \& Columbus, R. (2016). Innovate and evaluate: Expanding the research base for competency-based education (ED566655). ERIC. https://eric.ed.gov/?id=ED566655 
Kitching, J. J., Cassidy, S. F., Eachus, P., \& Hogg, P. (2011). Creating and validating self-efficacy scales for students. Radiologic Technology, 83, 10-19. http://usir.salford.ac.uk/17673/

Klein-Collins, R. (2012). Competency-based degree programs in the U.S.: Postsecondary credentials for measurable student learning and performance. CAEL. Retrieved from http://cdn2.hubspot.net/hubfs/617695/CAEL_Reports/2012_CompetencyBasedPr ograms.pdf

Klein-Collins, R. (2013). Sharpening our focus on learning: The rise of competencybased approaches to degree completion. National Institute for Learning Outcomes Assessment. https://learningoutcomeassessment.org/

Koellner, K., \& Jacobs, J. (2015). Distinguishing models of professional development: The case of an adaptive model's impact on teachers' knowledge, instructions, and student achievement. Journal of Teacher Education, 66, 51-67. https://doi.org/10.1177/0022487114549599

Kratsas, G. (2017). 50 best colleges for adult education 2017-2018. Great Value Colleges. https://www.greatvaluecolleges.net/best-colleges-adult-education-2017$\underline{2018 /}$

Krauss, S. M. (2017). How competency-based education may help reduce our nation's toughest inequities. Lumina Foundation. https://www.luminafoundation.org/files/resources/how-cbe-may-reduceinequities-1.pdf

Kreighbaum, A., \& Fain, P. (2019, January 7). Overhauling rules for higher ed. Inside Higher Education. https://www.insidehighered.com/news/2019/01/07/trump$\underline{\text { admbinistration-wants-flexibility-accreditors-and-encourage-alternative }}$

Laerd. (2020). Understanding inferential statistics. https://statistics.laerd.com/statisticalguides/descriptive-inferential-statistics.php

Laitinen, A. (2012). Cracking the credit hour. (ED540304). ERIC. https://eric.ed.gov/?id=ED540304 
Lakin, M. B., Seymour, D., Nellum, C. J., Crandall, J. R. (2015). Credit for prior learning: Charting instructional practice for sustainability. American Council on Education. https://www.acenet.edu/Documents/Credit-for-Prior-LearningCharting-Institutional-Practice-for-Sustainability.pdf

Lawrence, M., Parry, S. \& Vandeford, R. (2018). Examination of prior learning assessment (PLA) as strategy for achieving workforce development system success. National Association of Workforce Boards. https://irpcdn.multiscreensite.com/dc0a626e/files/uploaded/PLA_CWA_White Paper \%20 August 2018.pdf

Le, C., Wolfe, R. E., \& Steinberg, A. (2014). The past and the promise: Today's Competency education movement. (ED561253). ERIC. https://eric.ed.gov/?id=ED561253

LeBlanc, P. (2020, May 3). It's time to take time out of learning and reinvent higher education. Forbes. https://www.forbes.com/sites/paulleblanc/2020/05/03/its-timeto-take-time-out-of-learning-and-reinvent-higher-education/\#73f330c25de5

Levinson-Rose, J., \& Menges, R. J. (1981). Improving college teaching: A critical review of research. Review of Educational Research, 51, 403-434. https://doi.org/10.3102/00346543051003403

Lieberman, M. (2019, January 16). Comparing and contrasting competency-based programs. Inside Higher Education. https://www.insidehighered.com/digitallearning/article/2019/01/16/competency-based-programs-offer-flexible-learningvariety-models

Lincoln, Y. S. \& Guba, E. G. (1985). Naturalistic inquiry. Sage.

Lopez, F. G., \& Lent, R. L. (1992). Sources of mathematics self-efficacy in high school students. The Career Development Quarterly, 41, 3-12. https://doi.org/10.1002/j.2161-0045.1992.tb00350.x

Manning, J. (2017). InVivo coding. In J. Matthes (Ed.)., The International Encyclopedia of Communication Research Methods. Wiley-Blackwell. 
Matthias, L. R. (2019). Faculty development: A review of the (relatively recent) literature and implications for Christian higher education. Christian Higher Education, 18, 260-275. https://doi.org/10.1080/15363759.2018.1517618

McAuley, E., \& Gill, D. L. (1983). Reliability and validity of the Physical Self-efficacy Scale in a competitive sport setting. Journal of Sport \& Exercise Psychology, 5, 410-418. https://pdfs.semanticscholar.org/e536/d98f5f7a77f981bf8aa909f460cb7143bf82.p $\underline{\mathrm{df}}$

McClean, M., Cilliers, F., \& Van Wyk, J. M. (2008). Faculty development: Yesterday, today, and tomorrow. Medical Teacher, 30, 555-584. https://doi.org/10.1080/01421590802109834

McPhail, C. J. (2011). The completion agenda: A call to action. (ED532208). ERIC. https://files.eric.ed.gov/fulltext/ED532208.pdf

Miles, M. B., Huberman, A. M., \& Saldana, J. (2014). Qualitative data analysis (2nd ed.). SAGE.

Monahan, N. (2015, October 12). More content doesn't equal more learning. Faculty Focus. https://www.facultyfocus.com/articles/effective-teaching-strategies/morecontent-doesnt-equal-more-learning/

Morris, D. B., \& Usher, E. L. (2011). Developing teaching self-efficacy in research institutions: A study of award-winning professors. Contemporary Educational Psychology, 36, 232-245. https://doi.org/10.1016/j.cedpsych.2010.10.005

Muretta, R. J. (2004). Exploring the four sources of self-efficacy. Dissertation Abstracts International: Section B: The Sciences and Engineering, 65(10-B), 5447.

National Center for Educational Statistics (NCES). (2020a). Five Rivers Community College. https://nces.ed.gov/collegenavigator/?id=205470\#general

National Center for Educational Statistics (NCES). (2020b). Peirce College. https://nces.ed.gov/collegenavigator/?q=Peirce+College\&s=all\&id=214883\#progr $\underline{\text { ams }}$ 
National Center for Educational Statistics (NCS). (2020c). University of Michigan. https://nces.ed.gov/collegenavigator/?q $=$ university + of + michigan $\& s=$ all $\& \mathrm{id}=1709$ 76\#retgrad

National Center for Educational Statistics (NCES). (2020d). Western Governors University. https://nces.ed.gov/collegenavigator/?q=wgu\&s=all\&id=433387\#enrolmt

Neem, J. N. (2013). Experience matters: Why competency-based education. Liberal Education, 99(4), 26-29. https://www.aacu.org/publicationsresearch/periodicals/experience-matters-why-competency-based-education-willnot-replace

Newbold, C., Seifert, C., Doherty, B., Scheffler, A., \& Ray, A. (2017). Ensuring faculty success in online competency-based education programs. The Journal of Competency-based Education, 2. e0152. https://doi.org/10.1002/cbe2.1052

Nodine, T. R. (2015). How did we get here? A brief history of competency-based education in the United States. Competency-Based Education, 1, 5-11. https://doi.org/10.1002/cbe2.1004

Nodine, T., \& Johnstone, S. M. (2015). Competency-based education: Leadership challenges. Change, 47(4), 61-66. https://doi.org/10.1080/00091383.2015.1060101

O’Donoghue, T., \& Chapman, E. (2010). Problems and prospects in competencies-based education: A curriculum studies perspective. Education Research and Perspectives, 37, 85-104. http://www.erpjournal.net/?page id=779

Ohio Board of Regents. (2014). PLA with a purpose: Prior learning assessment \& Ohio'scompletion agenda. https://www.ohiohighered.org/sites/ohiohighered.org/files/uploads/PLA/PLAwith-a-Purpose Report_FINAL_041614_0.pdf

Ohio Department of Higher Education (ODE). (2016). Competency-based education: 9th report on the condition of higher education in Ohio. (ED572750). ERIC. https://eric.ed.gov/?id=ED572750 
Ohio Department of Higher Education. (2018). Competency-based education at Ohio colleges: A quick look at competency-based education in Ohio. https://www.ohiohighered.org/connected/competency_based_education_Ohio_colleges

Ohio TechCred. (2019). About. https://techcred.ohio.gov/wps/portal/gov/techcred/about

Oleson, A., \& Hora, M. T. (2013). Teaching the way they were taught? Revisiting the sources of teaching knowledge and the role of prior experience in shaping faculty teaching practices. Higher Education, 68. http://dx.doi.org/10.1007/s10734-013$\underline{678-9}$

Online Learning Consortium (OLC). (2019). Regular and substantive interaction: background, concerns, and guiding principles. Newburyport, MD: Online Learning Consortium. (ERIC Document Reproduction Services No. ED593878)

Onwuegbuzie, A. J., \& Collins, K. M. T. (2007). A typology of mixed methods sampling designs in social science research. The Qualitative Report, 12, 281-316. https://doi.org/10.46743/2160-3715/2007.1638

Onwuegbuzie, A. J., Frels, R. K., \& Hwang, E. (2016). Mapping Saldana’s coding methods onto the literature review process. Journal of Educational Issues, 2, 130150. http://dx.doi.org/10.5296/jei.v2i1.8931

Ordonez, B. (2014). Competency-based education: Changing the traditional college degree power, policy, and practice. New Horizons in Adult Education \& Human Resource Development, 26(4), 47-53. https://doi.org/10.1002/nha3.20085

Palardy, J. M., \& Eisele, J. E. (1972). Competency based education. The Clearing House: A Journal of Educational Strategies, Issues, and Ideas, 46, 545-548. https://doi.org/10.1080/00098655.1972.11478097

Peirce College. (2020a). Peirce competency-based IT program. https://www.peirce.edu/degrees-programs/ways-to-learn/competency-basededucation

Peirce College. (2020b). Tuition and fees. https://www.peirce.edu/tuition-financialaid/tuition-fees 
Peller, J. (2019). Balancing quality with innovation: Key issues at stake in Negotiated Rulemaking. Insights \& Outlooks, 16. https://higherlearningadvocates.org/2019/01/31/balancing-quality-withinnovation-key-issues-at-stake-in-negotiated-rulemaking/

Pelletier, S. G. (2010). Success for adult students. Public Purpose, 5, 2-6. https://www.aascu.org/uploadedFiles/AASCU/Content/Root/MediaAndPublicatio $\underline{\text { ns/PublicPurposeMagazines/Issue/10fall_adultstudents.pdf }}$

Peterson, R. A. (2000). Constructing effective questionnaires. Thousand Oaks, CA: Sage.

Porter, S. R., \& Reilly, K. (2014). Competency-based education as a potential strategy to increase learning and lower costs HCM Strategists. http://hcmstrategists.com/maximizingresources/images/CBE_Paper.pdf

Rivers, C., \& Sebesta, J. A. (2017). "Right on the money": CBE student satisfaction and postgraduation outcomes. The Journal of Competency-based Education, 2:e01042. https://doi.org/10.1002/cbe2.1042

Robbins, J. (2017). Why 'competency-based education' will deepen America's education crisis. The Federalist. https://thefederalist.com/2017/05/04/competency-basededucation-will-deepen-americas-education-crisis/

Robison, J. (2012, November 21). The benefits of competency-based education for adults. Evolllution. https://evolllution.com/opinions/the-benefits-of-competency-basededucation-for-adults/

Ross, J. A. (1994). The impact of an in-service to promote cooperative learning on the stability of teacher efficacy. Teaching and Teacher Education, 10, 381-394. https://doi.org/10.1016/0742-051X(94)90020-5

Schaffhauser, D. (2017). 6 ways to build a better CBE program. Campus Technology. https://campustechnology.com/Articles/2017/08/02/6-Ways-to-Build-a-BetterCBE-Program.aspx?Page $=1$

Schwarzer, R., Schmitz, G. S., \& Daytner, G. T. (1999). The teacher self-efficacy scale. http://www.fu-berlin.de/gesund/skalen/t se.htm 
Scoles, J. E., McArthur, J., \& Huxham, M. (2014). Mixed-methods research in education: Exploring students' response to a focused feedback initiative. SAGE.

Sherer, M., Maddux, J. E., Mercandanate, B., Prentice-Dunn, S., Jacobs, B., \& Rogers, R. W. (1982). The Self-efficacy Scale: Construction and validation. Psychological Reports, 51, 663-667. https://doi.org/10.2466\%2Fpr0.1982.51.2.663

Smith-Barrow, D. (2018). Is college enrollment among older adults increasing? Depends who you ask. Hechinger Report. https://hechingerreport.org/is-college-enrollmentamong-older-adults-increasing-depends-who-you-ask/

Soulunii, S. (2019). Challenges facing traditional education and the need to shift to smart learning. EdTech Review. https://edtechreview.in/trends-insights/insights/3553challenges-traditional-education-faces-today-and-the-need-to-shift-to-smartclassroom

Southern New Hampshire University (SNHU). (2020). Program finder. https://www.snhuedu/program-finder/cbe-2

Staley, D., \& Trinkle, D. (2011). The changing landscape of higher education. EDUCAUSE Review, 46(1), 16-32. https://er.educause.edu/articles/2011/2/thechanging-landscape-of-higher-education

Steinert, Y. (2014). Faculty development in the health professions: A focus on research and practice. Springer.

Steinert, Y., Mann, K., Anderson, B., Barnett, B. M., Centeno, A., Naismith, L., Prideaux, D., Spencer, J., Tullo, E., Viggiano, T., Ward, H., \& Dolmans, D. (2016). A systematic review of faculty development initiatives designed to enhance teaching effectiveness: A 10-year update. Medical Teacher, 38, 769-786. https://doi.org/10.1080/0142159x.2016.1181851

Stes, A., Min-Leliveld, M., Gijbels, D., \& Van Petegem, P. (2009). The impact of instructional development in higher education: The state-of-the-art research. Educational Research Review, 5, 25-49. http://dx.doi.org/10.1016/j.edurev.2009.07.001 
Sturgis, C., \& Casey, K. (2018). Quality principles for competency-based education. iNACOL. https://aurora-institute.org/resource/quality-principles-for-competencybased-education/

Sullivan, S. C., \& Downey, J. A. (2015). Shifting educational paradigms: From traditional to competency-based education for diverse students. American Secondary Education, 43(3), 4-19. http://oer.galileo.usg.edu/educationcollections $/ 4$

Tavakol, M., \& Dennick, R. (2011). Making sense of Cronbach's alpha. International Journal of Medical Education, 2, 53-55. https://dx.doi.org/10.5116/ijme.4dfb.8dfd

ten Cate, O. (2005). Entrustability of professional activities and competency-based training. Medical Education, 39, 1176-1177. https://doi.org/10.1111/j.13652929.2005.02341.x

ten Cate, O. (2013). Competency-based education, entrustable professional activities, and the power of language. Journal of Graduate Medical Education, 5. https://dx.doi.org/10.4300/JGME-D-12-00381.1

Texas A\&M University - Commerce (TAMU-C). (2020a). Current CBE program at TAMU-C. http://www.tamuc.edu/aboutUs/IER/icbe/baas-in-organizationalleadership.aspx

Texas A\&M University - Commerce (TAMU-C). (2020b). Institute for competencybased education. http://www.tamuc.edu/aboutUs/IER/icbe/default.aspx

Texas A\&M University - Commerce (TAMU-C). (2020c). TAB Program at a glance. http://www.tamuc.edu/aboutUs/IER/icbe/Images\%20ICBE/TABINFOGRAPHFINAL.pdf

Thiebault, N., Amato, C. (2016). CBE: Ready, set, go Competency-based education model. Ohio Community Colleges. https://ohiocommunitycolleges.org/wpcontent/uploads/2016/11/CBE-Ready-Set-Go-Thibeault-Amato-SinclairCommunity-College.pdf?x57939 
Thurman, G. K., \& Sanders, M. K. (1987). Competency-based education versus traditional education: A comparison of effectiveness. Radiologic Technology, 59, 164-169.

Torres, A. S., Brett, J., Cox, J., \& Greller, S. (2018). Competency education implementation: Examining the contextual forces in three New Hampshire Secondary Schools. AERA Open, 4(2) 1-13. https://doi.org/10.1177/2332858418782883

Tracy, S. J. (2010). Qualitative quality: Eight "big-tent" criteria for excellent qualitative research. Qualitative Inquiry, 16, 837-851. https://doi.org/10.1177/1077800410383121

Tschannen-Moran, M., \& Woolfolk Hoy, A. (2001). Teacher efficacy: Capturing an elusive construct. Teaching and Teacher Education, 17, 783-805. https://doi.org/10.1016/S0742-051X(01)00036-1

Tschannen-Moran, M., \& Woolfolk Hoy, A. (2007). The differential antecedents of selfefficacy beliefs of novice and experienced teachers. Teaching and Teacher Education, 23, 944-956. https://doi.org/10.1016/j.tate.2006.05.003

United States Air Force. (2020). U.S. Air Force - Career detail: Remotely piloted aircraft pilot. https://www.airforce.com/careers/detail/remotely-piloted-aircraft-pilot

United States Department of Education. (2013). Applying for Title IV eligibility for direct assessment programs. http://ifap.ed.gov/dpcletters/GEN1310.html

United States Department of Education. (2020). Accreditation in the United States. https://www2.ed.gov/admins/finaid/accred/accreditation_pg12.html

University of Michigan. (2020). Master of health professions education. https://medicine.umich.edu/dept/lhs/education/master-health-professionseducation

University of Texas System. (2014). The University of Texas System makes bold move into competency-based education. https://www.utsystem.edu/news/2014/11/03/university-texas-system-makes-bold$\underline{\text { move-competency-based-education }}$ 
University of Wisconsin. (2020). Frequently asked questions.

https://flex.wisconsin.edu/faqs/

Valenzuela, I., MacIntyre, D., Klein-Collins, B., \& Clerx, J. (2016). Prior learning assessment and competency-based education: An overview of programs, policies, and practices. (ED570321). ERIC. https://files.eric.ed.gov/fulltext/ED570321.pdf

Viola, V. (2016). Critiques and issues of competency based education (CBE). LethbridgeCollege Learning Connections. http://www.lc2.ca/item/274-critiquesand-issues-of-competency-based-education-cbe

Wang, J. (2015). The student perspective on competency-based education: Qualitative research on support, skills, and success. Young Invincibles. https://younginvincibles.org/wp-content/uploads/2015/10/Young-InvinciblesCBE-Paper.pdf

Wang, L., Ertmer, P A., \& Newby, T. J. (2004). Increasing preservice teachers' selfefficacy beliefs for technology integration. Journal of Research on Technology in Education, 36, 231-250. https://doi.org/10.1080/15391523.2004.10782414

Ward, S. C. (2016, February 1). Let the eat cake (competently). Inside Higher Education. https://www.insidehighered.com/views/2016/02/01/competency-based-educationthreatens-further-stratify-higher-education-essay

Wax, D., \& Klein-Collins, B. (2015, October 16). Competency-based education: A powerful way to link learning and the workplace. Evolllution. https://evolllution.com/programming/applied-and-experientiallearning/competency-based-education-a-powerful-way-to-link-learning-and-theworkplace/

Weise, M. R. (2014). Got skills? Why online competency-based education is the disruptive innovation for higher education. EDUCAUSE Review, 49(6) 27-35. https://er.educause.edu/articles/2014/11/got-skills-why-online-competencybased$\underline{\text { education-is-the-disruptive-innovation-for-higher-education }}$ 
Wertheim, C., \& Leyser, Y. (2002). Efficacy beliefs, background variables, and differentiated instruction of Israeli prospective teachers. The Journal of Educational Research, 96(1), 54-63. https://doi.org/10.1080/00220670209598791

Western Governors University (WGU). (2020a). About. https://www.wgu.edu/about/competency-based-education.html

Western Governors University (WGU). (2020b). A guide for implementing a CBE program. https://www.wgu.edu/about/competency-basededucation/implementation.html

Western Governors University (WGU). (2020c). Resources for developing CBE programs. https://www.wgu.edu/about/competency-based-education/what-iscbe.html\#close

Western Governors University (WGU). (2020d). Tuition and financial aid. https://www.wgu.edu/financial-aid-tuition.html

Woodruff, S. L., \& Cashman, J. F. (1993). Task, domain, and general efficacy: A reexamination of the Self-Efficacy Scale. Psychological Reports, 72, 423-432. https://doi.org/10.2466/pr0.1993.72.2.423

Woolfolk Hoy, A. (2004). Self-efficacy in college teaching. Essays on Teaching Excellence: Toward the Best in the Academy, 15, 8-11. https://podnetwork.org/content/uploads/V15-N8-Woolfolk-Hoy.pdf 
APPENDIX 


\section{Interview Solicitation Email}

Dear Faculty Member,

My name is Christopher Prokes and I work here at [Five Rivers].

I am investigating Competency-based education (CBE) for my dissertation. The goal of the study is to explore faculty views of self-efficacy with CBE and related areas. I'm contacting you because of your prior experience with CBE in some capacity. At this stage, I am looking to interview different faculty about CBE. Participation is voluntary and you will not be harmed nor affected negatively by taking part in this study.

If you choose to participate, you're asked to take part in a short interview (likely via Zoom due to COVID-19) for an estimated 30 minutes. Please reply to this email if you are interested. Participants (desiring 10) will receive a \$15 Amazon Gift Card for participation. Thank you for your consideration!

Sincerely,

Christopher Prokes 


\section{Interview Informed Consent}

Study Title: Faculty Perceptions of CBE, Self-efficacy, and institutional support: An exploratory mixed methods study

Principal Investigator: Patrick Lowenthal, Co-Principal Investigator: Christopher Ph.D Prokes

This consent form will give you the information you will need to understand why this research study is being done and why you are being invited to participate. It will also describe what you will need to do to participate as well as any known risks, inconveniences or discomforts that you may have while participating. We encourage you to ask questions at any time. If you decide to participate, you will be asked to sign this form and it will be a record of your agreement to participate. You will be given a copy of this form to keep.

\section{PURPOSE AND BACKGROUND}

The purpose of this research is to examine the views of CBE, self-efficacy, and institutional support in the community college setting. Ultimately we wish to know these perceptions via interviews with ten faculty and then a survey, derived from the results of the interviews, administered to all faculty with CBE experience.

\section{PROCEDURES}

If you agree to be in this study, you will participate in the following:

- One interview of no more than 30 minutes for phase one which will be audiorecorded.

Interview responses (including audio recordings and notes) will be stored on a secure server with pseudonyms used to protect identities.

\section{RISKS}

No demographic information is asked for. We will make every effort to protect participants' confidentiality. However, if you are uncomfortable answering any of these questions, you may pass on answering.

Please know that direct quotes related to your responses may be used in the final version of this research to support findings or results. In this case, your identity will be anonymized and a pseudonym will be used.

\section{BENEFITS}

There will be no direct benefit to you from participating in this study. However, the information that you provide may help develop improved support mechanisms for the support of competency-based education faculty.

\section{EXTENT OF CONFIDENTIALITY}


Reasonable efforts will be made to keep the personal information in your research record private and confidential. Any identifiable information obtained in connection with this study will remain confidential and will be disclosed only with your permission or as required by law. The members of the research team, and the Boise State University Office of Research Compliance (ORC) may access the data. The ORC monitors research studies to protect the rights and welfare of research participants.

Your name will not be used in any written reports or publications which result from this research as pseudonyms will be incorporated. Data will be kept for three years (per federal regulations) after the study is complete and then destroyed.

\section{PAYMENT}

You will receive a \$15 Amazon gift card for participation in the interview.

\section{PARTICIPATION IS VOLUNTARY}

You do not have to be in this study if you do not want to. You may also refuse to answer any questions you do not want to answer. If you volunteer to be in this study, you may withdraw from it at any time without consequences of any kind or loss of benefits to which you are otherwise entitled.

\section{QUESTIONS}

If you have any questions or concerns about your participation in this study, you may contact the Principal Investigator Dr. Patrick Lowenthal (Patrick.lowenthal@,boisestate.edu) or Co-PI Chris Prokes (christopherproke@u.boisestate.edu)

If you have questions about your rights as a research participant, you may contact the Boise State University Institutional Review Board (IRB), which is concerned with the protection of volunteers in research projects. You may reach the board office between 8:00 AM and 5:00 PM, Monday through Friday, by calling (208) 426-5401 or by writing: Institutional Review Board, Office of Research Compliance, Boise State University, 1910 University Dr., Boise, ID 83725-1138.

\section{DOCUMENTATION OF CONSENT}

I have read this form and decided that I will participate in the project described above. Its general purposes, the particulars of involvement and possible risks have been explained to my satisfaction. I understand I can withdraw at any time. 


\section{Survey Solicitation Email}

Dear Faculty member,

My name is Christopher Prokes and I work here at [Five Rivers].

I previously contacted you in July for your participation in my dissertation research study which was phase I of the process. In that, I conducted interviews with selected participants.

Now, I am reaching out for phase II which is a survey on CBE, perceptions, confidence, and support ideas based on the responses from such interviews. I'd love your input and participation in this critical instrument. I'm hoping for 50 responses.

If you choose to participate, you'll be entered into a drawing to win a $\$ 100$ Amazon eGift Card.

Thank you for considering participation!

(LINK)

Stay Well,

Chris 


\section{Survey Reminder Email}

Hello! I first reached out on August $31^{\text {st }}$ regarding the survey below. I'm hoping you'll still be able to assist with the survey - I'm hoping to have 50 responses in total from a pool of 56, so everyone's input is critical. If you have a few minutes before the end of September, would you be able to complete the survey? Thanks so much!

Dear Faculty member,

My name is Christopher Prokes and I work here at Sinclair Community College.

I previously contacted you in July for your participation in my dissertation research study which was phase I of the process. In that, I conducted interviews with selected participants.

Now, I am reaching out for phase II which is a survey on CBE, perceptions, confidence, and support ideas based on the responses from such interviews. I'd love your input and participation in this critical instrument. I'm hoping for 50 responses.

If you choose to participate, you'll be entered into a drawing to win a $\$ 100$ Amazon eGift Card.

Thank you for considering participation!

(LINK)

Stay Well,

Chris 


\section{Survey Informed Consent}

Study Title: Faculty Perceptions of CBE, Self-efficacy, and institutional support: An exploratory mixed methods study

Principal Investigator: Patrick Lowenthal, Co-Principal Investigator: Christopher Ph.D Prokes

This consent form will give you the information you will need to understand why this research study is being done and why you are being invited to participate. It will also describe what you will need to do to participate as well as any known risks, inconveniences or discomforts that you may have while participating. We encourage you to ask questions at any time. If you decide to participate, you will be asked to sign this form and it will be a record of your agreement to participate. You will be given a copy of this form to keep.

\section{PURPOSE AND BACKGROUND}

The purpose of this research is to examine the views of CBE, self-efficacy, and institutional support in the community college setting. Ultimately we wish to know these perceptions via a survey, derived from the results of interviews with faculty, administered to all faculty with CBE experience.

\section{PROCEDURES}

If you agree to be in this study, you will participate in the following:

- One survey of approximately 15-20 minutes for phase two (a separate consent form will follow with the survey information)

Interview responses will be stored on a secure server with pseudonyms used to protect identities.

\section{RISKS}

No demographic information is asked for. We will make every effort to protect participants' confidentiality. However, if you are uncomfortable answering any of these questions, you may pass on answering.

\section{BENEFITS}

There will be no direct benefit to you from participating in this study. However, the information that you provide may help develop improved support mechanisms for the support of competency-based education faculty.

\section{EXTENT OF CONFIDENTIALITY}

Reasonable efforts will be made to keep the personal information in your research record private and confidential. Any identifiable information obtained in connection with this study will remain confidential and will be disclosed only with your permission or as required by law. The members of the research team, and the Boise State University 
Office of Research Compliance (ORC) may access the data. The ORC monitors research studies to protect the rights and welfare of research participants.

Your name will not be used in any written reports or publications which result from this research as pseudonyms will be incorporated. Data will be kept for three years (per federal regulations) after the study is complete and then destroyed.

\section{PAYMENT}

You may be selected for a \$100 Amazon gift card for participation.

\section{PARTICIPATION IS VOLUNTARY}

You do not have to be in this study if you do not want to. You may also refuse to answer any questions you do not want to answer. If you volunteer to be in this study, you may withdraw from it at any time without consequences of any kind or loss of benefits to which you are otherwise entitled.

\section{QUESTIONS}

If you have any questions or concerns about your participation in this study, you may contact the Principal Investigator Dr. Patrick Lowenthal (Patrick.lowenthal@boisestate.edu) or Co-PI Chris Prokes (christopherproke@u.boisestate.edu)

If you have questions about your rights as a research participant, you may contact the Boise State University Institutional Review Board (IRB), which is concerned with the protection of volunteers in research projects. You may reach the board office between 8:00 AM and 5:00 PM, Monday through Friday, by calling (208) 426-5401 or by writing: Institutional Review Board, Office of Research Compliance, Boise State University, 1910 University Dr., Boise, ID 83725-1138.

\section{DOCUMENTATION OF CONSENT}

I have read this form and decided that I will participate in the project described above. Its general purposes, the particulars of involvement and possible risks have been explained to my satisfaction. I understand I can withdraw at any time. 